Marcus Fernando Kodama Pertille Ramos

\title{
Caracterização dos subtipos moleculares do câncer gástrico por expressão gênica e proteica
}

Tese apresentada à Faculdade de Medicina da Universidade de São Paulo para obtenção do título de Doutor em Ciências em Gastroenterologia

Programa de Ciências em Gastroenterologia Orientador: Prof. Ulysses Ribeiro Junior

\section{São Paulo}


Marcus Fernando Kodama Pertille Ramos

\title{
Caracterização dos subtipos moleculares do câncer gástrico por expressão gênica e proteica
}

\author{
Tese apresentada à Faculdade de Medicina \\ da Universidade de São Paulo para \\ obtenção do título de Doutor em Ciências \\ em Gastroenterologia \\ Programa de Ciências em Gastroenterologia \\ Orientador: Prof. Ulysses Ribeiro Junior
}

\section{São Paulo}


Dados Internacionais de Catalogação na Publicação (CIP)

Preparada pela Biblioteca da

Faculdade de Medicina da Universidade de São Paulo

Creprodução autorizada pelo autor

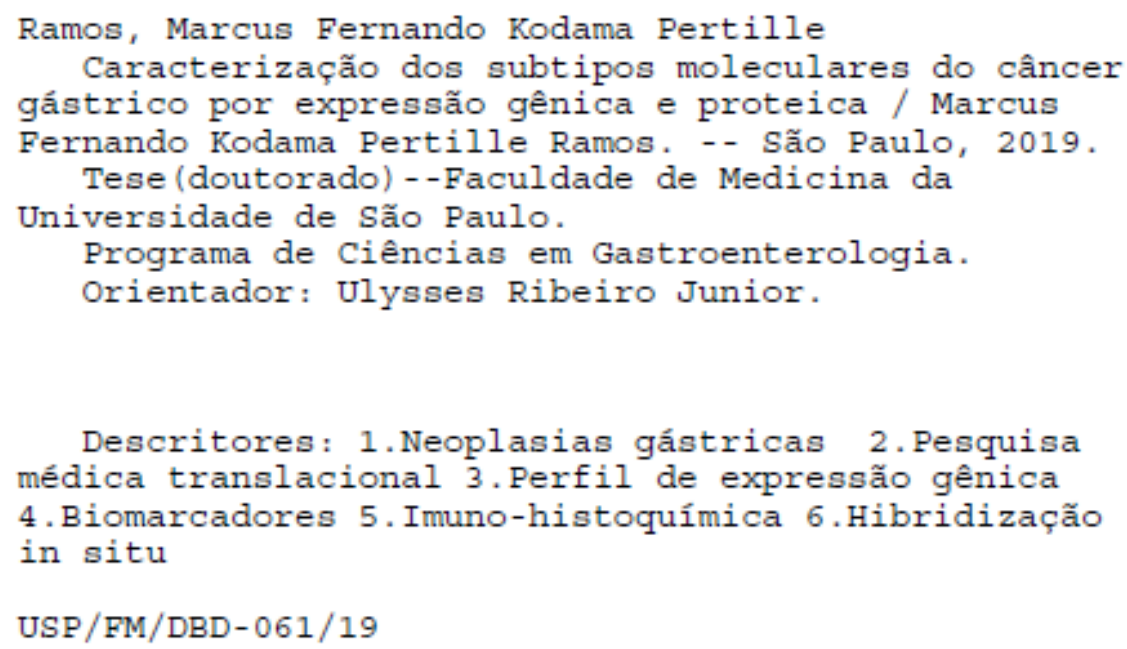

Responsável: Erinalva da Conceição Batista, CRB-8 6755 


\section{AGRADECIMENTOS}

À minha esposa, Ana Carolina, e aos meus filhos Murilo e Marcela, por novamente terem compreendido minha ausência em muitas atividades e "aventuras" familiares. Aos meus pais e meus irmãos, por sempre me apoiarem e possibilitarem minha dedicação integral aos estudos, ao longo da minha vida.

Ao Professor Ulysses Ribeiro Júnior, pela orientação e estímulo em exercer atividades relacionadas à pesquisa.

Aos colegas Marina Alessandra Pereira, Sheila Friedrich Faraj, Cinthya dos Santos Cirqueira e Evandro Sobroza de Mello, pelo imenso apoio oferecido no Serviço de Patologia, para realização dessa tese.

Ao Professor Bruno Zilberstein, pela oportunidade e estímulo a seguir na área de estudo do câncer gástrico.

Aos Professores Ivan Cecconello e Luiz Augusto Carneiro D’Albuquerque, pelas oportunidades oferecidas desde a residência, preceptoria e contratação no ICESP. Ao Professor José Eluf Neto, pelos ensinamentos passados durante o mestrado, os quais me auxiliaram muito durante o doutorado.

Ao colega, Professor Osmar Kenji Yagi, e aos colegas Donato Roberto Mucerino e André Roncon Dias, pelas valiosas sugestões.

Aos colegas do Serviço de Cirurgia do Estômago do Hospital das Clínicas e do Serviço de Cirurgia Oncológica do Aparelho Digestivo do ICESP, pelo grande estímulo e companheirismo diário.

À Marta Regina Rodrigues, pelo grande auxílio com o material de apoio. 
Aos colegas Carlos Brunetti Netto, Murilo Rodrigues Caldas e Paulo Cesar Pagliarde, pelo apoio e cobertura nas atividades profissionais diárias.

Ao demais amigos e colegas que me auxiliaram durante essa jornada. 


\section{NORMALIZAÇÃO ADOTADA}

Esta Tese está de acordo com as seguintes normas, em vigor no momento desta publicação:

Referências: adaptado de International Committee of Medical Journals Editors (Vancouver).

Universidade de São Paulo. Faculdade de Medicina. Divisão de Biblioteca e Documentação. Guia de apresentação de dissertações, teses e monografias. Elaborado por Anneliese Carneiro da Cunha, Maria Julia de A. L. Freddi, Maria F. Crestana, Marinalva de Souza Aragão, Suely Campos Cardoso, Valéria Vilhena. 3a ed. São Paulo: Divisão de Biblioteca e Documentação; 2011.

Abreviaturas dos títulos dos periódicos de acordo com List of Journals Indexed in Index Medicus. 


\section{SUMÁRIO}

Lista de abreviaturas e siglas

Lista de tabelas

Lista de figuras

Resumo

Abstract

1 INTRODUÇÃO .1

1.1 Classificação do Câncer Gástrico .............................................................4

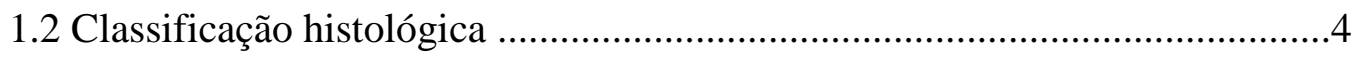

1.3 Classificação Molecular ...........................................................................

1.3.1 Tumores gástricos associados ao EBV ....................................8

1.3.2 Tumores com microssatélites instáveis......................................11

1.3.3 Tumores com instabilidade cromossômica (CIN).....................15

1.3.4 Tumores com genoma estável.................................................16

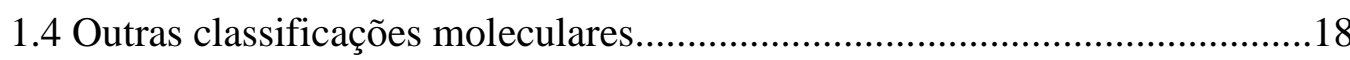

1.4.1 Classificação de Singapura-Duke...........................................18

1.4.2 Classificação asiática.............................................................18

1.4.3 Classificação baseada na expressão gênica e proteica................19

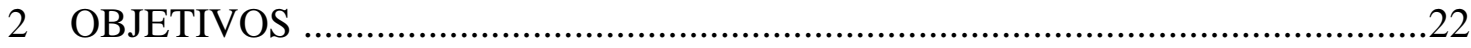

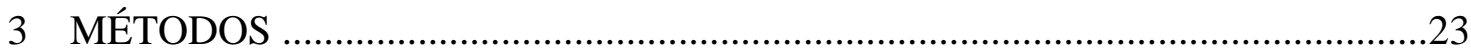

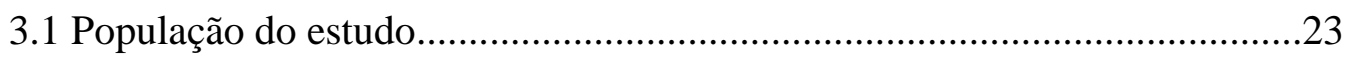

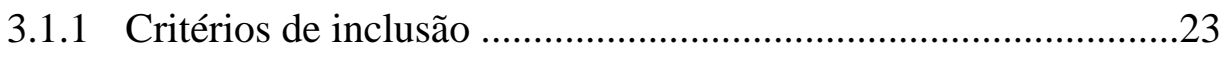

3.1.2 Critérios de exclusão ............................................................23

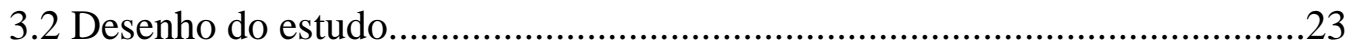

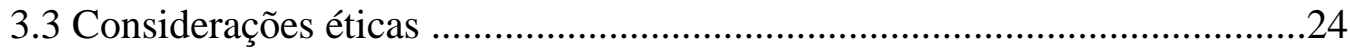

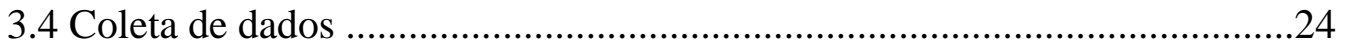

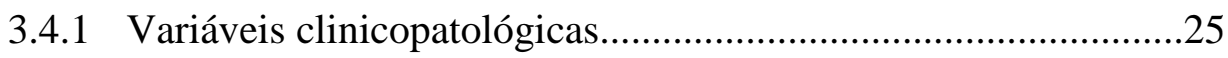

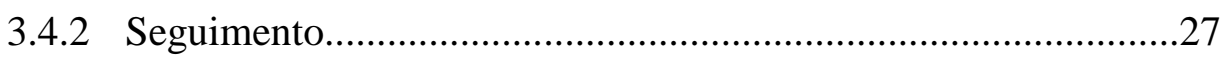


3.5 Análise

Anatomopatológica.

3.5.1 Confecção dos blocos de TMA...............................................27

3.5.2 Análise dos blocos de TMA - Técnica histológica ...................29

3.5.3 Análise dos blocos de TMA - Técnica Imuno-histoquímica.......30

3.5.4 Interpretação dos resultados de expressão proteica.....................32

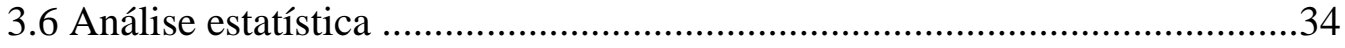

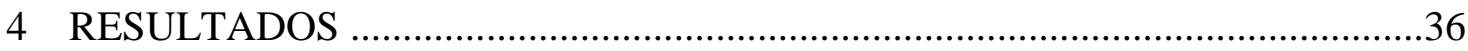

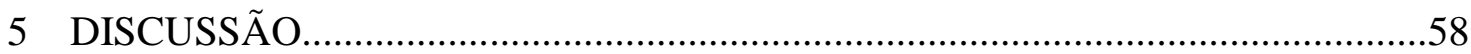

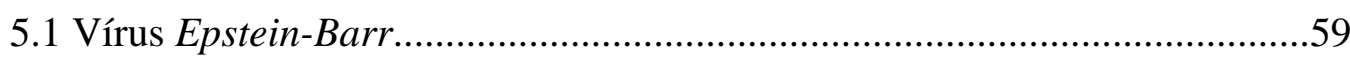

5.2 Instabilidade de microssatélites ...........................................................60

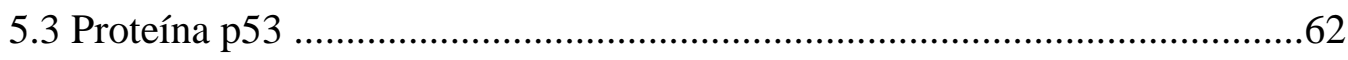

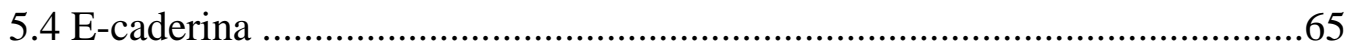

5.5 Considerações sobre classificações baseadas na expressão gênica

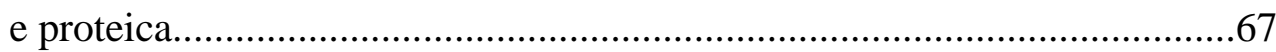

5.6 Considerações metodológicas .............................................................. 71

5.7 Perspectiva da aplicação da classificação molecular....................................73

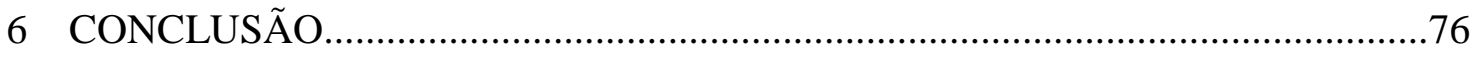

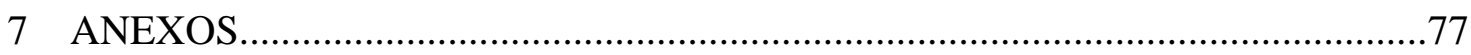

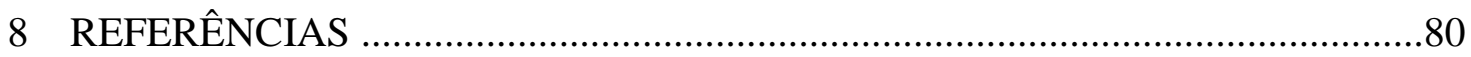

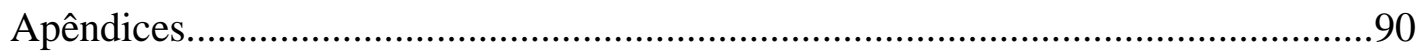




\section{LISTA DE ABREVIATURAS E SIGLAS}

ASA

AUC

$\mathrm{CCI}$

$\mathrm{CG}$

CGaEBV

CIN

CID10

CK

DNA

EBV

ET AL

EGFR

EMT

FDA

GS

GCLS

HCFMUSP

$\mathrm{HE}$

HER2

H.pylori

$H R$

IARC

ICESP

$\mathrm{IH}$

IMC

INCA

ISH

IC95\%

JGCA
American Society of Anesthesiologists

Área sob a curva

Charlson-Deyo comorbidity index

Câncer gástrico

Carcinoma gástrico associado ao EBV

Instabilidade cromossômica

Classificação Internacional de Doenças $10^{\mathrm{a}}$ Revisão

Citoqueratina

Ácido desoxirribonucleico

Vírus Epstein-Barr

E outros

Epidermal growth fator

Transição epitélio-mesenquimal

Food and Drug Administration

Genoma estável

Gastric carcinoma with lymphoid stroma

Hospital das Clínicas da Faculdade de Medicina da Universidade de São Paulo

Coloração de hematoxilina e eosina

Human epidermal growth factor 2 receptor

Helicobacter pylori

Hazard ratio

International Agency for Research on Cancer

Instituto do Câncer do Estado de São Paulo

Imuno-histoquímica

Índice de massa corpórea

Instituto Nacional do Câncer José Alencar Gomes da Silva

Hibridização in situ

Intervalo de $95 \%$ de confiança

Japanese Gastric Cancer Association 
MMR

MSI

MSS

NLR

OMS

OR

PDL1

$\mathrm{pH}$

RNA

RNAm

SCE

SG

SLD

SNP

TCLE

TCGA

TMA

VEGFR-2
Mismatch repair

Instabilidade de microssatélites

Microssatélites estáveis

Razão neutrófilo/linfócito

Organização Mundial da Saúde

Odds ratio

Programmed death-ligand 1

Potencial hidrogeniônico

Ácido ribonucleico

Ácido ribonucleico mensageiro

Sobrevida câncer específica

Sobrevida global

Sobrevida livre de doença

Single nucleotide polymorphisms

Termo de consentimento livre e esclarecido

The Cancer Genome Atlas Research Network

Tissue microarray

Vascular endothelial growth fator 2 receptor 


\section{LISTA DE TABELAS}

Tabela 1 - $\quad$ Especificações dos anticorpos e clones utilizados............................. 31

Tabela 2 - Características clínicas e cirúrgicas dos pacientes ........................... 36

Tabela 3 - Características patológicas dos pacientes ........................................ 37

Tabela 4 - $\quad$ Resultados cirúrgicos ................................................................ 38

Tabela 5 - Características clinicopatológicas de acordo com a classificação molecular TCGA .......................................................................... 41

Tabela 6 - $\quad$ Análise univariada e multivariada para o estado "recidiva".............. 44

Tabela 7 - $\quad$ Análise univariada e multivariada para o estado "óbito".................. 45

Tabela 8 - $\quad$ Estratificação dos marcadores baseados no risco de recidiva. Retirada do marcador menos significativo a cada passo................... 51

Tabela 9 - $\quad$ Comparação entre os grupos de cada classificação............................ 55

Tabela 10 - $\quad$ Desempenho das classificações para determinação de recidiva......... 55

Tabela 11 - $\quad$ Desempenho das classificações para determinação de óbito ............ 56 


\section{LISTA DE FIGURAS}

Figura 1 - Carcinogênese do adenocarcinoma gástrico ....................................... 3

Figura 2 - Adenocarcinoma gástrico tipo intestinal de Laurén............................. 5

Figura 3 - Adenocarcinoma gástrico tipo difuso de Laurén .................................... 6

Figura 4 - Características morfológicas de tumores associados ao EBV................ 9

Figura 5 - Características morfológicas de tumores com MSI................................ 14

Figura 6 - Equipamento utilizado para construção dos blocos de TMA.................. 28

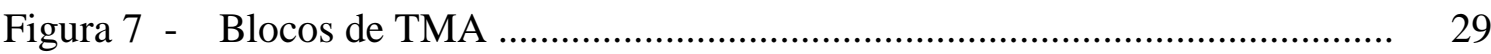

Figura 8 - Lâminas de TMA coradas.................................................................. 32

Figura 9 - Interpretação dos resultados de expressão gênica e proteica.................... 34

Figura 10- Frequência de expressão dos marcadores avaliados............................... 39

Figura 11- Fluxograma da classificação molecular TCGA.................................... 40

Figura 12- Distribuição dos casos de acordo com a classificação TCGA................. 40

Figura 13- Sobrevida livre de doença de acordo com a classificação TCGA............ 43

Figura 14- Sobrevida global de acordo com a classificação TCGA …..................... 43

Figura 15- Fluxograma da classificação asiática.................................................. 46

Figura 16- Distribuição dos casos de acordo com a classificação asiática................ 46

Figura 17- Sobrevida livre de doença de acordo com a classificação asiática.......... 47

Figura 18- Sobrevida global de acordo com a classificação asiática ....................... 47

Figura 19- Fluxograma da classificação por cluster ............................................... 48

Figura 20- Distribuição dos casos de acordo com a classificação por cluster........... $\quad 49$

Figura 21- Sobrevida livres de doença de acordo com a classificação por cluster.... 49

Figura 22- Sobrevida global e acordo com a classificação por cluster.................... 50 
Figura 23- Fluxograma da classificação por risco

Figura 24- Distribuição dos casos de acordo com a classificação por risco.............. 52

Figura 25- Sobrevida livre de doença de acordo com a classificação por risco......... 53

Figura 26- Sobrevida global de acordo com a classificação por risco....................... 54

Figura 27- Curva ROC para determinação de recidiva............................................ 56

Figura 28- Curva ROC para determinação de óbito................................................ 57 


\section{RESUMO}

Ramos MFKP. Caracterização dos subtipos moleculares do câncer gástrico por expressão gênica e proteica [Tese]. São Paulo: Faculdade de Medicina, Universidade de São Paulo; 2019.

INTRODUÇÃO: Recentemente, a classificação molecular do câncer gástrico (CG) emergiu como opção promissora para definir subgrupos prognósticos, distinguir o comportamento biológico, além de permitir a identificação de potenciais alvos terapêuticos para drogas específicas. Por meio de técnicas moleculares, o CG foi dividido em 4 subtipos: instabilidade de microssatélites (MSI), vírus EpsteinBarr (EBV)-positivo, genomicamente estável (GS) e instabilidade cromossômica (CIN). Os custos associados à complexidade técnica das metodologias moleculares são ainda um obstáculo para sua implantação na prática de rotina. OBJETIVOS: Determinar os grupos da classificação molecular por meio da expressão proteica de marcadores associados a cada subtipo. Comparar as diferentes classificações moleculares existentes e propor um novo modelo. MÉTODOS: Foram avaliados, retrospectivamente, 287 pacientes com CG submetidos à gastrectomia-D2 curativa, por meio da construção de tissue microarray. A expressão das proteínas de reparo do DNA, E-caderina e p53 foram avaliadas por imuno-histoquímica (IH), determinando os grupos MSI, GS e CIN, respectivamente. O EBV foi detectado por hibridização in situ (ISH). RESULTADOS: Após avaliação histopatológica, 179 $(62,4 \%)$ pacientes foram classificados como CIN, 58 (20,2\%) MSI, 30 (10,5\%) EBV e $20(7 \%)$ como GS. Os subtipos associaram-se com características distintas, tais como: gênero masculino (EBV, $p=0.101$ ); idade avançada (MSI, $p=0,017$ ), menor relação neutrófilo-linfócito ( $\mathrm{CIN}, p=0,029)$, gastrectomia total (EBV, $p<0,001)$, localização distal (MSI, $p=0,004)$, Laurén difuso (GS, $p<0,001$ ), e estádio avançado (GS, $p=0,014)$. O subtipo MSI apresentou melhor sobrevida livre de doença (SLD) (82,8\%), seguido pelo EBV e CIN (ambos com 70\%) e GS $(50 \%)(p=0.005)$. A sobrevida global (SG) foi maior nos tumores MSI (75,9\%), seguido pelo EBV (73,3\%), CIN (65.4\%) e GS (45\%, mediana de 25 meses) $(p=0.007)$. Em análise multivariada, gastrectomia total, $\mathrm{pT}, \mathrm{pN}$ e os subtipos tumorais foram fatores significativos associados à SLD (MSI $p=0,012$; EBV $p=0,037$; CIN $p=0,018$; GS referência). Do mesmo modo, o tipo de cirurgia, pT, e os subtipos tumorais foram fatores independentes associados a SG (MSI $p=0,010$; EBV $p=0,006$; CIN $p=0,025$; GS referência). Com base no risco de recidiva dos pacientes do estudo, nova classificação, que inclui 5 subtipos, foi proposta. Evidenciou-se que a classificação por risco e cluster tiveram melhor acurácia para identificar recidivas e óbitos respectivamente. CONCLUSÃO: A análise IH/ISH foi capaz de determinar subtipos de CG com características clinicopatológicas e prognósticos distintos, reproduzindo os subtipos obtidos pela classificação molecular.

Descritores: neoplasias gástricas; pesquisa médica translacional; perfil de expressão gênica; biomarcadores; imuno-histoquímica; hibridização in situ. 


\begin{abstract}
Ramos MFKP. Characterization of the molecular subtypes of gastric cancer by gene and protein expression [Thesis]. São Paulo: "Faculdade de Medicina, Universidade de São Paulo"; 2018.

BACKGROUND: Recently, the molecular classification of gastric cancer (CG) emerged as a promising option to define prognostic subgroups, to distinguish biological behavior, and to identify potential therapeutic targets for specific drugs. Through molecular techniques, GC was divided into 4 subtypes: microsatellite instability (MSI), Epstein-Barr virus (EBV) positive, genomically stable (GS) and chromosomal instability (CIN). The costs associated with the technical complexity of the molecular methodologies are still an obstacle to its implementation in routine practice. OBJECTIVES: To determine molecular classification groups by means of protein expression of markers associated with each subtype. To compare the different existing molecular classifications and propose a new model. METHODS: We retrospectively evaluated $287 \mathrm{CG}$ patients submitted to curative D2-gastrectomy through the construction of tissue microarray. Expression of the DNA repair proteins, E-cadherin and p53 were evaluated by immunohistochemistry (IH), determining the MSI, GS and CIN subtypes, respectively. EBV was detected by in situ hybridization (ISH). RESULTS: After the histopathological evaluation, 179 (62.4\%) patients were classified as CIN, 58 (20.2\%) MSI, 30 (10.5\%) EBV and 20 GS (7\%) as GS. The subtypes presented associations with distinct characteristics, such as: male gender (EBV, $p=0.101$ ); advanced age (MSI, $p=0.017$ ), Laurén diffuse type (GS, $p<0.001$ ), lower neutrophil-lymphocyte ratio (CIN, $p=0.029$ ), total gastrectomy (EBV, $p<0.001$ ), distal location (MSI, $p=0.004$ ), and advanced stage (GS, $p=0.014$ ). The MSI subtype presented better disease-free survival (DFS) (82.8\%), followed by the EBV and CIN subtypes (both with 70\%) and GS (50\%) $(p=0.005)$. Overall survival (OS) was higher in MSI tumors (75.9\%), followed by EBV (73.3\%), CIN (65.4\%) and GS (45\%, median of 25 months) ( $p=0.007)$. In multivariate analysis, total gastrectomy, tumor invasion, lymph node metastasis, and tumor subtypes were significant factors associated with SLD (MSI $p=0.012$, EBV $p=0.037, \mathrm{CIN} p=0.018$, GS reference). Likewise, type of surgery, $\mathrm{pT}$, and tumor subtypes were independent factors associated with OS $(p=0.010, p=0.010$, EBV $p=0.006$, CIN $p=0.025$, GS reference). Based on the risk of recurrence, a new classification including 5 subtypes was proposed. It was evidenced that the risk classification and cluster had better accuracy to identify recurrences and deaths respectively. CONCLUSION: The IH / ISH analysis was able to determine CG groups with clinicopathological characteristics and distinct prognoses, reproducing the subtypes obtained by the molecular classification.
\end{abstract}

Descriptors: stomach neoplasms; translational medical research; gene expression profile; biomarkers; immunohistochemistry; in situ hybridization. 


\section{INTRODUÇÃO}

Estima-se que mais de um milhão (1.033.701) de casos novos de câncer gástrico (CG) tenham ocorrido no mundo em 2018 (Bray et al., 2018). Excluindo-se o câncer de pele não melanoma, o câncer de estômago é atualmente o quinto tipo de câncer de ocorrência mais comum no mundo, após o câncer de pulmão, mama, colorretal e próstata. Com relação à mortalidade, o CG é o terceiro mais impactante, após o câncer de pulmão e colorretal. O Instituto Nacional do Câncer (INCA) estima para o Brasil 13.540 casos novos de CG em homens e 7.750 em mulheres no biênio 2018-2019 (Brasil, 2018). Esses valores correspondem a um risco estimado de 13,11 casos novos para cada 100 mil homens e 7,32 para cada 100 mil mulheres.

Diversos fatores genéticos, epigenéticos e ambientais interagem na carcinogênese gástrica. A maioria dos cânceres de estômago surge de maneira esporádica, sem evidência de componentes hereditários. Desta forma, a maior parte das alterações genéticas associadas ao câncer gástrico é adquirida. Menos de $15 \%$ dos casos apresentam agrupamento em famílias. Entretanto, não há associação com mutações germinativas, e menos de $3 \%$ dos casos fazem parte de síndromes de câncer hereditário (Mclean et al., 2014).

As síndromes hereditárias mais comuns são: Câncer gástrico hereditário difuso, associada à mutação germinativa do gene CDH1; Li-Fraumeni; Peutz-Jeghers; Câncer colorretal hereditário não polipóide, e Polipose adenomatosa familiar.

Os fatores de risco ambientais e comportamentais mais comumente relacionados ao desenvolvimento do adenocarcinoma gástrico incluem a infecção pelo $H$. pylori, a baixa ingestão de frutas e vegetais frescos, o alto consumo de sal e o tabagismo (Kelley et al., 2003; Ramos et al., 2018).

Diversos estudos prospectivos relataram forte associação entre infecção crônica pelo $H$. pylori e risco de desenvolvimento de câncer gástrico. A Organização Mundial da Saúde (OMS) classificou o H. pylori como carcinógeno do grupo 1 para humanos. É 
uma das infecções mais comuns no mundo, com prevalência estimada de 50\%, chegando a $90 \%$ nos países em desenvolvimento. Estima-se que cerca de $75 \%$ dos casos de adenocarcinoma gástrico distais sejam decorrentes da infecção crônica pelo $H$. pylori (De Martel et al., 2012). Na maioria das populações em que a prevalência da infecção é alta, ela é geralmente adquirida na infância, persistindo ao longo da vida. Inflamação gástrica crônica e interação entre $H$. pylori e células gástricas epiteliais foram sugeridos como mecanismos de carcinogênese gástrica. Entretanto, apenas uma pequena parcela dos indivíduos infectados por $H$. pylori desenvolve câncer gástrico, indicando a necessidade de interação de fatores ambientais, susceptibilidade genética e variação da cepa da bactéria (IARC, 2012).

A principal via descrita da carcinogênese gástrica é um processo de múltiplas etapas, resultado da exposição e interação de diferentes fatores (Correa et al., 1992). A maioria destes age no microambiente da mucosa gástrica por um prolongado período, ocasionando uma cascata de processos degenerativos, quando a mucosa gástrica normal é alterada para gastrite crônica atrófica, a qual progride para atrofia multifocal e metaplasia intestinal, displasia que, ao final do processo, resulta no aparecimento do carcinoma (Figura 1). 


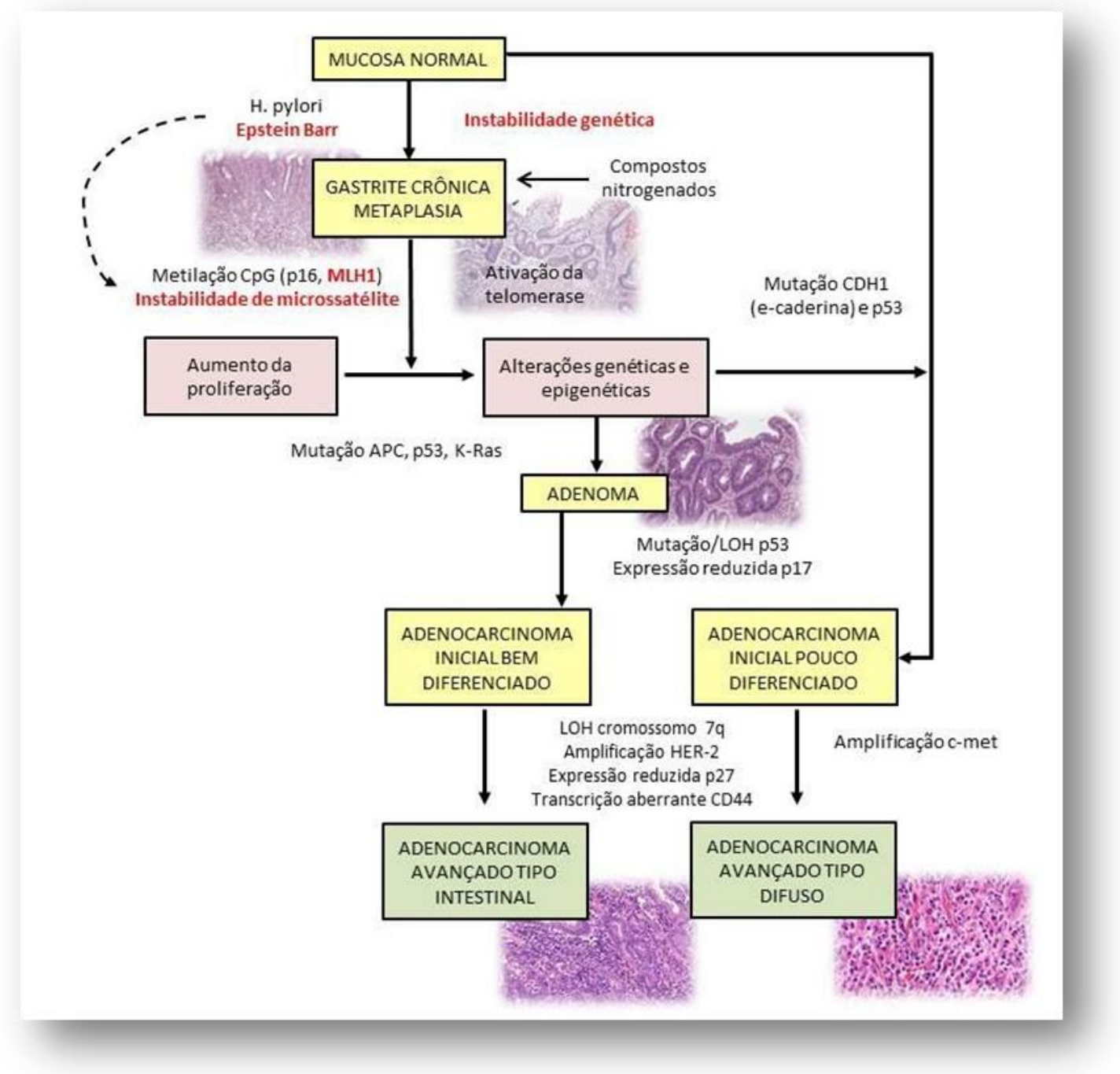

Figura 1. Carcinogênese do adenocarcinoma gástrico. Fluxograma das alterações genéticas e epigenéticas associadas aos tipos intestinal e difuso de Láuren (Modificado de Correa et al., 1992).

Durante o processo de carcinogênese, diferentes genes que desempenham papéis importantes em diversas funções celulares, tais como adesão celular, transdução de sinal, diferenciação, desenvolvimento ou reparo do DNA são alvos dos carcinógenos. Desta forma, a patogênese molecular é multifatorial e heterogênea, e representa um amplo espectro de inúmeras influências genéticas importantes, as quais incluem: instabilidade cromossômica, instabilidade de microssatélites, mudanças no perfil de microRNA, mutações genéticas somáticas ou de polimorfismos de nucleotídeos únicos (single nucleotide polymorphisms - SNP), além de alterações epigenéticas que 
envolvem metilação de DNA. Assume-se que essas alterações sejam responsáveis pela progressão das células de estágio a estágio, até originar o câncer (Tan et al., 2015).

\subsection{Classificação do Câncer gástrico}

Os tumores têm sido classificados de diferentes maneiras ao longo dos anos. Essa estratégia auxilia no entendimento da doença e permite comparações entre tipos semelhantes de tumores, possibilitando o emprego de novas modalidades terapêuticas. Inicialmente, utilizava-se uma classificação anatômica baseada no órgão acometido.

O conceito de benigno e de maligno também começou a ser empregado com base primariamente nas características macroscópicas das lesões. Posteriormente, tentou-se classificar os tumores de acordo com a região do órgão acometido. Por fim, o desenvolvimento de técnicas de microscopia e fixação de tecidos possibilitou a criação de classificações baseadas na histologia, as quais persistem até hoje como principal forma de classificar o CG.

\subsection{Classificação histológica}

A análise histológica dos tumores e a definição de diferentes subtipos propiciou grande impulso no entendimento das neoplasias gástricas. $\mathrm{O}$ adenocarcinoma é o tipo histológico mais comumente encontrado, representando cerca de $95 \%$ das neoplasias gástricas. As outras neoplasias encontradas no estômago incluem tumores do estroma gastrointestinal, leiomiomas, linfomas e tumores neuroendócrinos.

Os adenocarcinomas podem ser divididos de acordo com a classificação histológica mais comumente utilizada em dois subtipos: intestinal e difuso (Laurén, 1965). Estes dois tipos histológicos de adenocarcinoma apresentam diferenças em relação a aspectos epidemiológicos, etiológicos, patogênese e comportamento biológico.

O tipo intestinal ocorre comumente em pacientes mais idosos, com predileção pelo sexo masculino, associado à presença de gastrite crônica atrófica e metaplasia intestinal decorrentes da inflamação gástrica crônica associada à infecção pelo $H$. pylori. Predomina em áreas geográficas com alta incidência de câncer gástrico, como a 
Ásia Oriental, Europa Oriental, América Central e do Sul, e está relacionado à recente redução de incidência do CG. Essas características sugerem que o desenvolvimento de tumores do tipo intestinal está mais relacionado a fatores ambientais e comportamentais do indivíduo.

Morfologicamente, as células tumorais tendem a se agrupar em formações glandulares ou tubulares similares a outros tipos de adenocarcinoma do trato gastrointestinal (Figura 2). Apresentam predileção por disseminação linfática e hematogênica, com menor grau de infiltração na parede gástrica (Correa et al., 1992; Bray et al., 2018).

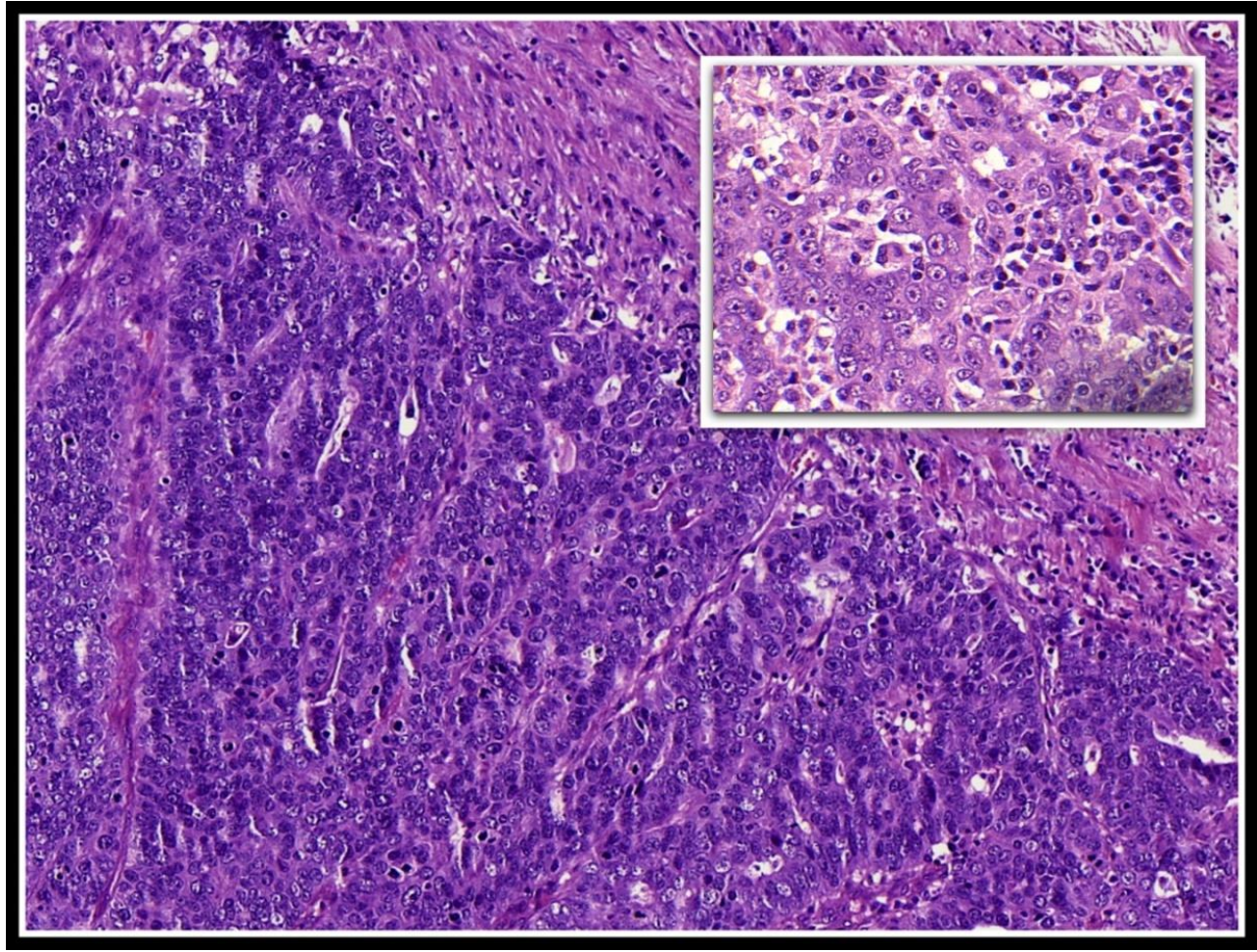

Figura 2 - Adenocarcinoma gástrico tipo intestinal de Laurén. Observam-se células neoplásicas formando estruturas tubulares ou glandulares. Adenocarcinoma Tubular (OMS), moderadamente diferenciado (coloração hematoxilina-eosina, aumento de 200x).

O tipo difuso ocorre em pacientes mais jovens, com distribuição igualitária entre os sexos, e tem comportamento mais agressivo quando comparado ao tipo intestinal. Origina-se do epitélio gástrico normal, sem aparente lesão pré-neoplásica, e pode estar relacionado à mutação somática do gene $\mathrm{CDH} 1$. 
O CDH1 é um gene supressor tumoral que codifica a E-caderina, uma proteína de adesão celular que mantém a polaridade celular. Sob o ponto de vista histológico, tumores difusos apresentam perda da coesão celular com formação de células em anel de sinete (Figura 3). As células tumorais crescem e invadem as estruturas adjacentes sem a formação de estruturas glandulares ou tubulares. A maioria dos pacientes não apresenta infecção pelo $H$. pylori. A distribuição de sua incidência é semelhante em todo o mundo, sem apresentar tendência de queda temporal como vem ocorrendo com o tipo intestinal. O padrão de disseminação é hematogênico e peritoneal, com maior grau de infiltração na parede gástrica (Pernot et al., 2015).

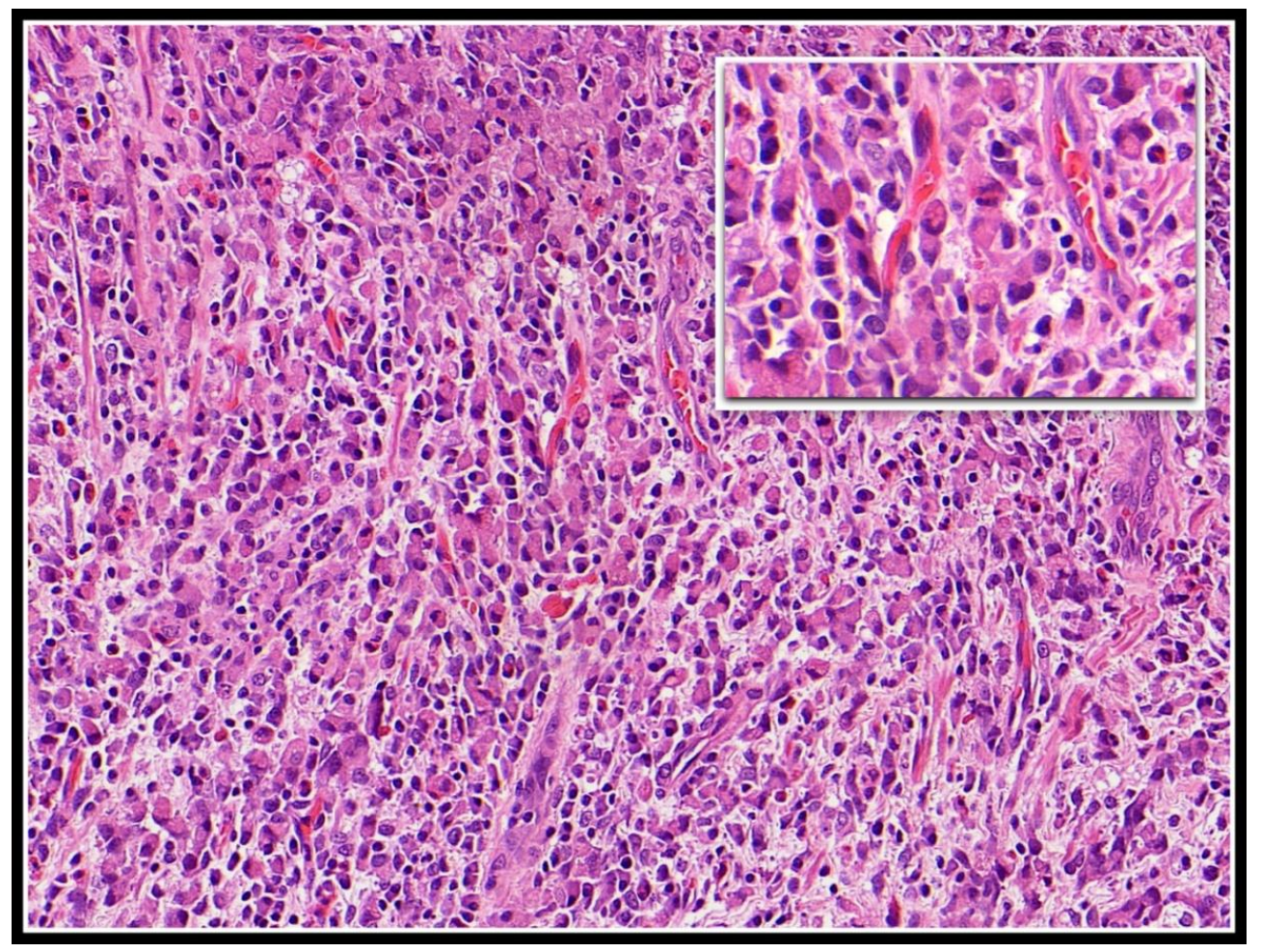

Figura 3 - Adenocarcinoma gástrico tipo difuso de Laurén. Notam-se várias células neoplásicas difusamente distribuídas, caracterizadas por alteração da relação núcleo-citoplasma, com presença de células em anel de sinete. Carcinoma de células pouco coesas (OMS), pouco diferenciado (coloração hematoxilina-eosina, aumento de 200x).

Outras classificações histológicas foram desenvolvidas e são empregadas em diferentes regiões do mundo (JGCA, 2010). A classificação da Organização Mundial da Saúde inclui subtipos raros não discriminados na de Laurén (Bosman et al., 2010). Sem dúvida, todas as classificações representam avanços na classificação dos tumores gástricos. Porém, a heterogeneidade da doença e sua gênese multifatorial não é 
devidamente contemplada por quaisquer delas. A correlação com desfecho clínico também é insuficiente, visto que pequena diferença de sobrevida é encontrada entre diferentes subtipos de tumores.

\subsection{Classificação Molecular}

Em 2014, uma nova classificação baseada no perfil molecular do câncer gástrico foi proposta pela The Cancer Genome Atlas Research Network (TCGA). O objetivo dessa classificação foi caracterizar as alterações nas vias de regulação intracelular e os possíveis candidatos que contribuíam para o desenvolvimento das distintas categorias de tumores gástricos. Para sua definição, utilizaram-se múltiplas e avançadas técnicas moleculares que incluíam: sequenciamento de DNA; sequenciamento de RNA; sequenciamento de todo o exoma; análise de variação do número de cópias; sequenciamento do microRNA, e análise de metilação de DNA.

Deste modo, os tumores gástricos foram categorizados em quatro subtipos com base no perfil molecular:

1) Epstein-Barr virus (EBV) positivo, com frequente hipermetilação do DNA;

2) "Microssatélites instáveis" (MSI) caracterizados por apresentar hipermutação, fenótipo metilador de ilhotas $\mathrm{CpG}$ (CpG-island methylator phenotype, gastric) e frequente silenciamento do MLH1;

3) "Genoma estável” (GS), que apresenta histologia difusa, frequentes mutações no CDH1 e RHOA, e fusão do CLDN18-ARHGAP;

4) "Instabilidade cromossômica" (CIN), a qual tem como características principais a histologia intestinal, frequentes mutação da p53, aneuploidia e amplificação dos receptores de tirosina quinase.

Cada um desses subtipos apresenta um conjunto de características distintas, com alterações genéricas e epigenéticas próprias, os quais refletem em um fenótipo específico.

Algumas características clínicas dos subtipos merecem ser citadas. 
Todos os subtipos foram encontrados em todas as regiões do estômago. Porém, tumores com instabilidade cromossômica (CIN) tiveram maior ocorrência na cárdia e transição esofagogástrica $(65 \%, p=0,012)$. Em contrapartida, a maioria dos tumores associados ao EBV estavam presentes no fundo gástrico ou corpo $(62 \%, p=0,03)$.

Outros achados evidenciaram que tumores com genoma estável (GS) foram diagnosticados em idade mais precoce (mediana=59 anos), enquanto que os tumores com instabilidade de microssatélites (MSI) ocorreram em idades relativamente mais avançadas (mediana=72 anos). Pacientes com MSI tenderam a ser mulheres (56\%, $p=0,001)$, mas a maioria dos tumores associados ao EBV eram em pacientes homens (81\%, $p=0,037)$. Infelizmente, como muitos pacientes do estudo haviam sido operados em tempo recente, o período de seguimento desses casos foi curto e incompleto.

As características de cada subtipo molecular são detalhadas na sequência.

\subsubsection{Tumores gástricos associados ao EBV}

O Epstein-Barr virus (EBV) está implicado na etiologia de várias desordens linfoproliferativas, como a mononucleose infecciosa, alguns tipos de linfoma de células B e neoplasias epiteliais, como o carcinoma de nasofaringe indiferenciado (Connolly et al., 2011; Shibata et al., 1992; Tsao et al., 2015). No câncer gástrico, o EBV está associado principalmente à ocorrência de um subtipo específico de câncer gástrico denominado carcinoma gástrico com estroma linfóide - gastric carcinoma with lymphoid stroma (GCLS) - também conhecido como carcinoma medular ou carcinoma do tipo "lymphoepithelioma-like". A infecção pelo EBV está presente em cerca de $80 \%$ dos casos de GCLS. Além disso, cerca de 9\% dos demais adenocarcinomas gástricos também apresentam infecção pelo EBV (Shibata et al., 1992; Fukayama et al., 2011; Ramos et al., 2017).

O GCLS é um tipo especial de CG que compreende cerca de $1 \%$ a $4 \%$ de todos os casos de CG. É microscopicamente um carcinoma pouco diferenciado, caracterizado por apresentar intenso infiltrado linfocitário (denso e difuso), sendo que a quantidade de células do infiltrado é maior do que a de tumor. Devido à proeminente infiltração linfocítica, muitas vezes se torna difícil identificar células tumorais em meio ao infiltrado somente com a coloração de hematoxilina e eosina (HE). É possível 
diferenciar as células neoplásicas em meio ao infiltrado inflamatório, usando-se a coloração imuno-histoquímica $(\mathrm{IH})$, com anticorpos para citoqueratina $(\mathrm{CK})$, ou pela técnica hibridização in situ (ISH) para o transcrito viral EBER, uma vez que as células tumorais são positivas para CK e para EBER (Figura 4).

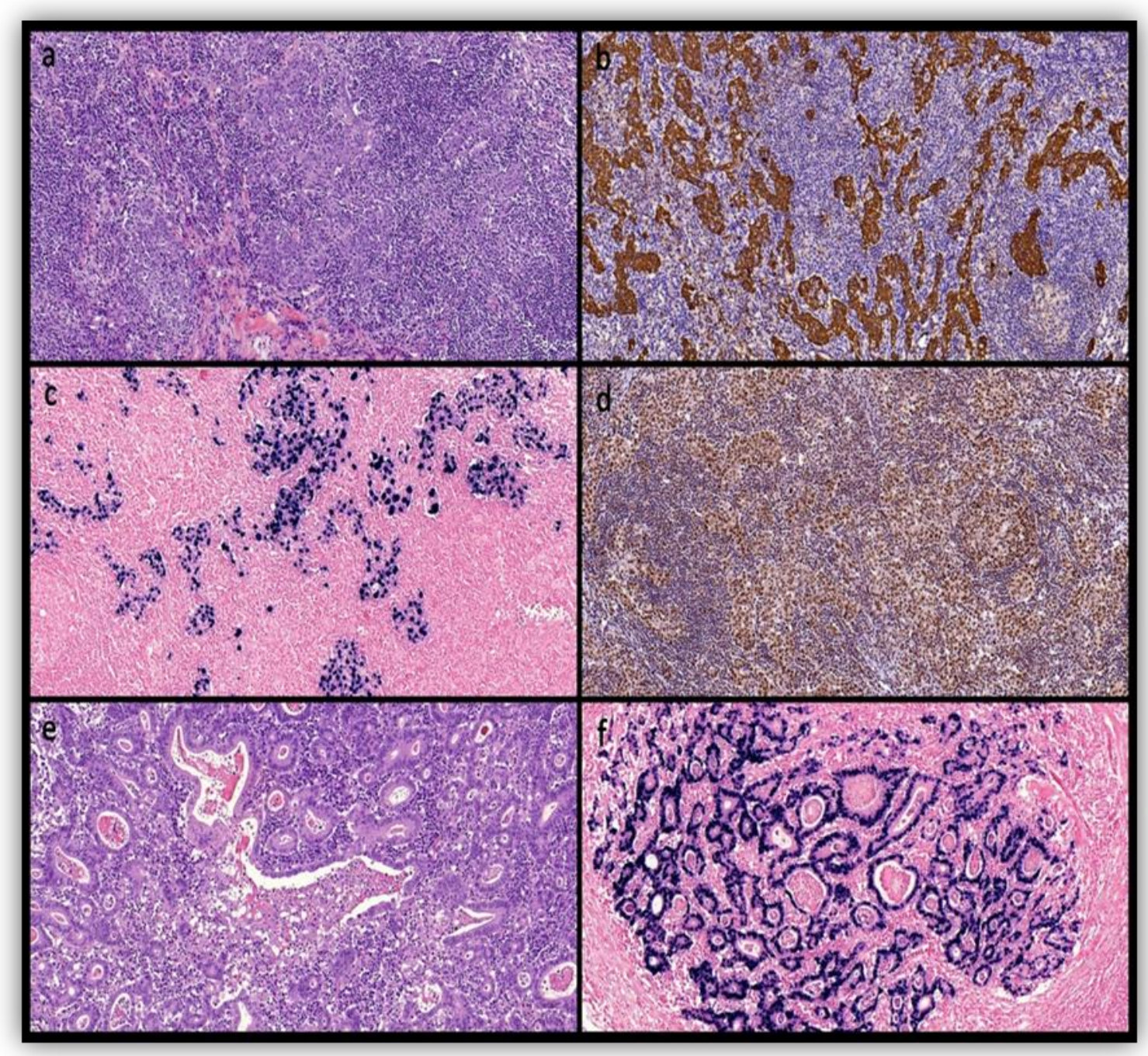

Figura 4. Características morfológicas de tumores associados ao EBV. (a) CG do tipo GCLS, mostrando células tumorais em meio a intenso infiltrado inflamatório (HE); (b) IH para CK AE1/AE3, apresentando as células tumorais positivas para citoqueratina; (c) reação ISH positiva para EBV; (d) IH positiva para expressão de MLH1 (linfócitos e epitélio normal exibindo marcação nuclear serviram como controles internos positivos); (e) área tumoral com diferenciação tubular (HE); (f) reação de ISH positiva para EBV na região de adenocarcinoma tubular. Note que o epitélio não neoplásico adjacente aparece negativo para a reação.

Além do GCLS, 9\% dos adenocarcinomas gástricos apresentam ainda infecção associada pelo EBV, sendo denominados carcinoma gástrico associado ao EBV CGaEBV (Ooi et al., 2009; TCGA, 2014; Cristescu et al., 2015, Pereira et al., 2018). 
Esses tumores ocorrem com maior frequência em homens $(2: 1)$, pacientes em idade menos avançada, e os tumores geralmente são da porção proximal do estômago ou de coto gástrico (Shinozaki-Ushiku et al., 2015). A frequência de tumores EBV-positivos em pacientes submetidos à degastrectomia varia de 6\% a 30\% (Murphy et al., 2012). Tais achados sugerem que danos repetitivos à mucosa gástrica, como refluxo biliar e alterações no microambiente, podem estar envolvidos no desenvolvimento de CGaEBV. Fatores de risco, como a ingestão de alimentos salgados ou picantes; consumo frequente de café e bebidas quentes, e tabagismo são também associados ao desenvolvimento de CGaEBV. (Shinozaki-Ushiku et al., 2015).

Uma das principais características geralmente relacionadas ao CGaEBV é a baixa incidência de metástase linfonodal, menor invasão tumoral e invasão linfática, com sobrevida relativamente maior em comparação aos casos de câncer gástrico EBV negativo. Entretanto, essa associação ainda é controversa, visto que alguns autores apontam não haver correlação entre a infecção por EBV e as categorias pT e pN (Lee et al., 2009).

Macroscopicamente, os CGaEBV são tumores ulcerados de bordas elevadas ou ulcerados (Borrmann II ou III). Nos estágios inicias, tendem a formar lesões nodulares bem delimitadas na submucosa, com menos fibrose quando comparados aos casos EBV negativos, podendo ser bons candidatos à ressecção endoscópica. Histologicamente, apresentam padrão cribiforme, classificados como tipo intestinal de Laurén, com quantidades variáveis de linfócitos infiltrantes. Morfologicamente, é quase idêntico ao carcinoma gástrico EBV negativo, fazendo como que a EBER-ISH seja também recomendada para identificar a presença de EBV nas células tumorais e confirmar o diagnóstico (Shinozaki-Ushiku et al., 2015).

A indicação de que o EBV esteja relacionado ao processo oncogênico é baseada na presença do vírus em quase todas as células tumorais dos CGaEBV, e no caráter monoclonal dessas células. A entrada do EBV nos Linfócitos B ocorre por meio da ligação da proteína gp350 ao receptor CD21. Entretanto, as células epiteliais não expressam CD21. Deste modo, acredita-se que a infecção do vírus na célula epitelial gástrica ocorra principalmente pelo contato célula-célula entre linfócitos infectados e a célula gástrica. A gastrite crônica pode aumentar a chance de interação entre células epiteliais gástricas e os Linfócitos $\mathrm{B}$, permitindo às citocinas produzidas por células 
inflamatórias dar suporte ao crescimento de células epiteliais gástricas infectadas com EBV (Iizasa et al., 2012).

O ensaio de hibridização in situ (ISH), utilizando sondas complementares ao EBER1, é considerado padrão-ouro para a detecção do EBV, admitindo a identificação das células infectadas pelo vírus. Os EBERs são os transcritos virais mais abundantes encontrados em células latentes infectadas pelo EBV (Tsuchiya, 2012; ShinozakiUshiku et al., 2015). Todas as células tumorais apresentam positividade nuclear para EBER-ISH. Embora bastante rara, a infecção por EBV já foi também descrita em pequenas porções da mucosa gástrica não neoplásica em uma única célula ou em algumas glândulas, sugerindo que a infecção por EBV precede o crescimento clonal e o desenvolvimento do carcinoma (Fukayama et al., 1994).

Uma característica do CGaEBV é a presença de inúmeras células inflamatórias no infiltrado tumoral, fato que também é compartilhado por outras doenças malignas relacionadas ao EBV, tais como o linfoma de Hodgkin e linfoma difuso de grandes células B EBV-positivos, os quais são geralmente acompanhados por numerosas células inflamatórias reativas. Esta característica reflete a imunogenicidade do EBV e reforça a hipótese de que a resposta imune do hospedeiro é uma das razões para o melhor prognóstico observado nesses tumores (Fukayama et al., 2011).

\subsubsection{Tumores com microssatélites instáveis}

O DNA é uma molécula que frequentemente sofre alterações advindas de perdas de segmentos e mutações ocorridas durante o processo de divisão celular. Para corrigir tais alterações, são produzidas algumas proteínas com a função de realizar reparos necessários para manter a integridade do DNA, a partir de genes conhecidos como "genes de reparo" (mismatch repair genes - MMR genes). Os genes MMR atuam de forma contínua, assegurando que cada informação genética seja corretamente copiada durante a replicação do DNA. Mutações nesses genes levam ao aumento na frequência de outras mutações (Gervaz et al., 2003).

A Instabilidade de microssatélites (MSI) é uma forma de instabilidade genética resultante da inativação das proteínas codificadas pelos genes de reparo do DNA. Os principais genes de reparo do DNA envolvidos na MSI são: hMLH1 (Gene Human mut- 
L Homologue 1), hMSH2 (Gene Human mut-S Homologue 2), hMSH6 (Gene Human mut-S Homologue 6). Embora os genes estejam suscetíveis a mutações ao acaso, a maioria delas é eliminada pelo sistema de reparo (Jeon et al., 2008).

Os tumores com MSI podem ser divididos em dois grupos, de acordo com o nível de instabilidade: os de "alta-MSI" (high-level instability, MSI-H) e aqueles com "baixaMSI" (low-level instability, MSI-L). Os tumores que não apresentam instabilidade são denominados “estáveis" (microsatellite stable, MSS). A MSI-H pode ser evidenciada pela perda da expressão das proteínas MMR determinada por imuno-histoquímica. Os MSI-L não apresentam geralmente alterações na expressão das proteínas visualizadas pela avaliação IH (Umar et al., 2004).

A ausência de função normal de reparo do DNA, demonstrada pela ocorrência de grande número de alterações nas sequências de microssatélites, podem originar o desenvolvimento neoplásico, acelerando o acúmulo de mutações em oncogenes e genes supressores tumorais. A MSI pode ser encontrada em tumores de pacientes com câncer colorretal não-polipoide hereditário e em vários outros subconjuntos de tumores esporádicos, incluindo o câncer gástrico (Zhu et al., 2015). Tendo em vista a importância no desenvolvimento de processos neoplásicos, os microssatélites são considerados marcadores fenotípicos de prognóstico e resposta terapêutica, sendo que a identificação de pacientes com mutação nos genes de reparo do DNA pode ter importante aplicação na prática clínica (Falchetti et al., 2008).

O silenciamento do gene hMLH1 pode também ser visto nas etapas morfológicas consideradas pré-malignas, relatando-se o aumento progressivo na frequência de metilação do gene em amostras de carcinoma, adenomas e áreas de metaplasia. Este achado na mucosa não tumoral fortalece a proposição de que a MSI seria um fenômeno precoce ocorrido de forma gradual ao longo da progressão da carcinogênese. A metilação precoce pode, portanto, representar um fator de risco para identificação de pacientes com maiores chances de desenvolver um tumor (Waki et al., 2002).

Os tumores com MSI são também caracterizados pelas altas taxas de mutação. A perda de função de MLH1, resultante da metilação do gene, pode ocasionar mutações principalmente nos genes TP53, KRAS, ARID1A, PIK3CA, ERBB3 e PTEN (TCGA, 2014) 
Estima-se que a frequência de MSI no câncer gástrico esteja em torno de 20\%, variando conforme o grupo de pacientes estudados e a quantidade de marcadores examinados. A metilação de ilhas $\mathrm{CpG}$ em regiões promotoras do gene hMLH1 é a alteração mais frequentemente associada aos carcinomas gástricos esporádicos que exibem fenótipos MSI-H e MSI-L (Perez et al., 2004; Yasui et al. 2005; Zhu et al., 2015).

Os carcinomas gástricos com MSI apresentam algumas características particulares quando comparados aos carcinomas com fenótipo MSS. De modo geral, são mais frequentes em pacientes com idade mais avançada, tumores de maior extensão, localização distal e configuração macroscópica Borrmann II. São predominantemente do tipo intestinal de Laurén, pouco diferenciados, com expressão de MUC6 (mucina do tipo gástrico) e apresentam fenótipo foveolar com morfologia papilar e infiltrado linfocitário acentuado. Outra característica importante é a menor incidência de metástase linfonodal (Seo et al.; 2009; Yasui et al., 2005; Zhu et al., 2015). Não obstante, alguns relatos referem que a frequência de MSI é significativamente maior em pacientes com mais de um foco tumoral. Esse fenômeno é provavelmente desencadeado pelo acúmulo de alterações genéticas, as quais criam um ambiente propicio ao desenvolvimento de outro tumor primário (Takahashi et al., 2002; Ribeiro et al., 2007). 


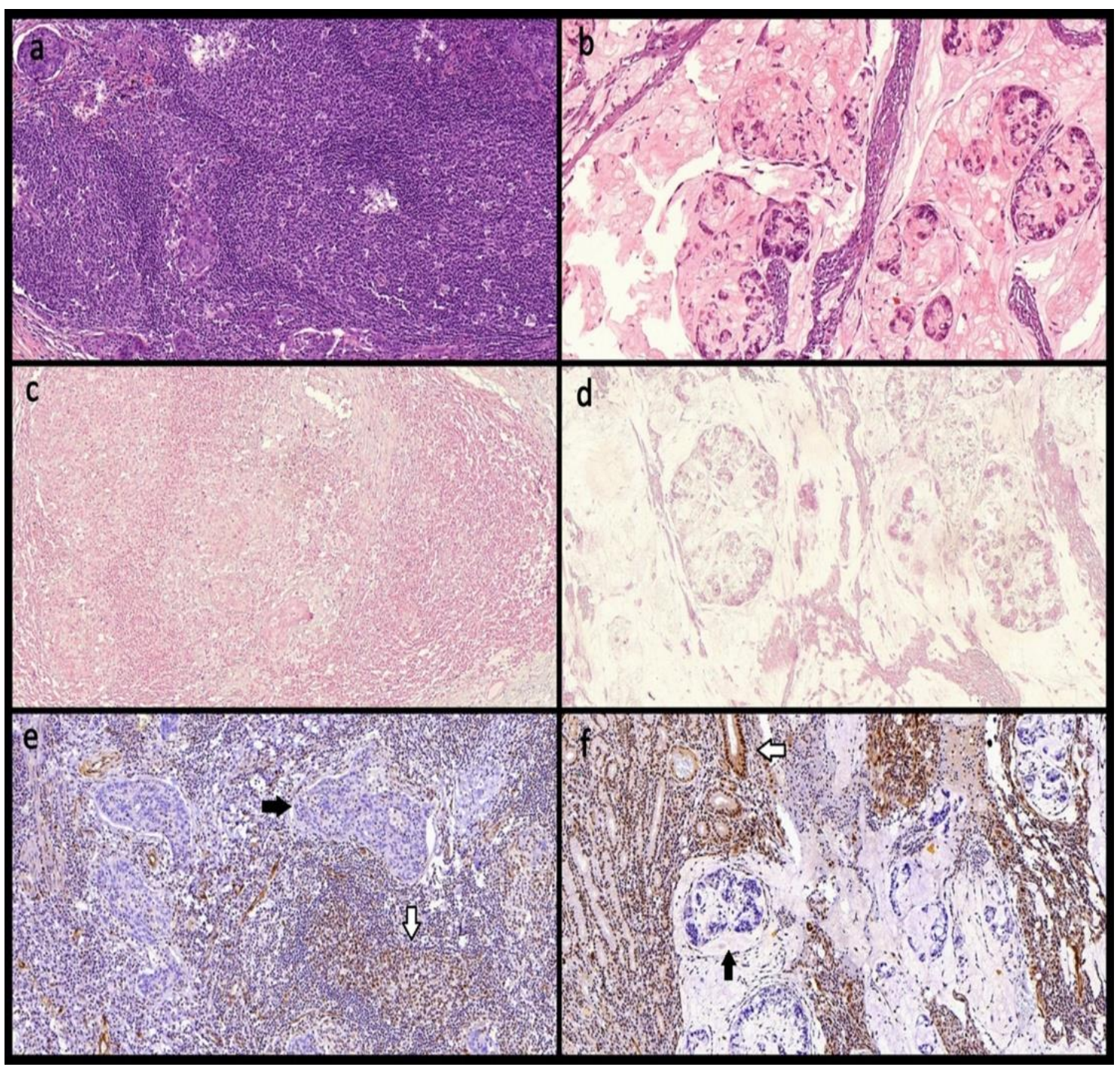

Figura 5. Características morfológicas de tumores com MSI. (a) CG do tipo GCLS, apresentando intenso infiltrado inflamatório entre as células tumorais; (b) área tumoral com diferenciação mucinosa (HE); (c) Reação de ISH negativa para EBV; (d) Reação de ISH negativa para EBV na área mucinosa; (e) IH mostrando perda da expressão de MLH-1 no tumor (seta preta). Linfócitos e células estromais servem como controle interno positivo (seta branca); (f) IH mostrando perda da expressão de MLH-1 na área mucinosa (seta preta). Note a presença de coloração positiva nos linfócitos e mucosa normal (seta branca).

A relação entre a MSI e o prognóstico de pacientes com câncer gástrico é um aspecto ainda controverso, com resultados variados sobre sua relação com agressividade tumoral e sobrevida em comparação aos tumores gástricos MSS. Entretanto, a maioria dos estudos associa a presença de MSI a um comportamento menos agressivo e menor estádio pTNM, reduzindo o risco de mortalidade em até $37 \%$ em comparação com aqueles com MSS (Kim et al., 2014; Zhu et al., 2015, Pereira et al., 2018). Uma das características nos carcinomas gástricos com MSI se refere à presença de acentuado 
infiltrado linfocitário, particularmente o composto por Linfócitos T CD8. Tumores de diferentes órgãos e com apresentação desse fenótipo são geralmente associados a melhor prognóstico. Uma possível hipótese para isso seria de que a deficiência na expressão das enzimas de reparo provoca a geração de múltiplos peptídeos imunogênicos, os quais estimulam a resposta imune antitumoral.

\subsubsection{Tumores com instabilidade cromossômica (CIN)}

A Cancer Genome Atlas Research Network definiu o critério de instabilidade cromossômica baseada na presença de extensas aberrações somáticas. Inicialmente, apenas mutações de substituições de base foram avaliadas e dez genes significativamente mutados foram encontrados. Estes genes incluíam TP53, KRAS, ARID1A, PIK3CA, ERBB3, PTEN e HLA-B. Posteriormente, ao incluir na análise também inserções e deleções, a lista de genes aumentou para 37, incluindo o RNF43, B2M e NF1. Dentre os genes encontrados, destaca-se a mutação do gene TP53, que ocorreu em $71 \%$ dos casos. Alterações de CMET, HER2, EGFR e VEGFR também foram encontradas, abrindo a possibilidade do emprego de anticorpos monoclonais já disponíveis na prática clínica neste subtipo.

O Trastuzumabe é um anticorpo monoclonal, cujo alvo terapêutico é o receptor HER2 (Human epidermal growth factor 2 receptor), sendo indicado como $1^{\text {a }}$ linha no tratamento paliativo de tumores gástricos HER2 positivos (Bang et al., 2010). O Ramucirumabe é um anticorpo monoclonal empregado no tratamento de $2^{\mathrm{a}}$ linha do câncer gástrico metastático, cujo alvo é o Vascular endothelial growth fator 2 receptorVEGFR2 (Fuchs et al., 2014).

O TP53 é um gene supressor tumoral composto por onze exons, que codifica a proteína p53. A p53 é uma proteína nuclear considerada a guardiã do genoma, envolvida em muitas funções celulares relacionadas ao ciclo celular, apoptose, restauração do DNA, envelhecimento celular e angiogênese (Gonçalves et al., 2011). Uma quebra na via de supressão tumoral da p53 pode resultar no desenvolvimento de diversas neoplasias, incluindo o câncer gástrico. Especula-se que a infecção pelo $H$. pylori, um dos fatores envolvidos na carcinogênese gástrica, antagoniza a função de 
supressão tumoral da p53. Além disso, a infecção pode causar mutações no gene TP53 (Wei et al., 2010).

Sequenciamento do gene TP53 é o método empregado para detectar uma mutação. Cerca de $75 \%$ das mutações são do tipo missense. Outras alterações possíveis incluem mutações pontuais, perda de heterozigose e polimorfismos. Na prática clínica, uma forma de verificar alterações do gene TP53 é estudar a expressão da proteína p53, com emprego da IH (Ando et al., 2015). Embora a localização nuclear seja essencial para sua atividade, o acúmulo da proteína no núcleo pode não ser detectado devido ao curto tempo de meia-vida da proteína "selvagem" (wild-type). Em contraste, mutações do TP53 resultam na produção de proteínas com meia-vida prolongada, fazendo com que essa se acumule no núcleo. Muitos anticorpos empregados na IH detectam tanto formas mutantes quanto formas selvagens da p53, possibilitando a detecção de acúmulos nucleares fisiológicos (Fenoglio-Preisier et al., 2003). Dessa forma, a expressão aberrante da p53 pode ser definida tanto pela ausência de expressão quanto pela expressão difusa exacerbada.

Tumores com mutação do gene TP53 são frequentemente observados em pacientes com idade mais avançada e histologia do tipo intestinal associada a gastrite crônica atrófica multifocal, metaplasia intestinal e displasia (Safatle-Ribeiro et al., 1996). Infecção pelo $H$. pylori pode induzir mutações no TP53, sugerindo uma ação sinérgica de ambos na carcinogênese gástrica (Ando et al., 2015).

\subsubsection{Tumores com genoma estável (GS)}

Os tumores GS também apresentam diferentes mutações somáticas, embora com carga menor em relação aos CIN. Os genes mais tipicamente alterados são o CDH1 e o RHOA. Mutações somáticas do CDH1 ocorrem com maior frequência nos tumores GS (37\%). Mutações de inativação do ARID1A também são prevalentes. Sugere-se que a perda da expressão da E-caderina seja a manifestação fenotípica de mutações do CDH1 e RHOA (Carneiro et al., 2012).

A E-caderina é uma molécula de adesão essencial para consolidação da arquitetura epitelial, manutenção da polaridade celular e diferenciação tanto durante o desenvolvimento fetal quanto na vida adulta. Ela age como um supressor tumoral de 
ampla atuação. É codificada pelo gene CDH1 localizado no cromossomo 16q22 (Carneiro et al., 2012). Alterações na sua expressão ocasionam distúrbios na adesão e estrutura celular, interações estromais aberrantes, alterações na migração e sinalização celular, promovendo o desenvolvimento de um potencial oncogênico. Desta forma, a expressão reduzida de E-caderina, devida majoritariamente à diminuição dos níveis da proteína e expressão de RNAm, é considerada indicativo de pior prognóstico.

A expressão alterada da E-caderina pode ser evidenciada pela sua perda total de expressão na membrana celular ou pela expressão citoplasmática aberrante. A expressão citoplasmática também já foi relatada como "marcação aberrante heterogênea" ou "marcação paranuclear". Sugere-se que isso ocorra por aprisionamento da E-caderina no complexo de Golgi, pela falta de modificações pós-translacionais que permitem seu transporte para a membrana (Carpenter et al., 2002).

Já as mutações do RHOA ocorrem quase que exclusivamente nos tumores GS, sendo encontrada em 15\% dos casos. Devido ao papel da RHOA na motilidade celular, sua modulação pode contribuir para o crescimento descontrolado e perda da coesão celular, características dos tumores difusos (Chang et al., 2016). Outra proteína associada aos tumores GS é a Claudina 18 (CLDN18), que faz parte dos componentes da estrutura de adesão celular "tight junctions". A fusão da CLDN18 com o ARHGAP26 afeta potencialmente a regulação da RHOA, alterando a motilidade e coesão celular. Alterações da CLDN18 ou da RHOA são encontradas em $30 \%$ dos tumores com genoma estável (TCGA, 2014).

Tumores GS tendem a ocorrer em pacientes mais jovens com categorias $\mathrm{T}$ e $\mathrm{N}$ mais avançadas, apresentando pior prognóstico. Do ponto de vista morfológico, a principal característica desse subtipo é a maior ocorrência de tumores do tipo difuso com células em anel de sinete. Outra maneira de denominar esse subtipo é transição epitélio-mesenquimal (epithelial-to-mesenchymal transition - EMT) (Cristescu et al., 2014). 


\subsection{Outras classificações moleculares}

Além da classificação molecular proposta pela TCGA demonstrada acima, outras classificações foram realizadas, utilizando-se diferentes métodos e subgrupos para caracterização molecular do CG.

\subsubsection{Classificação de Singapura-Duke}

Apesar de ter sido realizada no ano de 2009, anteriormente à classificação da TCGA, a Classificação de Singapura-Duke acabou não alcançando tanto destaque (Ooi et al., 2009). Para sua definição, foram estudadas onze vias de carcinogênese gástrica: RAS, p53, BRCA1, p21, Wnt/B-catenina, E2F, SRC, MYC, NF-KB, histonas deacetiladas e assinaturas relacionadas a células-tronco. Com base no padrão de ativação das vias oncogênicas, três grupos foram identificados, representando assinaturas moleculares distintas com diferentes expressões genéticas e epigenéticas:

1) Proliferativo: caracterizado por alta taxa de mutação do gene TP53 e ativação de vias oncogênicas;

2) Metabólico: baixa taxa de mutação do TP53, com expressão de genes característicos de mucosa gástrica normal e vias metabólicas;

3) Mesenquimal: baixa expressão de CDH1 e TP53, aumento de marcadores de células tronco, características genéticas da via transição epitéliomesenquimal.

\subsubsection{Classificação Asiática - Asian Cancer Reserch Group (ACRG)}

Cristescu et al. publicaram em 2015 a proposta do Grupo Asiático de Pesquisa do Câncer ("Asian Cancer Research Group”) para classificação molecular do CG. Posteriormente, essa classificação ficou mais conhecida como Classificação Asiática. Foram incluídos trezentos pacientes sul-coreanos e a análise avaliou o perfil de expressão genética (genome-wide copy number microarray), por meio do sequenciamento de genes alvos. Os autores propuseram a divisão em quatro subtipos:

1) Instabilidade de microssatélites (MSI): associado principalmente à mutação/silenciamento do gene MLH1. Ocorre com maior frequência em 
tumores de localização distal, tipo histológico intestinal e estádios mais precoces;

2) Transição epitélio-mesenquimal (MSS/EMT): associado à perda da expressão da E-caderina (CDH1). Apresenta menor ocorrência de mutações do que os outros tumores com MSS. Ocorre em pacientes mais jovens, com tumores do tipo difuso e estádios mais avançados;

3) Microssatélite estável/P53+ (MSS/TP53+): apresenta função preservada do gene TP53 e CDKN1A (p21). Apresenta maior associação com EBV;

4) Microssatélite estável/p53- (MSS/TP53-): é o maior dos grupos, representando 35\% dos casos, e apresenta perda funcional do gene TP53. Apresenta maior número de alterações de cópias, como deleções e amplificações. Localizados preferencialmente no antro e com histologia do tipo intestinal.

Importante destacar que os grupos MSI e MSS/EMT, tendo demonstrado padrões de exclusão mútuos, foram os primeiros classificados na amostra. Posteriormente, os tumores remanescentes foram divididos com base no estado de ativação do gene TP53, nos grupos MSS/TP53+ e MSS/TP53-.

A análise de sobrevida evidenciou que o tipo MSI apresentou melhor prognóstico, seguido pelo MSS/TP53+, MSS/TP53- e MSS/EMT. A ocorrência de recidiva foi mais frequente no tipo MSS/EMT, sendo o sítio peritoneal o mais comum. Metástases hepáticas isoladas foram mais frequentes no tipo MSI e MSS/TP53-.

\subsubsection{Classificação baseada na expressão gênica e proteica}

Conforme descrito anteriormente, as classificações do TGCA e asiática utilizaram múltiplas e avançadas técnicas de análise molecular para definir os seus subtipos. As técnicas utilizadas incluíram: sequenciamento do DNA; sequenciamento do RNA; sequenciamento de todo o exoma; análise de variação do número de cópias; sequenciamento do microRNA, e avaliação da metilação do DNA. Isso garantiu tanto a avaliação de alterações genéticas quanto epigenéticas, tais como a metilação, a qual, em muitos casos, é o principal mecanismo envolvido na carcinogênse (Yoda et al., 2015). 
Entretanto, o emprego dessas técnicas na rotina é difícil, devido ao alto custo e complexidade.

$\mathrm{Na}$ tentativa de aplicar a classificação molecular na prática clínica, foram empregadas formas de reproduzir os subtipos moleculares por meio da avaliação da expressão proteica e de RNAm. Para isso, empregaram-se técnicas disponíveis na prática diagnóstica de rotina como a imuno-histoquímica (IH) e a hibridização in situ (ISH). Essa estratégia também é denominada avaliação da imunoexpressão, expressão gênica e proteica ou apenas expressão proteica (Setia et al., 2015; Ahn et al., 2017; Birkman et al., 2017).

Avaliando o perfil de expressão proteica, uma nova classificação para definição de cinco grupos (“clusters") foi proposta, utilizando-se quatro marcadores e o emprego da análise de cluster hierarquizada não supervisionada. Inicialmente, a classificação foi empregada em uma coorte ocidental de 146 casos (Setia et al., 2015) e, posteriormente, foi empregada em uma população asiática de 349 casos (Ahn et al., 2016). Os grupos apresentavam as seguintes características:

1) EBV positivo (cluster 1) - expressão abundante de RNA EBER1 ou EBER2 identificado por ISH;

2) MSI (cluster 2) - perda de expressão de MLH1 e PMS2, identificado por IH;

3) Expressão aberrante de E-caderina (cluster 3) - perda total da expressão da E-caderina ou expressão granular citoplasmática;

4) Expressão aberrante de p53 (cluster 4) - perda total da expressão ou hiperexpressão;

5) Expressão normal de p53 (cluster 5) - último grupo, que não apresentou alteração de expressão de quaisquer dos marcadores avaliados anteriormente.

A avaliação da expressão gênica e proteica já é realizada rotineiramente em algumas dessas situações. Conforme discutido anteriormente, a técnica destacada como padrão ouro para a avaliação da infecção pelo EBV é a ISH. Este método já é empregado não apenas para avaliar a infecção nos casos de CG, mas também em outros tumores associados à infecção pelo EBV (Tsao et al., 2015). A avaliação do fenótipo de MSI já é comumente realizada por IH, por meio da pesquisa das proteínas MMR em 
tumores colorretais, com o objetivo de identificar casos de Câncer colorretal nãopolipoide hereditário (Syngal et al., 2015). A expressão aberrante da p53, é um marcador prognóstico para alguns tumores, podendo se relacionar à maior agressividade tumoral e à perda de diferenciação celular nos tumores de tireoide, próstata, gliomas malignos e melanomas (Wei et al, 2015). Já a expressão de E-caderina é utilizada no diagnóstico diferencial entre o carcinoma ductal e o lobular da mama. No entanto, a determinação do padrão de expressão desses marcadores não é estabelecida como rotina na avaliação dos tumores gástricos. Visto que a classificação molecular apresenta a capacidade de diferenciar diferentes subtipos de CG, o emprego de técnicas de imunoexpressão para avaliação de marcadores e definição dos seus subgrupos pode ser uma estratégia útil na prática clínica. 


\section{OBJETIVOS}

Primários:

- Classificar os casos de adenocarcinomas gástricos, de acordo com os subtipos moleculares EBV positivo, microssatélites instáveis, instabilidade cromossômica e com genoma estável, utilizando-se técnicas de análise de expressão gênica e proteica;

- Avaliar as características clinicopatológicas de cada subtipo encontrado, sua influência na sobrevida global (SG) e sobrevida livre de doença (SLD).

Secundários:

- Propor um modelo de classificação dos subtipos tumorais com base nos dados desta casuística;

- Comparar os diferentes modelos de classificação molecular propostos na Literatura, na população estudada. 


\section{MÉTODOS}

\subsection{População do estudo}

Incluíram-se os pacientes submetidos à ressecção cirúrgica por adenocarcinoma gástrico, no período de março de 2009 a fevereiro de 2016, pelo Serviço de Cirurgia do Aparelho Digestivo do Instituto do Câncer do Estado de São Paulo, ICESP-HCFMUSP. Os casos foram selecionados com base nos critérios abaixo relacionados.

\subsubsection{Critérios de inclusão}

a) Ausência de evidências clínicas, de imagem ou cirúrgicas de doença metastática à distância por ocasião do diagnóstico (M0);

b) Confirmação diagnóstica de adenocarcinoma gástrico;

c) Cirurgia curativa padrão: gastrectomia total ou subtotal com linfadenectomia D2;

d) Disponibilidade de blocos de parafina representativos da neoplasia nos arquivos da Divisão de Anatomia Patológica do ICESP.

\subsubsection{Critérios de exclusão}

a) Tipo histológico diferente de adenocarcinoma;

b) Pacientes sem proposta de tratamento cirúrgico com intenção curativa;

c) Doença metastática a distância;

d) Neoplasia sincrônica em tratamento;

e) Ausência de amostras tumorais suficientes para as análises.

Todos os casos do presente estudo foram operados por cirurgiões especialistas no tratamento cirúrgico do CG, com ampla experiência. A técnica cirúrgica, extensão de ressecção e cadeias linfonodais dissecadas, seguiram as recomendações da JGCA 
(JGCA, 2014) e foram definidas com base no julgamento do cirurgião responsável pelo caso.

\subsection{Desenho do Estudo}

Trata-se de um estudo retrospectivo, com base em dados clinicopatológicos de um banco de dados coletado prospectivamente.

\subsection{Considerações éticas.}

O presente estudo representa a continuidade de dois projetos já aprovados e em execução no serviço de cirurgia do ICESP-HCFMUSP.

O primeiro estudo foi aprovado pelo Comitê de Ética em Pesquisa da Faculdade de Medicina da Universidade de São Paulo (ICESP-FMUSP), em 27 de fevereiro de 2015 com o título "CARACTERIZAÇÃO DA INFECÇÃO POR HELICOBACTER PYLORI, VÍRUS EPSTEIN-BARR E PERFIL DA EXPRESSÃO GÊNICOPROTEICA NOS ADENOCARCINOMAS GÁSTRICOS“, sob o número de registro NP 771/15. A aprovação na Plataforma Brasil, que engloba todas a pesquisa científicas envolvendo seres humano do país, foi obtida em 8 de abril de 2015, sob o CAAE 43453515.6.0000.0065.

Os dados clínicos dos pacientes foram coletados por meio de registros em prontuário eletrônico armazenados em banco de dados médicos do grupo do estômago, conforme projeto de pesquisa intitulado "BANCO DE DADOS DE PACIENTES DO SERVIÇO DE CIRURGIA ONCOLÓGICA DO APARELHO DIGESTIVO DO ICESP-HCFMUSP”, com aprovação pelo Comitê de ética em Pesquisa da Faculdade de Medicina da Universidade de São Paulo (ICESP-FMUSP) sob o número de registro NP 993/2016, em 5 de agosto de 2016, e na Plataforma Brasil, sob o registro CAAE: 62915516.2 .0000 .0065 .

Ambos os projetos têm como investigador principal o Prof. Dr. Ulysses Ribeiro Junior e como pesquisadores executantes Dr. Marcus Fernando Kodama Pertille Ramos.e Marina Alessandra Pereira. O projeto recebeu auxílio financeiro da Fundação 
de Amparo à Pesquisa do Estado de São Paulo (Fapesp), obtido em 16 de fevereiro de 2018, sob o registro 2016/25524-0.

\subsection{Coleta de dados}

\subsubsection{Variáveis clinicopatológicas}

Para compor o estudo, foram selecionadas as seguintes variáveis clínicopatológicas, com os respectivos critérios de avaliação:

a) Idade: determinada em anos, da data de nascimento à data da cirurgia;

b) Sexo: masculino ou feminino;

c) Índice de massa corpórea (IMC): avaliado numericamente pelo peso $(\mathrm{Kg})$ e altura $(\mathrm{cm})$, obtidos na consulta pré-operatória por meio da fórmula: IMC $\left(\mathrm{Kg} / \mathrm{m}^{2}\right)=$ peso $/(\text { altura })^{2}$;

d) Razão neutrófilo/linfócito (NLR): razão entre o número de linfócitos $\left(\mathrm{mil} / \mathrm{mm}^{3}\right)$ e neutrófilos $\left(\mathrm{mil} / \mathrm{mm}^{3}\right)$ obtidos em exame laboratorial no préoperatório;

e) Presença de comorbidades: Determinada pelo cirurgião responsável por meio classificação da Charlson-Deyo comorbidity index-CCI (Charlson et al., 1987). A partir da idade de 40 anos, foi acrescentado 1 ponto para cada década de vida. Valores de $C C I$ maiores ou iguais a 5 foram considerados como altos. Presença de neoplasia não foi considerada para pontuação;

f) ASA (American Society of Anesthesiologists): Classificação de ASA foi realizada pela equipe de anestesiologia e determinada como I - Paciente saudável; II - Doença sistêmica moderada, sem limitação das funções vitais; III Doença sistêmica severa, com funções vitais comprometidas; IV - Doença sistêmica severa com ameaça à vida (Doyle et al., 2017);

g) Presença de terapia neoadjuvante e/ou adjuvante: determinada como presente ou ausente;

h) Localização do tumor: classificada em proximal (cárdia e fundo), medial (corpo), distal (antro e incisura angular) ou total (acometimento difuso), de 
acordo com localização descrita em laudo anatomopatológico, exame endoscópico/biópsia e/ou tipo de ressecção cirúrgica;

i) Extensão da ressecção: classificada como total ou subtotal, conforme extensão da ressecção gástrica, determinada com base na localização do tumor para a obtenção de margens livres. A técnica cirúrgica, extensão de ressecção e cadeias linfonodais dissecadas seguiram as recomendações da JGCA (JGCA, 2014);

j) Configuração macroscópica: determinada conforme descrição do exame macroscópico, empregando-se a classificação da JGCA (JGCA, 2014), a qual é baseada na classificação de Borrmann;

k) Tamanho do tumor: determinado em centímetros, a partir de descrição macroscópica do espécime cirúrgico, avaliado em exame macroscópico e emitido laudo anatomopatológico;

1) Tipo histológico de Laurén: determinado como intestinal, difuso, misto ou indeterminado (não-classificável);

m) Grau de diferenciação histológica: classificado como bem diferenciado, moderadamente diferenciado e pouco diferenciado;

n) Invasão tumoral: determinada em pT1 (incluindo pT1a e pT1p), pT2, pT3 e pT4 (incluindo pT4a e pT4b), de acordo com a invasão do tumor na parede gástrica;

o) Número de linfonodos dissecados: determinado por meio do número total de linfonodos avaliados ao exame histológico, independente da cadeia do qual foi dissecado;

p) Presença de metástase linfonodal: qualitativamente determinada como presente ou ausente, independente do número de linfonodos acometidos;

q) Invasão linfática, venosa e perineural: qualitativamente determinadas como presentes ou ausentes, mediante a avaliação da presença de células tumorais nos espaços vasculares revestidos por endotélio (invasão linfática), nos vasos circundados por camada muscular lisa (invasão venosa), ou acometendo o perineuro ou o feixe neural (invasão perineural);

r) Infiltrado inflamatório peritumoral: determinado por meio de avaliação qualitativa/semi-quantitativa entre as células tumorais e peritumorais como ausente, leve, moderado e intenso. Agrupados dicotomicamente para análise em ausente/leve e moderado/intenso; 
s) Estádio TNM: determinado pelo agrupamento TNM $8^{a}$ edição, simplificado em estádio I, II, III e IV (UICC, 2016);

t) Complicação cirúrgica: determinada com a utilização da classificação de Clavien-Dindo (Dindo et al., 2004). Complicações maiores foram consideradas Clavien III-IV e V. A mortalidade cirúrgica (Clavien V) foi considerada quando ocorrida nos primeiros trinta dias após a cirurgia ou durante a internação hospitalar, após o procedimento.

\subsubsection{Seguimento}

Avaliaram-se todos os pacientes no pós-operatório de maneira trimestral no primeiro ano, e semestral nos anos seguintes. Realizaram-se exames de seguimento para detecção de recidivas com base na presença de sintomas. A ausência em consultas por mais de doze meses foi considerada como perda de seguimento.

\subsection{Análise Anatomopatológica}

\subsubsection{Confecção dos blocos de TMA (tissue microarray)}

Para a confecção dos blocos de TMA, selecionaram-se os blocos mais representativos de todos os pacientes, contendo tumor e área adjacente não tumoral provenientes do Laboratório de Anatomia Patológica do ICESP. Os cortes histológicos representativos dos casos corados por hematoxilina e eosina (HE) foram revisados e as áreas de interesse para construção dos blocos de TMA marcadas sobre as lâminas, endereçando o tumor primário e a mucosa não-tumoral. Extraíram-se cilindros de 1,0 mm (ou spots) de diâmetro das áreas de interesse, selecionadas nos blocos de parafina doadores e transportados para os blocos de parafina receptores, utilizando-se equipamento MTA1 (Manual Tissue Microarray, Beecher Instruments, Silver Springs, MD, EUA) com espessamento de 0,3 mm entre os cilindros (Figura 6). Para efeito de orientação de posição, foram dispostos tecidos controles obtidos de necropsia (rim ou pulmão) na primeira linha horizontal e nas primeiras três posições da primeira coluna. 


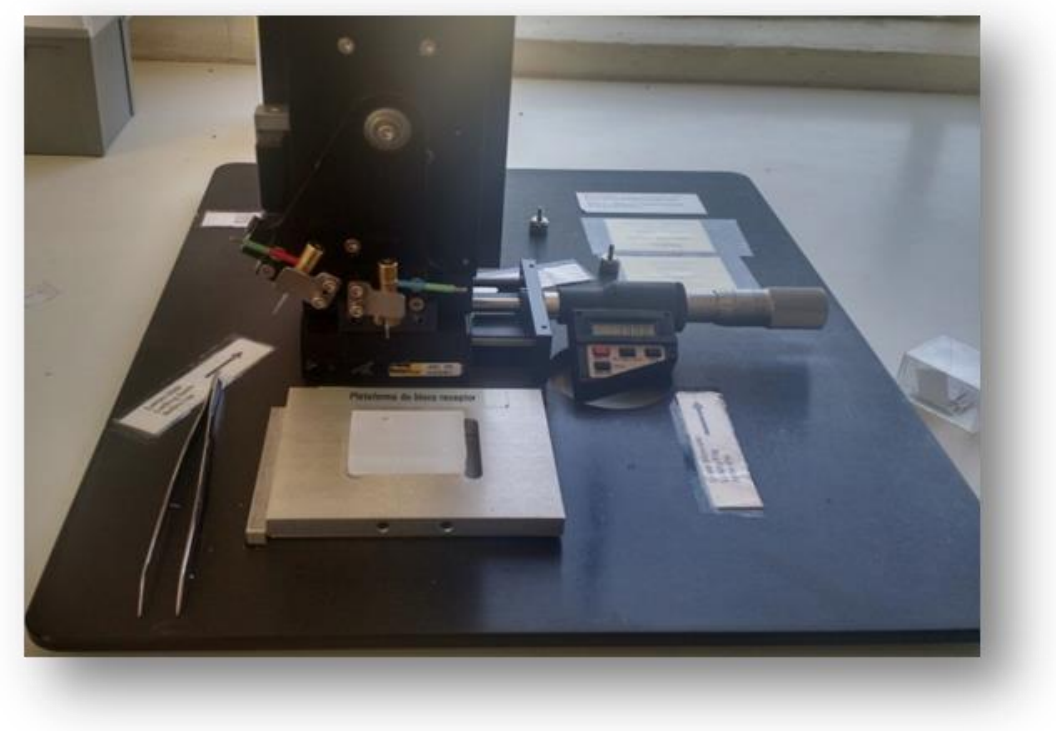

Figura 6. Equipamento utilizado para construção dos blocos de TMA.

A fim de minimizar as perdas de representatividade inerentes à metodologia do TMA, cada caso foi representado com cinco amostras, sendo três amostras correspondentes a tecido tumoral e duas amostras de mucosa gástrica não-tumoral por paciente. Alocou-se cada cilindro amostral em uma posição do bloco receptor definido por meio de um sistema cartesiano de coordenadas. Os blocos receptores foram confeccionados com parafina Histosec em pastilhas (Merk, EUA), no Laboratório de Patologia Hepática (LIM-14) da FMUSP (Figura 7).

Visando a evitar a perda de material (devido à necessidade de nivelar o bloco de parafina para a realização dos cortes histológicos), o mesmo foi submetido a sessão única de microtomia, na qual obteve-se uma média de 50 a 70 secções de $4-5 \mu$ m por bloco de TMA, dispostas em lâminas sinalizadas. As lâminas foram submetidas a banho de parafina e arquivadas em refrigeração $\left(-20^{\circ} \mathrm{C}\right)$ em caixa escura, visando à preservação dos antígenos das mesmas até o momento do uso.

Durante a construção do bloco de TMA, preparou-se mapa em planilha Excel com a localização e identificação das amostras de tecidos, objetivando orientar a leitura posterior das reações imuno-histoquímicas. 


\section{3}

Figura 7. Blocos de TMA. Amostras parafinadas de tumor e mucosa não-tumoral dos pacientes incluídos no estudo.

\subsubsection{Análise dos blocos de TMA - Técnica histológica convencional}

Secções histológicas de $4 \mu \mathrm{M}$ de espessura foram obtidas de cada bloco de TMA e submetidas a protocolo de coloração por hematoxilina e eosina de acordo com as seguintes etapas:

a) Retirada da parafina em xilol a $60^{\circ} \mathrm{C}$ por 10 minutos e Xilol em temperatura ambiente por 10 minutos;

b) Hidratação em três passagens em álcool absoluto, álcool 95\% e álcool 80\%, respectivamente;

c) Hidratação em água corrente e água destilada;

d) Hematoxilina de Harris por 3 minutos;

e) Lavagem em água corrente e água destilada;

f) Oito imersões em solução de hidróxido de amônio 0,5\%;

g) Lavagem em água corrente e água destilada;

h) Passagens sucessivas em álcool 50\%, álcool $80 \%$ e álcool absoluto;

i) Eosina por 2 minutos;

j) Quatro passagens em álcool absoluto para desidratação;

k) Diafanização em xilol (4 passagens);

l) Montagem em Entellan (Merck, EUA). 


\subsubsection{Análise dos blocos de TMA - Técnica Imuno-histoquímica}

A pesquisa imuno-histoquímica foi realizada pelo Laboratório de Patologia (LIM14) da FMUSP, pelo Laboratório de Anatomia Patológica do ICESP-HCFMUSP e pelo Instituto Adolfo Lutz. A avaliação microscópica foi realizada por dois patologistas, sem conhecimento prévio dos dados clínicos dos pacientes contidos nas lâminas de TMA.

Os cortes histológicos de tecido, a partir dos blocos de TMA para as reações de $\mathrm{IH}$, foram retirados da parafina em xilol, reidratados em diluições de etanol $(100 \%$, $95 \%, 80 \%, 70 \%)$.

Todas as reações para as MMR proteínas foram realizadas em plataforma de imunocoloração automatizada VENTANA BenchMark ULTRA, seguindo-se estritamente o protocolo do fabricante, acompanhadas do kit de detecção OptiView DAB (Ventana, Ref. 790-700) em conjunto com o kit de amplificação OptiView Amplification Kit (Ventana, Ref.: 790-099), ambos prontos para uso, para aumentar a intensidade de coloração dos anticorpos primários.

Para avaliação da expressão da p53 e da E-caderina, as lâminas foram submetidas à recuperação antigênica por calor induzido, usando-se tampão citrato $(\mathrm{pH}$ 6,0) em panela a vapor (Antigen Retreival Buffer 4; 100x TRIS-EDTA Buffer - Spring Bioscience ref. PMB4-250) durante 30 minutos.

A atividade da peroxidase endógena foi bloqueada por imersão em peróxido de hidrogênio a 6\% (Merck S.A. Indústrias Químicas, Rio de Janeiro, RJ), com três trocas de 10 minutos cada. Em seguida, foi realizado o bloqueio de proteínas inespecíficas com solução salina tamponada, com fosfatos (PBS) 10mM, pH 7,4 (Merck S.A. Indústrias Químicas, Rio de Janeiro, RJ).

Posteriormente, aplicaram-se os anticorpos primários (todos prontos para uso) e as lâminas foram incubadas em câmara úmida a $4^{\circ} \mathrm{C}$ por $16-18$ horas.

Decorrido o tempo, realizaram-se novas lavagens com PBS, as lâminas foram incubadas com o anticorpo secundário conjugado com peroxidase (Post Primary Block, NovoLink Max Polymer Detection System, Newcastle, Reino Unido) por 30 minutos, a $37^{\circ} \mathrm{C}$, e em seguida, lavadas com PBS. Na sequência, procedeu-se à etapa da revelação em solução com substrato cromogênico, assim preparada: $100 \mathrm{mg} \%$ de 3,3' 
tetrahidrocloreto de diaminobenzidina (DAB) (Sigma, D- 5637, EUA), $1 \mathrm{ml}$ dimetilsulfóxido (DMSO), $1 \mathrm{ml}$ de $\mathrm{H} 2 \mathrm{O} 2$ 6\%, $100 \mathrm{ml}$ de PBS. As lâminas foram incubadas por 5 minutos, a $37^{\circ} \mathrm{C}$. Em seguida, removeu-se a solução DAB por lavagem com água destilada e as lâminas foram contra-coradas com hematoxilina.

Realizou-se a coloração das lâminas de IH com hematoxilina, conforme o protocolo descrito a seguir:

a) Mergulhar as lâminas em solução de Hematoxilina de Harris por 1 minuto;

b) Lavar em água corrente e destilada;

c) Mergulhar duas vezes em solução de hidróxido de amônio 0,5\%;

d) Lavar em água corrente e destilada;

e) Desidratar as lâminas em concentrações crescentes de etanol (50\%, 80\%, 95\%, 100\%; três passagens em sequência de 30 segundos).

f) Passar as lâminas em xilol para diafanização (quatro passagens de 30 segundos);

g) Montar as lâminas com lamínula e Entellan (Merck, EUA).

As informações referentes aos anticorpos primários utilizados na avaliação encontram-se descritos na Tabela 1.

Tabela 1 - Especificações dos anticorpos e clones utilizados

\begin{tabular}{llll}
\hline ANTICORPO & MARCA/REFERÊNCIA & CLONE & RECUPERAÇÃO ANTIGÊNICA \\
\hline p53 & Dako/Agilent & DO-7 & $\begin{array}{l}\text { solução de ácido cítrico 10mM pH6; } \\
\text { calor úmido em panela de pressão }\end{array}$ \\
E-caderina & Leica Biosystems & $36 \mathrm{~B} 5$ & $\begin{array}{l}\text { solução de ácido cítrico 10mM pH6; } \\
\text { calor úmido em panela de pressão }\end{array}$ \\
MLH-1 & Ventana/790-4535 & M1 & $\begin{array}{l}\text { Sistema automatizado VENTANA } \\
\text { BenchMark ULTRA }\end{array}$ \\
MSH-2 & Cell Marque/760-4265 & $\begin{array}{l}\text { G219- } \\
1129\end{array}$ & $\begin{array}{l}\text { Sistema automatizado VENTANA } \\
\text { BenchMark ULTRA }\end{array}$ \\
MSH-6 & Ventana/790-4455 & 44 & $\begin{array}{l}\text { Sistema automatizado VENTANA } \\
\text { BenchMark ULTRA }\end{array}$ \\
& & EPR & $\begin{array}{l}\text { Sistema automatizado VENTANA } \\
\text { BenchMark ULTRA }\end{array}$ \\
\hline PMS-2 & Cell Marque/760-453 & 3947 & \\
\hline
\end{tabular}




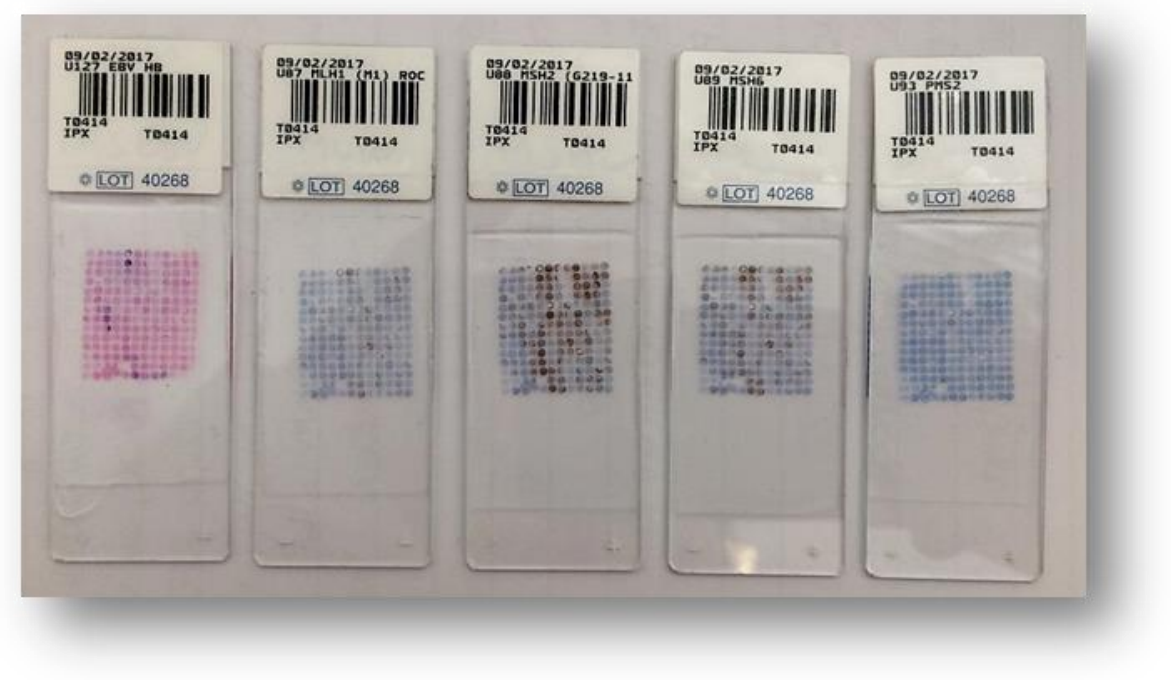

Figura 8. Lâminas de TMA coradas. Reações de IH para as proteínas MMR e ISH para EBV.

\subsubsection{Interpretação dos resultados de expressão gênica e proteica}

\section{- Proteínas de reparo do DNA: MLH-1, MSH-2, MSH-6 e PMS-2}

As reações IH para as proteínas MMR foram qualitativamente interpretadas como positivas ou negativas, ou de resultado inconclusivo, nas amostras dos tumores primários representados nas secções obtidas a partir dos blocos de TMA. O resultado positivo foi considerado somente para as amostras em que se identificou deposição do produto cromógeno sobre os núcleos das células neoplásicas, independente da proporção ou do número de células marcadas, em reação na qual não tenha sido identificada marcação de fundo interpretada como inespecífica. As amostras em que não foram evidenciadas imunomarcação sobre o núcleo das células neoplásicas foram qualificadas como negativas, quando paralelamente observados controles teciduais positivos representados pela mucosa normal adjacente. Os controles negativos foram obtidos por meio da omissão do anticorpo primário. Os tumores foram classificados em MSI ou MSS, quando ao menos um dos pares de dímeros foi avaliado (MLH1/PMS2 e MSH2/MSH6). 


\section{- p53}

Consideraram-se dois padrões diferentes como expressão aberrante da p53: tumores que apresentaram hiperexpressão, nos quais se observou coloração nuclear forte em pelo menos $70 \%$ das células tumorais; e tumores com perda completa de expressão da p53, aos quais incluíram-se tumores sem coloração ou com menos de 5\% das células positivas. A expressão não aberrante, por sua vez, caracterizou-se pela coloração fraca e irregular. As células do estroma e o epitélio benigno apresentaram níveis baixos de expressão da p53 e foram utilizados como controle. Controles negativos foram também obtidos por meio da omissão do anticorpo primário.

\section{- E-caderina}

Avaliou-se a expressão da E-caderina utilizando-se um escore de 0 a 3 , sendo: $0=$ correspondente à perda completa; 1=expressão citoplasmática; 2=marcação de citoplasma e membrana, e 3=marcação de membrana. Escores 0 e 1 foram considerados expressão aberrante. As amostras de mucosa não tumoral de cada paciente representado no TMA serviram de controle positivo da reação. Os controles negativos foram obtidos por meio da omissão do anticorpo primário.

\section{- Vírus Epstein-Barr (EBV)}

As lâminas de TMA foram submetidas à hibridização in situ para teste de infecção por EBV com sonda de 30pb (probe 5' AGACACCGTCCTCACCACCCGGGACTTGTA-3'), complementar ao RNA-1 (Eber1) (Y5200, DAKO, Carpinteria, USA), produto viral mais abundante nas células durante a infecção latente. A detecção da reação foi realizada pelo método avidinabiotina peroxidase e as lâminas coradas com Hematoxilina de Harris, avaliadas por microscopia óptica convencional.

Utilizaram-se amostras de tumor gástrico positivas para EBV como controle positivo e lâminas com amostra sem sonda como controle negativo. Consideraram-se positivas as amostras onde $5 \%$ ou mais de células neoplásicas coradas foram 
visualizadas. Aquelas sem marcação, por sua vez, foram classificadas como negativas para infecção por EBV.

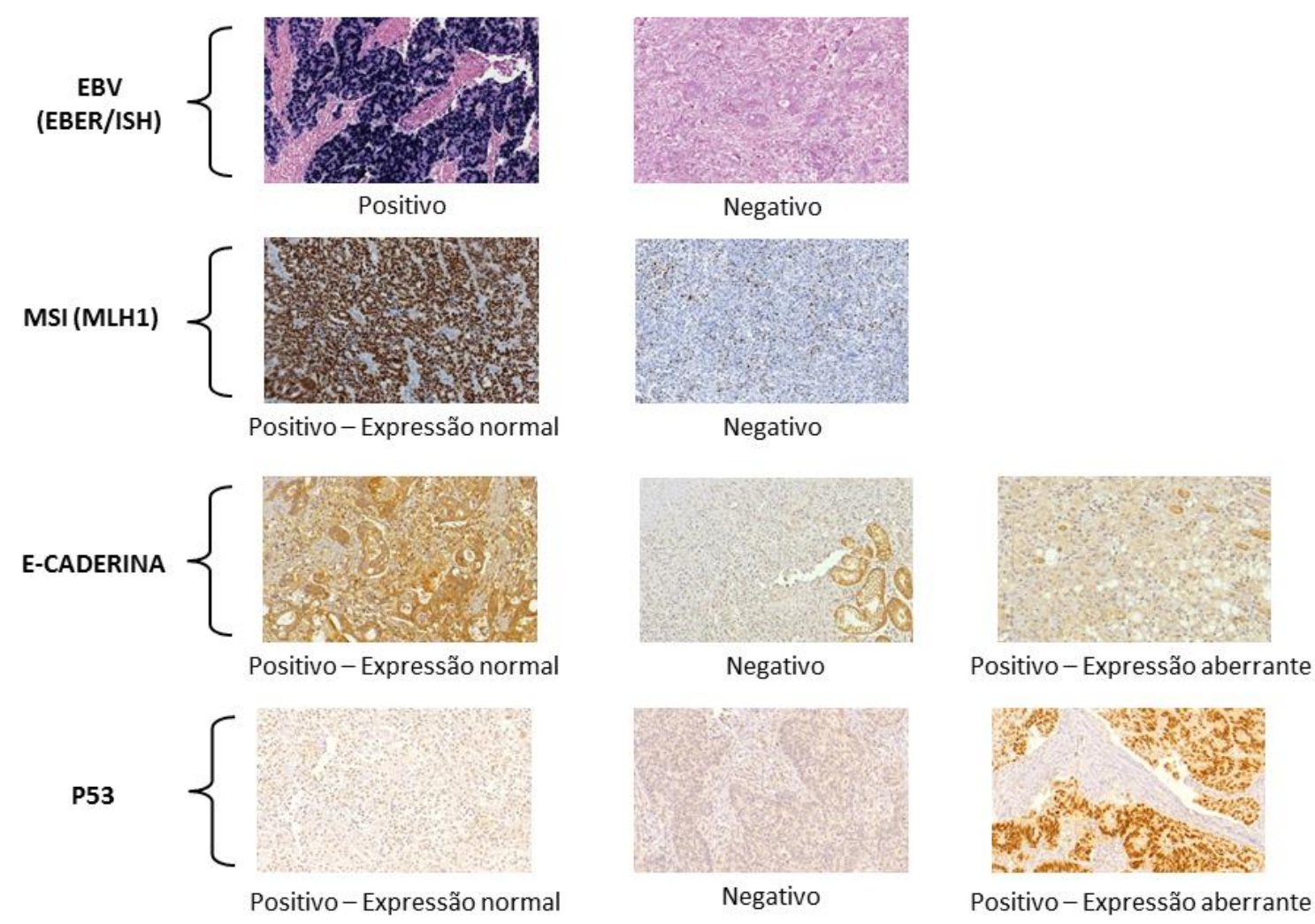

Figura 9. Interpretação dos resultados de expressão gênica e proteica. Reações de ISH para EBV e IH para MSI, E-caderina e p53.

\subsection{Análise estatística}

Os dados foram descritos em função da média, desvio padrão, mínima, máxima, para as variáveis quantitativas, e tabelas de frequência para as variáveis qualitativas. Realizou-se a comparação entre as variáveis quantitativas por meio do teste ANOVA. A correlação entre as variáveis categóricas foi determinada por meio do teste qui-quadrado de Pearson ou exato de Fisher.

Considerou-se, para a sobrevida global (SG), o tempo, em meses, entre a data da cirurgia e a data do óbito ou do último seguimento. Para a sobrevida livre de doença (SLD), considerou-se o tempo decorrido entre a cirurgia e a data de diagnóstico da 
recidiva. Ambas as curvas de sobrevida foram realizadas por meio do método de Kaplan-Meier, e a significância pelo teste de logrank.

Para verificar a relação das características anatomopatológicas com a sobrevida e estimar os riscos relativos ("hazard ratios"), foi utilizada a regressão de Cox. Para avaliar a relação conjunta entre as variáveis, foram selecionadas aquelas que atingiram $p<0,05$ na análise univariada, e ajustadas no modelo de Regressão de Cox Múltiplo. Permaneceram no modelo múltiplo apenas aquelas que atingiram significância.

Para determinar a hierarquia no fluxo de classificação com base na expressão gênica e proteica, optou-se pelo método de regressão de Cox, para avaliar o efeito de cada marcador (EBV, MSI, p53 e E-caderina). Estabeleceu-se o estado "recidiva" como desfecho de interesse, excluindo-se os óbitos cirúrgicos. A força da associação entre as variáveis foi expressa em valores de hazard ratio $(H R)$, com intervalo de confiança de 95\% (IC 95\%) e nível de significância estatística de 5\%. Determinaram-se as variáveis associadas aos desfechos por meio da estratégia de modelagem stepwise backward. A ordem das variáveis utilizadas para a estratificação dos grupos foi determinada por meio da significância estatística. $\mathrm{O}$ marcador que apresentou $H R$ com menor associação com o desfecho foi removido a cada passo, até que permanecesse no modelo o mais significativo. Para a avaliação do desempenho das diferentes classificações na determinação prognóstica, medidas de sensibilidade e especificidade para a ocorrência de recidiva e óbito, foi construída uma curva de característica operacionais, também conhecida como curva ROC.

As análises estatísticas foram realizadas utilizando-se o programa estatístico SPSS versão 20.0 (SPSS, Chicago, IL. EUA). Os gráficos foram construídos com o software Microsoft Excel, versão 2010. Consideraram-se os resultados significativos quando $p<0,05$. 


\section{RESULTADOS}

Incluíram-se 287 pacientes submetidos a gastrectomia com intuito curativo e linfadenectomia D2 no período. A média de idade foi 61,5 anos, sendo 168 pacientes $(58,5 \%)$ do sexo masculino e $119(41,5 \%)$ do sexo feminino. A maioria dos tumores apresentava localização distal e, consequentemente, $60,6 \%$ dos pacientes foram submetidos à gastrectomia subtotal. Características clínicas e cirúrgicas dos pacientes encontram-se descritas na tabela 2.

Tabela 2 - Características clínicas e cirúrgicas dos pacientes

\begin{tabular}{|c|c|c|}
\hline VARIÁVEIS & $\mathrm{n}=\mathbf{2 8 7}$ & $\%$ \\
\hline \multicolumn{3}{|l|}{ Idade (anos) } \\
\hline Média \pm DP & $61,5 \pm 12,07$ & - \\
\hline Min-max & $26-87$ & - \\
\hline \multicolumn{3}{|l|}{ Sexo } \\
\hline Feminino & 119 & 41,5 \\
\hline Masculino & 168 & 58,5 \\
\hline \multicolumn{3}{|c|}{ Índice de massa corpórea-IMC (Kg/cm²) } \\
\hline Média \pm DP & $24,4 \pm 5,4$ & - \\
\hline Min-max & $12,5-56,5$ & - \\
\hline \multicolumn{3}{|l|}{ Razão Neutrófilo/Linfocito (NLR)* } \\
\hline Média \pm DP & $2,55 \pm 2,24$ & - \\
\hline Min-max & $0,34-17,8$ & - \\
\hline \multicolumn{3}{|c|}{ Comorbidade - Charlson-Deyo Comorbidity Index (CCI) } \\
\hline$<5$ & 168 & 58,5 \\
\hline$\geq 5$ & 119 & 41,5 \\
\hline \multicolumn{3}{|c|}{ ASA (American Society of Anesthesiologists) } \\
\hline $1 / I I$ & 256 & 89,2 \\
\hline III/IV & 31 & 10,8 \\
\hline \multicolumn{3}{|l|}{ Extensão da ressecção } \\
\hline Subtotal & 174 & 60,6 \\
\hline Total & 113 & 39,4 \\
\hline \multicolumn{3}{|l|}{ Localização do tumor } \\
\hline Proximal & 34 & 11,8 \\
\hline Média & 52 & 18,1 \\
\hline Distal & 191 & 66,6 \\
\hline Todo órgão & 10 & 3,5 \\
\hline
\end{tabular}

* dados não disponíveis em 2 casos 
A configuração macroscópica mais comum foi a do tipo III $(48,4 \%)$ e o tipo histológico mais comum foi o intestinal $(47,4 \%)$, de acordo com a classificação de Láuren. Ressecaram-se em média 41,8 linfonodos em cada caso. Metástase linfonodal estava presente em $56,4 \%$ dos casos (tabela 3 ).

Tabela 3 - Características patológicas dos pacientes

\begin{tabular}{|c|c|c|}
\hline VARIÁVEIS & $\mathrm{n}=\mathbf{2 8 7}$ & $\%$ \\
\hline \multicolumn{3}{|l|}{ Configuração Macroscópica } \\
\hline I & 28 & 9,8 \\
\hline II & 41 & 14,3 \\
\hline III & 139 & 48,4 \\
\hline IV & 55 & 19,2 \\
\hline V & 24 & 8,4 \\
\hline \multicolumn{3}{|l|}{ Grau de diferenciação histológica } \\
\hline G1/G2 & 127 & 44,3 \\
\hline G3 & 160 & 55,7 \\
\hline \multicolumn{3}{|l|}{ Tipo histológico de Láuren } \\
\hline Intestinal & 136 & 47,4 \\
\hline Difuso & 109 & 38 \\
\hline Misto & 29 & 10,1 \\
\hline Indeterminado & 13 & 4,5 \\
\hline \multicolumn{3}{|l|}{ Invasão tumoral (pT) } \\
\hline pT1 & 78 & 27,2 \\
\hline pT2 & 37 & 12,9 \\
\hline рT3 & 88 & 30,7 \\
\hline pT4 & 84 & 29,3 \\
\hline \multicolumn{3}{|l|}{ Metástase Linfonodal (pN) } \\
\hline pNO & 125 & 43,6 \\
\hline pN1 & 37 & 12,9 \\
\hline pN2 & 58 & 20,2 \\
\hline pN3 & 67 & 23,3 \\
\hline \multicolumn{3}{|l|}{ Infiltrado inflamatório peritumoral } \\
\hline Ausente/leve & 191 & 66,6 \\
\hline Moderado/intenso & 96 & 33,4 \\
\hline \multicolumn{3}{|l|}{ Invasão linfática } \\
\hline Ausente & 142 & 49,5 \\
\hline Presente & 145 & 50,5 \\
\hline \multicolumn{3}{|l|}{ Invasão venosa } \\
\hline Ausente & 193 & 67,3 \\
\hline Presente & 94 & 32,7 \\
\hline \multicolumn{3}{|l|}{ Invasão perineural } \\
\hline Ausente & 149 & 51,9 \\
\hline Presente & 138 & 48,1 \\
\hline
\end{tabular}


O estádio patológico final predominante foi o III, que ocorreu em 43,6\% dos casos. A mortalidade cirúrgica foi de 4,2\%; 11,8\% dos casos receberam terapia neoadjuvante, e 55,1\% algum tipo de terapia adjuvante (tabela 4). Após seguimento médio de 37,9 meses, ocorreram 79 recidivas e 95 óbitos

Tabela 4 - Resultados cirúrgicos

\begin{tabular}{lrr}
\hline \multicolumn{1}{c}{ VARIÁVEIS } & $\mathbf{n}=\mathbf{2 8 7}$ & $\%$ \\
\hline Estádio pTNM final (8a edição) & & \\
I & 90 & 31,4 \\
II & 67 & 23,3 \\
III & 125 & 43,6 \\
IV & 5 & 1,7 \\
Complicações cirúrgicas - Clavien-Dindo & & \\
Grau O - II & 245 & 85,4 \\
Grau III - IV & 30 & 10,5 \\
Grau V (óbito) & 12 & 4,2 \\
Terapia neoadjuvante/adjuvante & & \\
Não & 95 & 33,1 \\
Sim & 192 & 66,9 \\
\hline
\end{tabular}

A alteração na expressão de apenas um marcador, de forma isolada, ocorreu em 175 casos, enquanto que a alteração na expressão de mais de um marcador, de forma simultânea, ocorreu em 23 casos. Os demais 89 casos não demonstraram qualquer alteração para o perfil de expressão avaliado (Figura 10). O marcador mais alterado foi a proteína p53, seguida pelas proteínas de reparo do DNA (MSI), EBV e E-caderina, nesta ordem. 
EBV

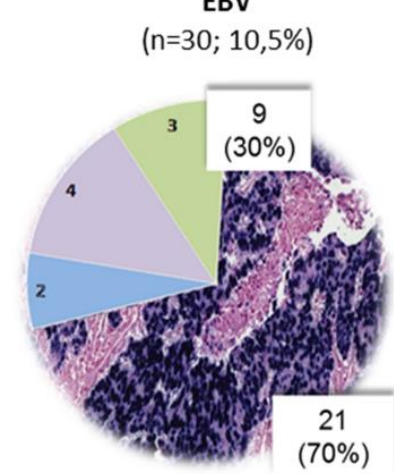

MSI

$(n=60 ; 20,9 \%)$

$(70 \%)$

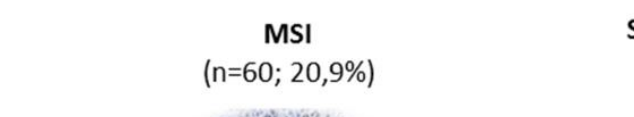

Sem alteração

( $n=89 ; 31 \%)$
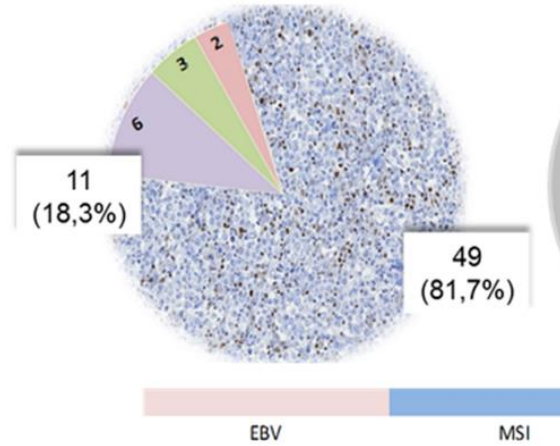

EBV

MSI

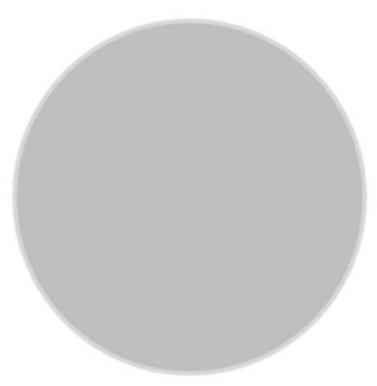

P53 alterado

( $n=105 ; 36,6 \%)$

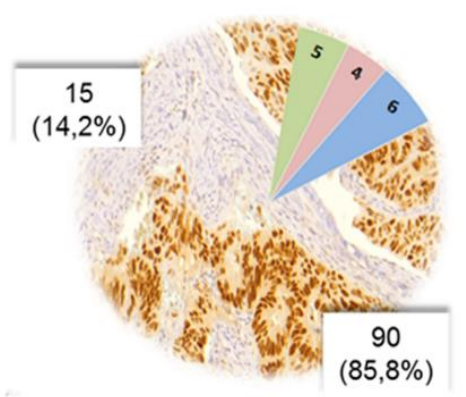

E-caderina alterado ( $n=26 ; 9,1 \%)$

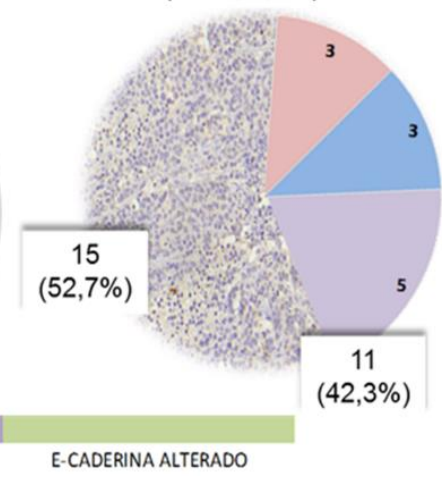

Figura 10 - Frequência de expressão dos marcadores avaliados. Expressão tanto dos valores absolutos quanto da expressão associada a outros marcadores.

\section{Classificação TCGA}

Aplicando-se a classificação proposta pela TCGA, o subtipo tumoral mais comum foi o de instabilidade cromossômica (CIN), ocorrido em $62,2 \%$ dos casos. O fluxograma de classificação dos pacientes é demonstrado na figura 11. Na sequência, os subtipos mais comuns foram o MSI, seguido pelo EBV positivo e com genoma estável (figura 12). 


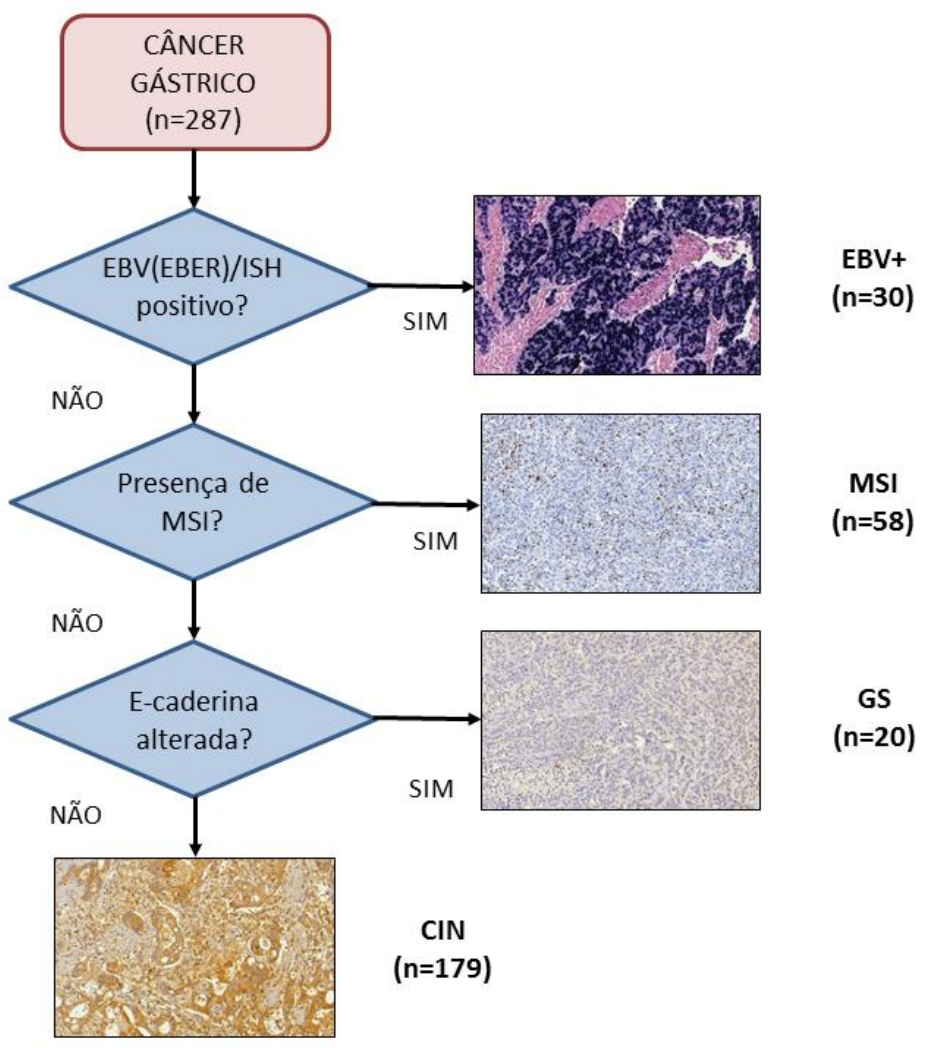

Figura 11 - Fluxograma da classificação molecular TCGA.

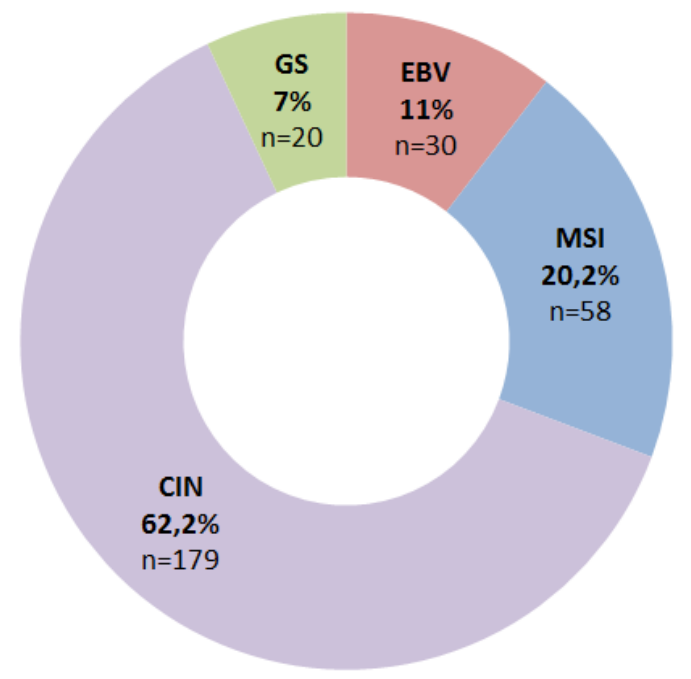

Figura 12 - Distribuição dos casos de acordo com a classificação TCGA 
As caraterísticas clinicopatológicas dos quatro subtipos tumorais da TCGA são demonstradas na tabela 5. Idade mais avançada e presença de comorbidades foram associadas ao tipo MSI. A ocorrência de tumores proximais foi maior no grupo EBV positivo, enquanto que tumores com MSI localizaram-se mais distalmente e foram mais submetidos à resseção subtotal. A presença de infiltrado inflamatório peritumoral acentuado foi associada a tumores EBV positivo $(p<0,001)$. Os tumores GS apresentaram o estádio patológico final mais avançado, comparado aos demais subtipos $(p=0,014)$.

Tabela 5 - Características clinicopatológicas de acordo com classificação molecular

\begin{tabular}{|c|c|c|c|c|c|}
\hline \multirow[t]{2}{*}{ VARIÁVEIS } & \multicolumn{4}{|c|}{ TIPOS MOLECULARES - TCGA } & \multirow[b]{2}{*}{$p$} \\
\hline & $\begin{array}{c}E B V \\
\mathrm{n}=30(10,5 \%)\end{array}$ & $\begin{array}{c}M S I \\
\mathrm{n}=58(20,2 \%)\end{array}$ & $\begin{array}{c}C I N \\
\mathrm{n}=179(62,4 \%)\end{array}$ & $\begin{array}{c}\text { GS } \\
\mathrm{n}=20(7 \%)\end{array}$ & \\
\hline Idade (anos) & & & & & 0,017 \\
\hline Média & 61,4 & 65,9 & 60,2 & 60,6 & \\
\hline Gênero & & & & & 0,101 \\
\hline Masculino & $23(76,7)$ & $29(50)$ & $103(57,5)$ & $13(65)$ & \\
\hline Feminino & $7(23,3)$ & $29(50)$ & $76(42,5)$ & $7(35)$ & \\
\hline IMC $\left(\mathrm{Kg} / \mathrm{m}^{2}\right)$ & & & & & 0,598 \\
\hline Média & 25,3 & 24,8 & 24,2 & 23,7 & \\
\hline NLR & & & & & 0,029 \\
\hline Média & 2,86 & 2,67 & 2,32 & 3,81 & \\
\hline \multicolumn{5}{|c|}{ ASA (American Society of Anesthesiologists) } & 0,753 \\
\hline $\mathrm{I} / \mathrm{II}$ & $27(90)$ & $50(85,2)$ & $160(89,4)$ & $19(95)$ & \\
\hline III/IV & $3(10)$ & $8(13,8)$ & $19(10,6)$ & $1(5)$ & \\
\hline \multicolumn{4}{|c|}{ Comorbidade - Charlson-Deyo Comorbidity Index (CCI) } & & 0,011 \\
\hline$<5$ & $19(63,3)$ & $23(39,7)$ & $112(62,6)$ & $14(70)$ & \\
\hline$\geq 5$ & $11(36,7)$ & $35(60,3)$ & $67(37,4)$ & $6(30)$ & \\
\hline \multicolumn{4}{|c|}{ Localização do tumor } & & 0,004 \\
\hline Proximal & $8(26,7)$ & $6(10,3)$ & $18(10,1)$ & $2(10)$ & \\
\hline Média & $7(23,3)$ & $8(13,8)$ & $34(19)$ & $3(15)$ & \\
\hline Distal & $11(36,7)$ & $44(75,9)$ & $123(68,7)$ & $13(65)$ & \\
\hline Todo órgão & $4(13,3)$ & $0(0)$ & $4(2,2)$ & $2(10)$ & \\
\hline \multicolumn{4}{|l|}{ Tipo de ressecção } & & $<0,001$ \\
\hline Subtotal & $8(26,7)$ & $45(77,6)$ & $110(61,5)$ & $11(55)$ & \\
\hline Total & $22(73,3)$ & $12(22,4)$ & $69(38,5)$ & $9(45)$ & \\
\hline \multicolumn{3}{|c|}{ Configuração macroscópica } & & & 0,244 \\
\hline $\mathrm{I} / \mathrm{II}$ & $9(34,6)$ & $19(34,5)$ & $37(22,7)$ & $4(21,1)$ & \\
\hline $\mathrm{III} / \mathrm{IV}$ & $17(65,4)$ & $36(65,5)$ & $126(77,3)$ & $15(78,9)$ & (Cont.) \\
\hline
\end{tabular}




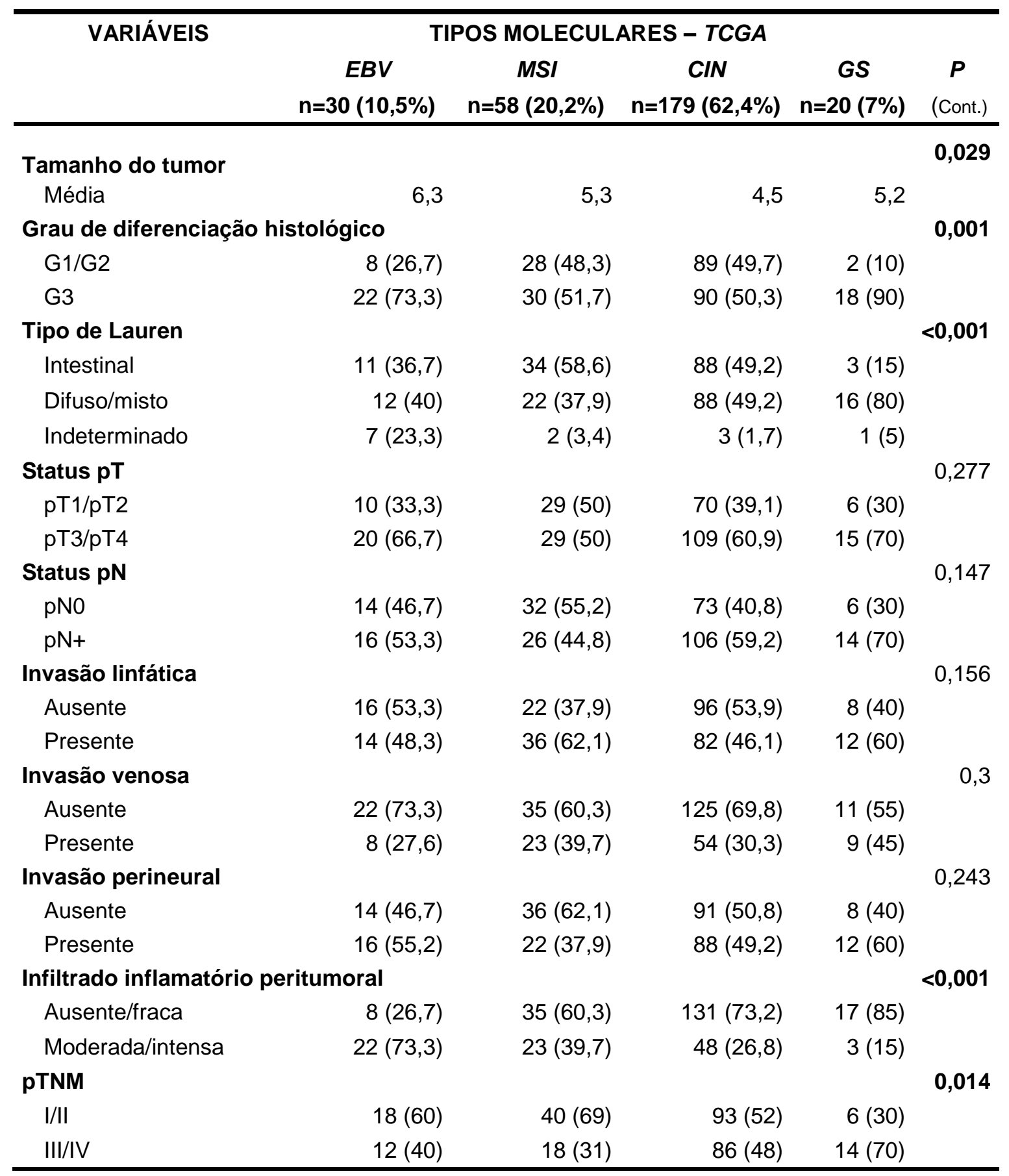

Análise de sobrevida mostrou que o grupo MSI apresentou melhor SLD e SG em relação aos outros grupos. Por outro lado, tumores GS apresentaram os piores resultados (Figuras 13 e 14). 


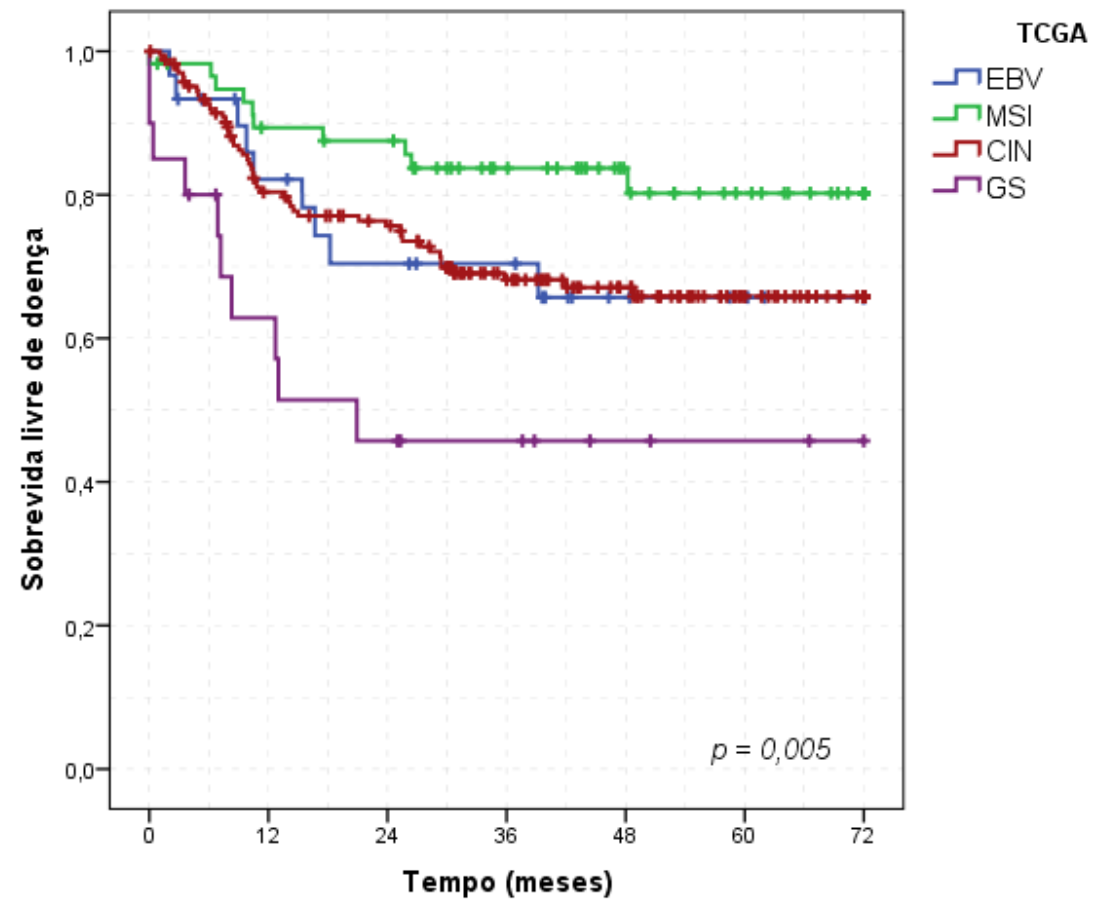

Figura 13 - Sobrevida livre de doença de acordo com a classificação TCGA.

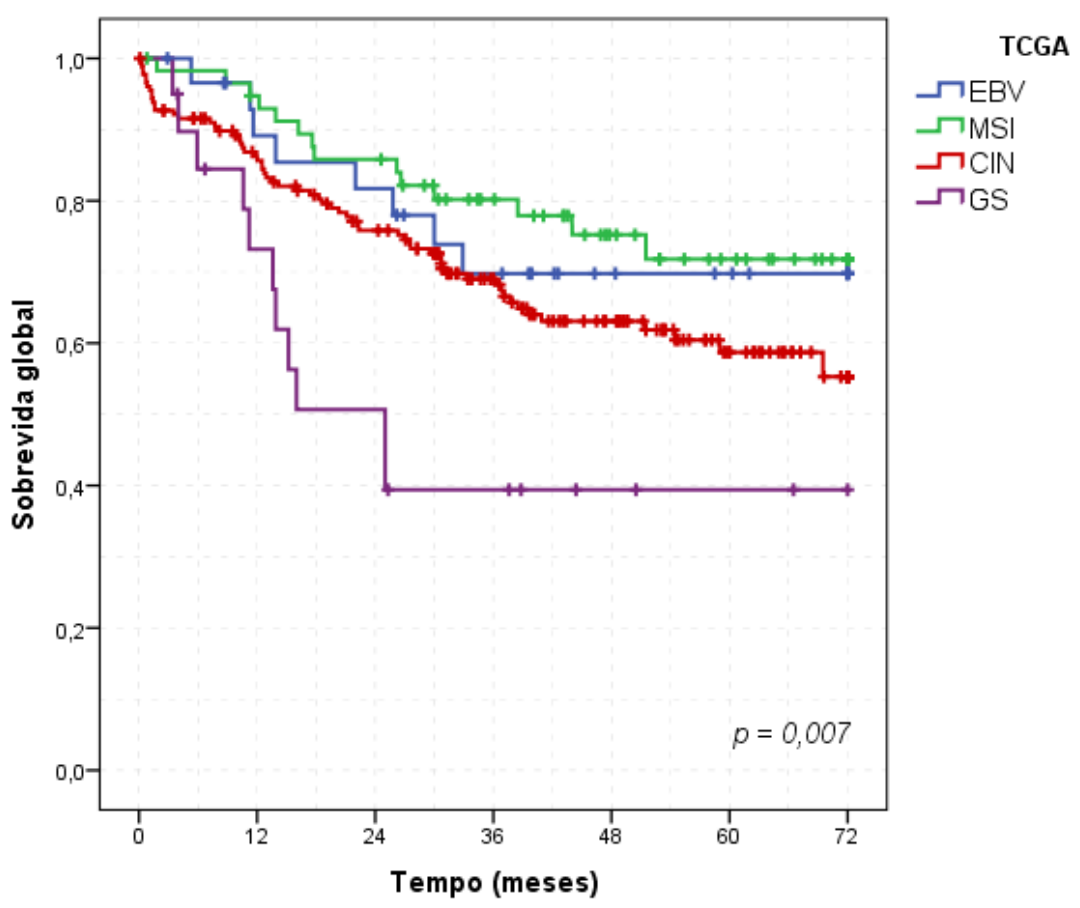

Figura 14 - Sobrevida global de acordo com a classificação TCGA. 
As análises univariada e multivariada, para a determinação das variáveis com impacto na ocorrência de recidiva (SLD), são demonstradas na tabela 6. Extensão da ressecção gástrica, categoria $\mathrm{pT}$, categoria $\mathrm{pN}$ e a classificação por subtipo tumoral foram fatores prognósticos independentes, associados à SLD.

Tabela 6 - Análise uni e multivariada para o estado "recidiva"

\begin{tabular}{|c|c|c|c|c|c|c|}
\hline \multirow[t]{2}{*}{ VARIÁVEIS } & \multicolumn{2}{|c|}{ UNIVARIADA } & \multirow[b]{2}{*}{$p$} & \multicolumn{2}{|c|}{ MULTIVARIADA } & \multirow[b]{2}{*}{$p$} \\
\hline & $H R$ & IC 95\% & & $H R$ & IC 95\% & \\
\hline Masculino (vs feminino) & 0,93 & $0,59-1,46$ & 0,745 & - & - & - \\
\hline Idade > 65 (vs <65 anos) & 1,52 & $0,95-2,45$ & 0,082 & - & - & - \\
\hline Charlson $<5$ (vs $\geq 5$ ) & 0,65 & $0,40-1,05$ & 0,076 & - & - & - \\
\hline Gastrectomia total (vs subtotal) & 2,33 & $1,49-3,62$ & $<0,001$ & 1,8 & $1,12-2,88$ & 0,015 \\
\hline Difuso/misto (vs outros) & 1,8 & $1,15-2,83$ & 0,011 & 1,24 & $0,78-1,97$ & 0,368 \\
\hline $\mathrm{pT} 3 / \mathrm{pT} 4$ status (vs pT1/pT2) & 10,87 & $4,72-24,98$ & $<0,001$ & 5,69 & $2,26-14,31$ & $<0,001$ \\
\hline $\mathrm{pN}+(\mathrm{vs} \mathrm{pN} 0)$ & 7,56 & $3,77-15,15$ & $<0,001$ & 3,25 & $1,53-6,90$ & 0,002 \\
\hline Neo/adjuvância (vs ausência) & 5,01 & $2,58-9,74$ & $<0,001$ & 0,98 & $0,46-1,08$ & 0,979 \\
\hline \multicolumn{7}{|l|}{ Classificação TCGA } \\
\hline GS & 1 & & & & & \\
\hline MSI & 0,22 & $0,09-0,52$ & 0,001 & 0,31 & $0,12-0,77$ & 0,012 \\
\hline EBV & 0,43 & $0,17-1,06$ & 0,068 & 0,37 & $0,14-0,94$ & 0,037 \\
\hline CIN & 0,42 & $0,21-0,84$ & 0,014 & 0,43 & $0,22-0,87$ & 0,018 \\
\hline
\end{tabular}

Com relação ao estado óbito (SG), extensão da gastrectomia, categoria pT e os subtipos tumorais da classificação TCGA foram fatores independentes associados (tabela 7). 
Tabela 7 - Análise uni e multivariada para o estado "óbito"

\begin{tabular}{|c|c|c|c|c|c|c|}
\hline \multirow[t]{2}{*}{ VARIÁVEIS } & \multicolumn{2}{|c|}{ UNIVARIADA } & \multirow[b]{2}{*}{$p$} & \multicolumn{2}{|c|}{ MULTIVARIADA } & \multirow[b]{2}{*}{$p$} \\
\hline & $H R$ & IC 95\% & & $H R$ & IC 95\% & \\
\hline Masculino (vs feminino) & 1,08 & $0,72-1,63$ & 0,708 & - & - & - \\
\hline Idade > 65 (vs <65 anos) & 1,16 & $0,77-1,74$ & 0,483 & - & - & - \\
\hline Charlson $<5$ (vs $\geq 5$ ) & 1,16 & $0,84-1,88$ & 0,273 & - & - & - \\
\hline Gastrectomia total (vs subtotal) & 1,9 & $1,27-2,84$ & 0,002 & 1,7 & $1,11-2,60$ & 0,014 \\
\hline Difuso/misto (vs outros) & 1,56 & $1,04-2,34$ & 0,032 & 1,16 & $0,77-1,77$ & 0,765 \\
\hline $\mathrm{pT} 3 / \mathrm{pT} 4$ status (vs pT1/pT2) & 4,5 & $2,59-7,82$ & $<0,001$ & 3,23 & $1,74-5,97$ & $<0,001$ \\
\hline $\mathrm{pN}+(\mathrm{vs} \mathrm{pN} 0)$ & 3,29 & $2,02-5,35$ & $<0,001$ & 1,69 & $0,98-2,92$ & 0,061 \\
\hline Neo/adjuvância (vs ausência) & 1,54 & $0,99-2,38$ & 0,054 & - & - & - \\
\hline Classificação TCGA & & & & - & - & - \\
\hline GS & 1 & & & & & \\
\hline MSI & 0,27 & $0,12-0,61$ & 0,001 & 0,35 & $0,15-0,78$ & 0,01 \\
\hline EBV & 0,33 & $0,13-0,82$ & 0,017 & 0,27 & $0,10-0,68$ & 0,006 \\
\hline $\mathrm{CIN}$ & 0,46 & $0,24-0,88$ & 0,019 & 0,47 & $0,25-0,91$ & 0,025 \\
\hline
\end{tabular}

\section{Classificação asiática}

Utilizando-se a estratégia de classificação proposta pelo grupo asiático, o subtipo tumoral mais comum de CG foi o microssatélite estável com expressão da p53 normal (MSS/p53 normal), ocorrido em 38,3\% dos casos. O fluxograma de classificação dos pacientes e a distribuição de cada subtipo tumoral podem ser vistos nas figuras 15 e 16 . 


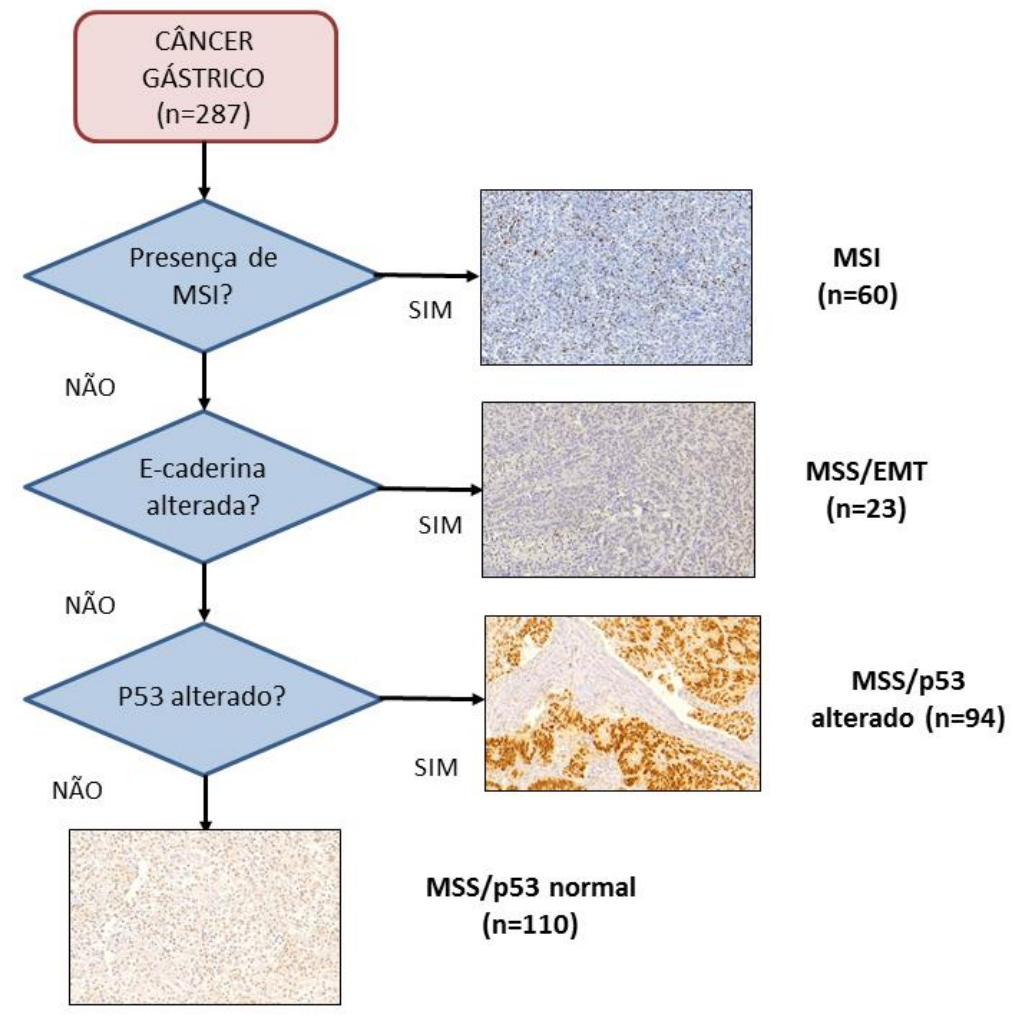

Figura 15 - Fluxograma da classificação asiática

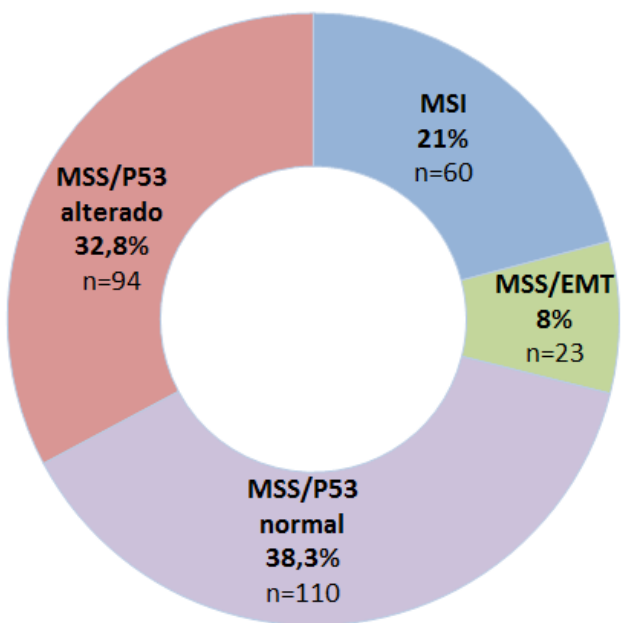

Figura 16 - Distribuição dos casos de acordo com a classificação asiática. 
A análise de sobrevida mostrou melhor SLD e SG para o tipo MSI. Os tumores MSS/EMT apresentaram os piores resultados (figuras 17 e 18).

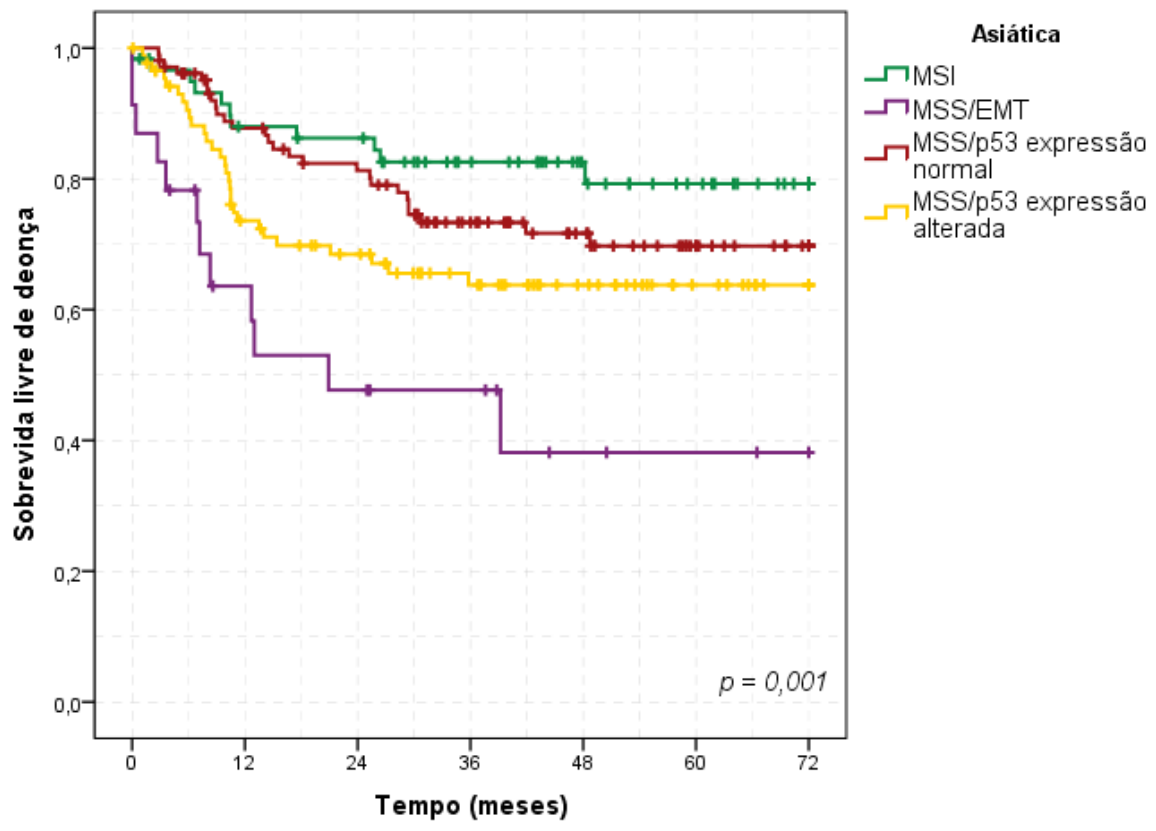

Figura 17 - Sobrevida livre de doença de acordo com a classificação asiática.

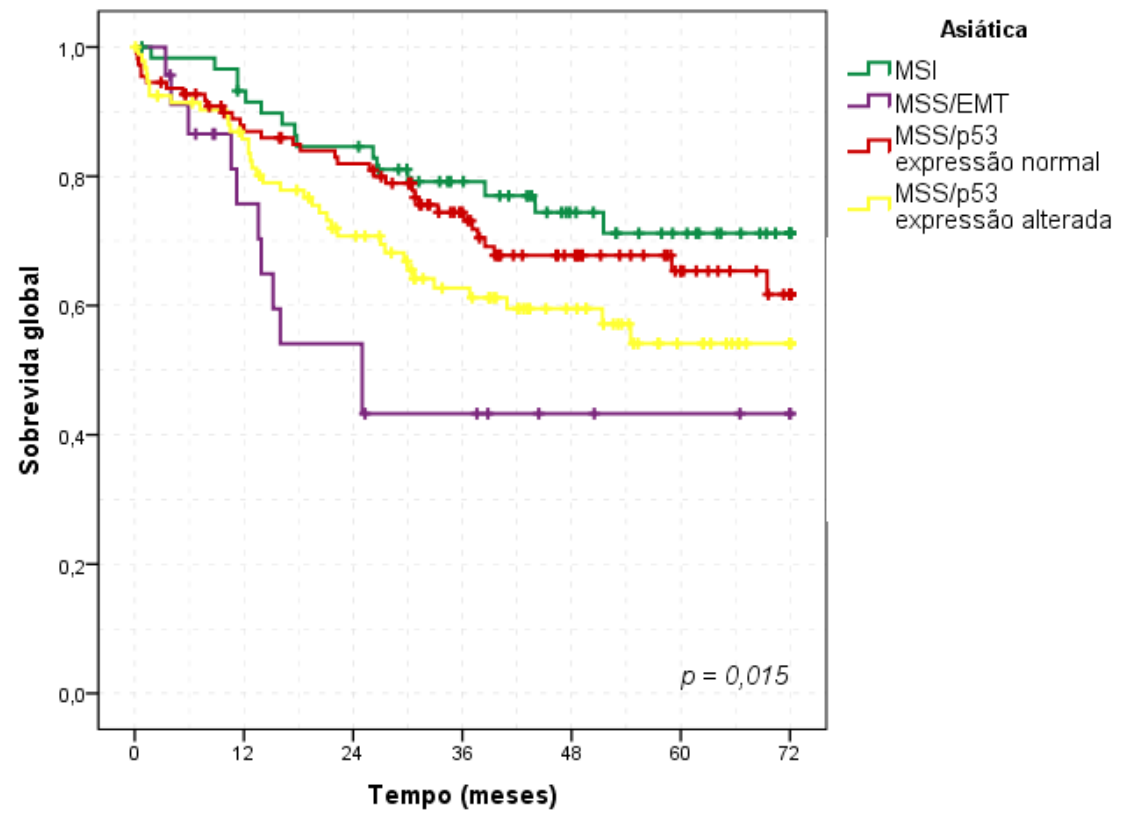

Figura 18 - Sobrevida global de acordo com a classificação asiática. 


\section{Classificação por cluster}

De acordo com a classificação por cluster, o subtipo mais comum foi o que apresentava alteração na expressão da p53 alterada, ocorrido em 31,4\% dos casos, conforme demonstrado nas figuras 19 e 20.

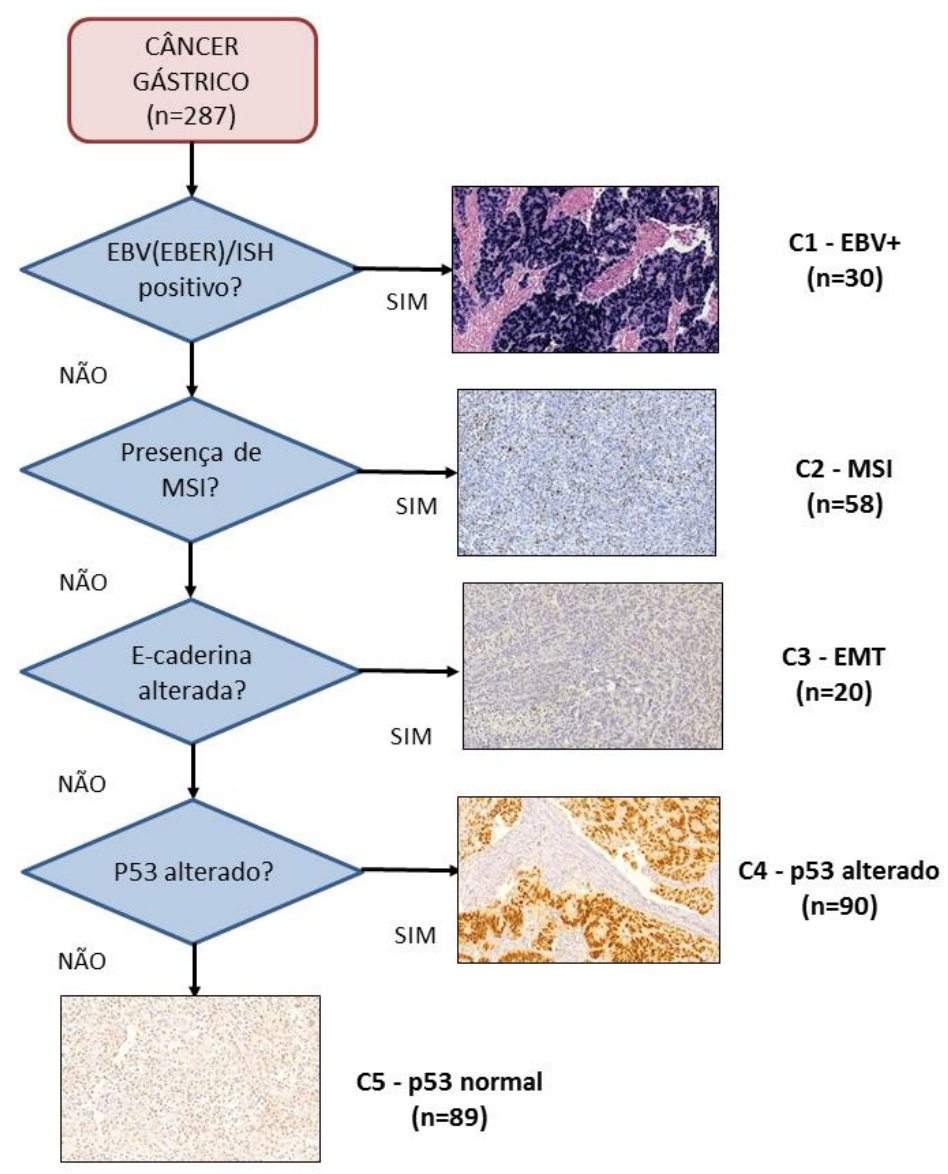

Figura 19 - Fluxograma da classificação por cluster. 


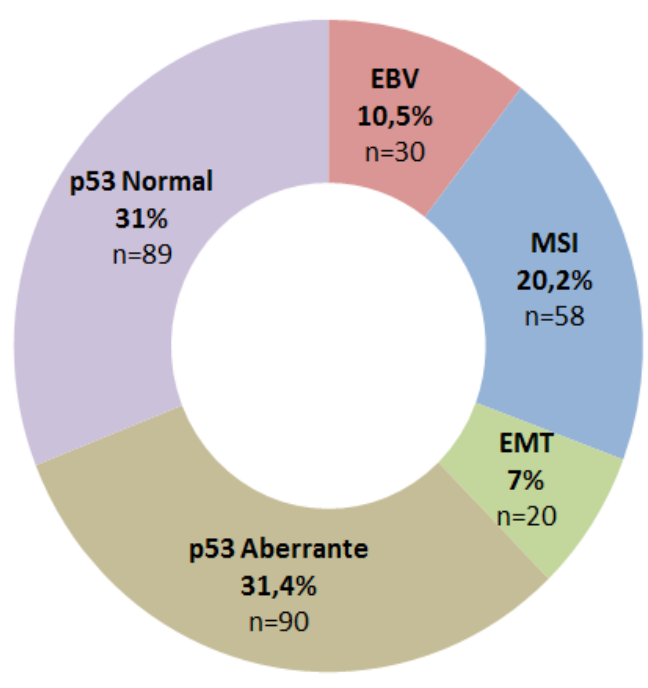

Figura 20 - Distribuição dos casos de acordo com a classificação por cluster.

Análise de sobrevida evidenciou impacto positivo, relacionado ao subtipo MSI tanto em relação a SLD quanto a SG. O subtipo EMT apresentou o pior resultado.

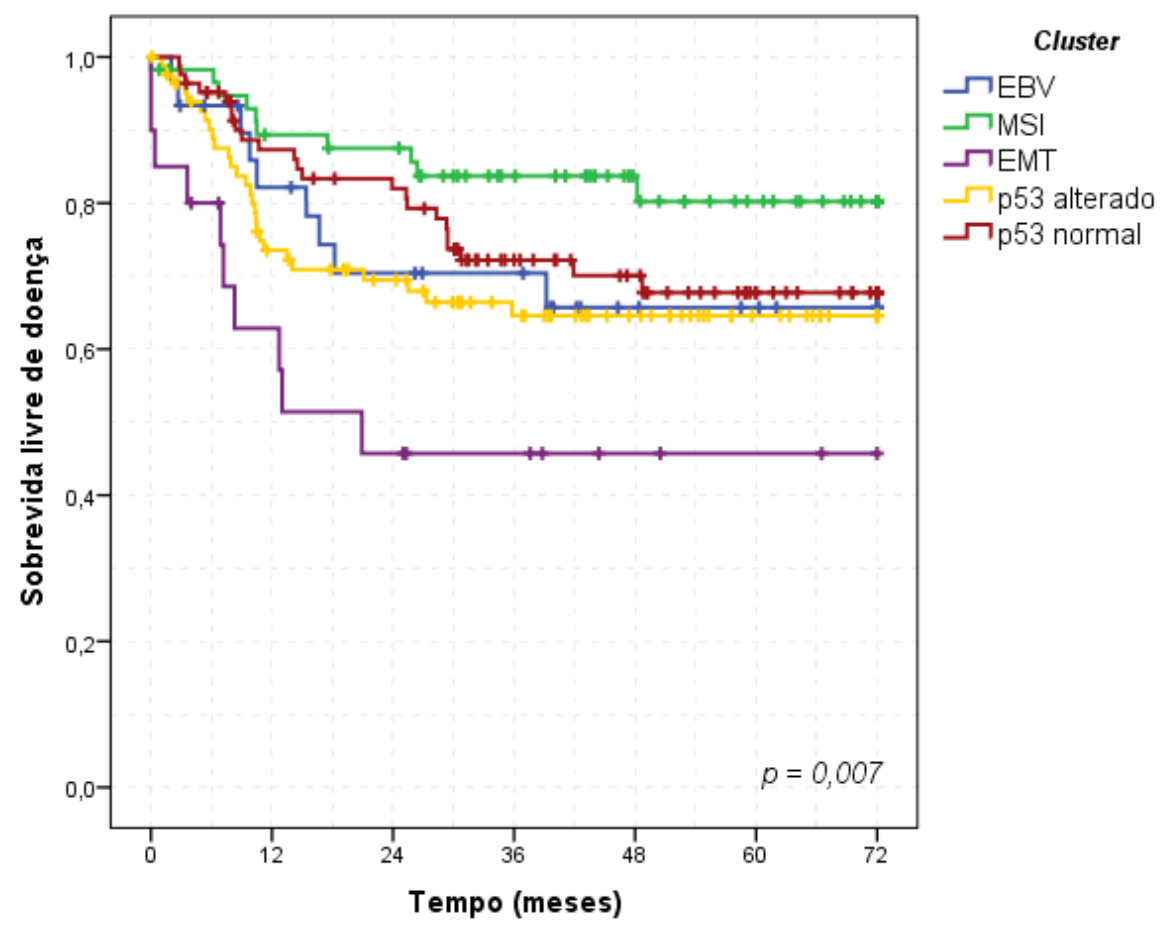

Figura 21 - Sobrevida livre de doença de acordo com a classificação por cluster. 


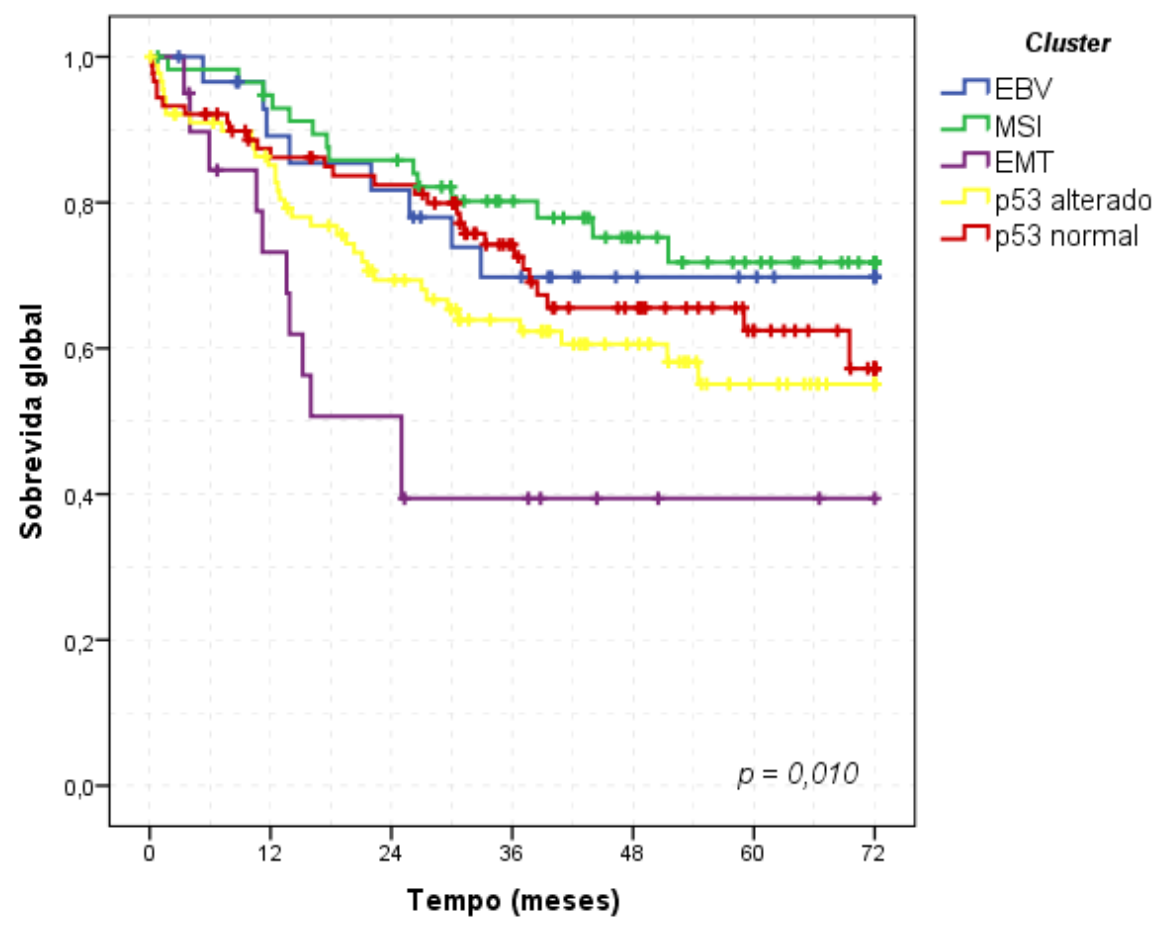

Figura 22 - Sobrevida global de acordo com a classificação por cluster.

\section{Classificação por risco}

Conforme demonstrado anteriormente na tabela 5, 23 casos apresentaram alterações na expressão de mais de um marcador. Deste modo, para determinar uma hierarquia no fluxo de classificação com base na expressão gênica e proteica, optou-se pelo método de regressão de Cox (stepwise backward), a fim de avaliar o efeito de cada marcador no desfecho "recidiva". Dessa forma, o marcador que apresentou menor $H R$ associado com o desfecho foi removido a cada passo, até que permanecesse no modelo o mais significativo (tabela 8). 
Tabela 8 - Estratificação dos marcadores com base no risco de recidiva. Retirada do marcador menos significativo a cada passo

\begin{tabular}{llcccc}
\hline Step & Expressão* & $\boldsymbol{\beta}$ & $\boldsymbol{H R}$ & IC 95\% & $\boldsymbol{p}$ \\
\hline $\mathbf{1}$ & EBV-negativo vs. EBV-positivo & 0,051 & 1,05 & $0,51-2,17$ & 0,889 \\
& MSI vs. MSS & 0,522 & 1,69 & $0,86-3,30$ & 0,127 \\
& p53 normal vs. alterada & 0,226 & 1,25 & $0,77-2,04$ & 0,362 \\
& E-caderina normal vs. alterada & 0,973 & 2,65 & $1,44-4,85$ & 0,002 \\
\hline $\mathbf{2}$ & MSI vs. MSS & 0,531 & 1,7 & $0,88-3,29$ & 0,115 \\
& p53 normal vs. alterada & 0,218 & 1,24 & $0,78-1,99$ & 0,366 \\
& E-caderina normal vs. alterada & 0,97 & 2,64 & $1,44-4,83$ & 0,002 \\
\hline $\mathbf{3}$ & MSI vs. MSS & 0,602 & 1,83 & $0.96-3,46$ & 0,065 \\
& E-caderina normal vs. alterada & 0,932 & 2,54 & $1,40-4,62$ & 0,002 \\
\hline
\end{tabular}

* primeira categoria serviu como referência

A presença de infecção por EBV apresentou menor associação com os desfechos, seguida da alteração na expressão da p53. A expressão de E-caderina apresentou maior $H R$, sendo, portanto, o primeiro grupo determinado pela classificação de risco. O fluxograma com a hierarquização obtida pelo modelo e a distribuição dos grupos são demonstrados nas figuras 23 e 24. 


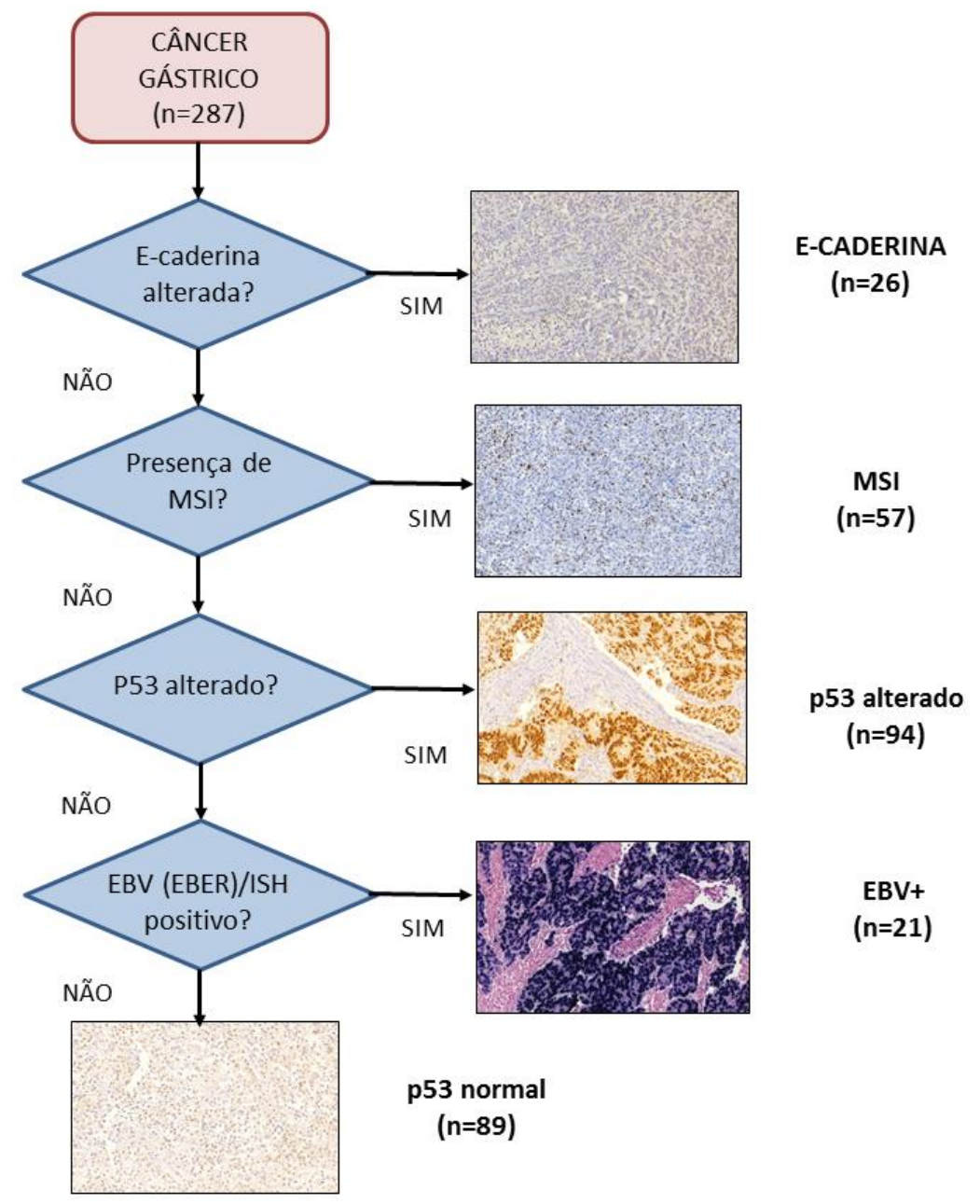

Figura 23 - Fluxograma da classificação por risco.

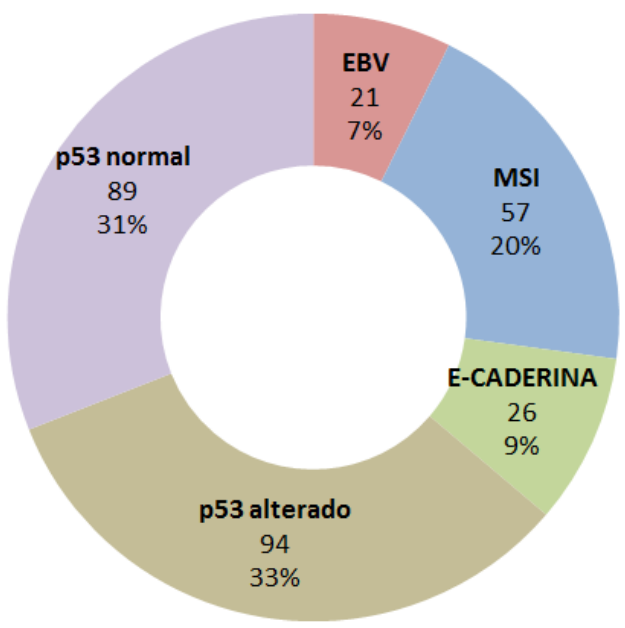

Figura 24 - Distribuição dos casos de acordo com a classificação por risco. 
De acordo com os subtipos obtidos pela classificação por risco, o MSI apresentou a melhor SLD, enquanto que o EBV positivo apresentou a melhor SG. O subtipo E-caderina apresentou o pior prognóstico em relação aos demais (Figuras 25 e 26).

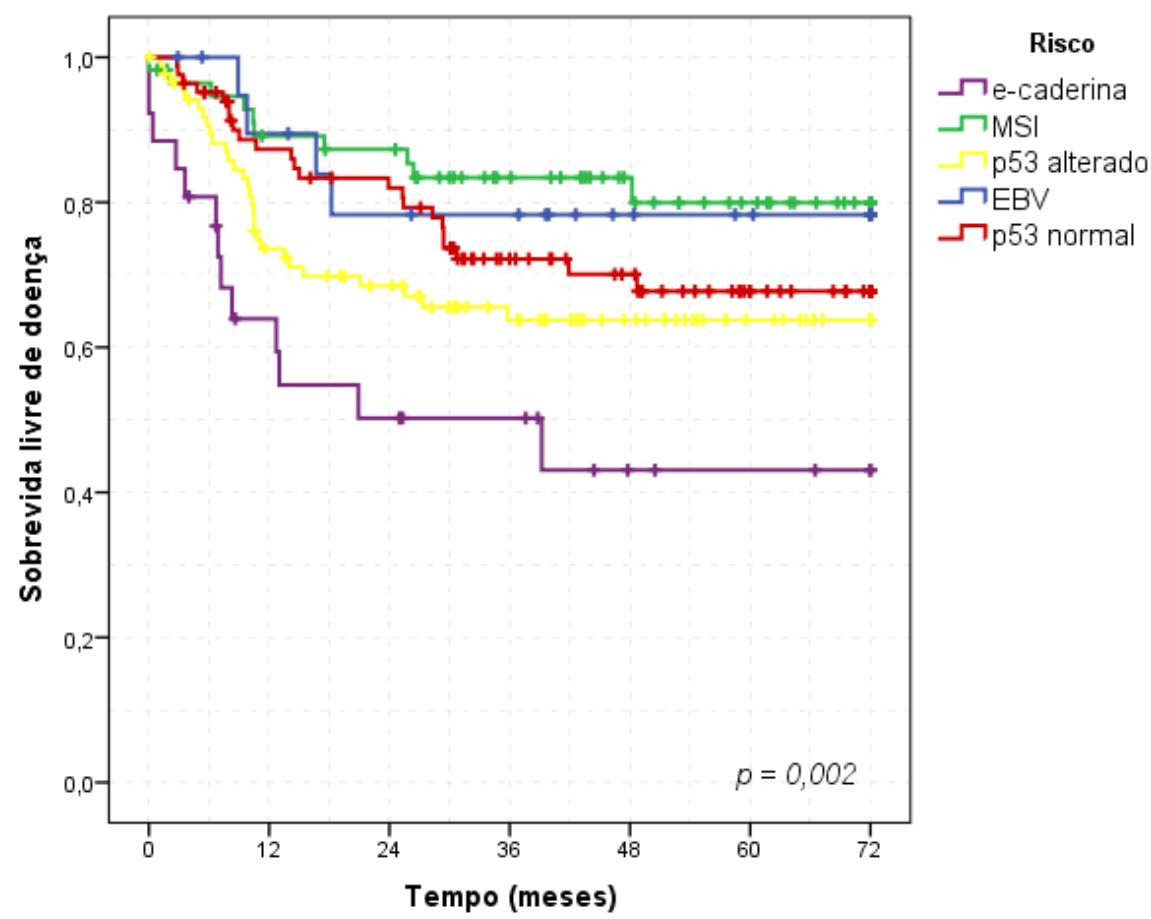

Figura 25 - Sobrevida livre de doença de acordo com a classificação por risco 


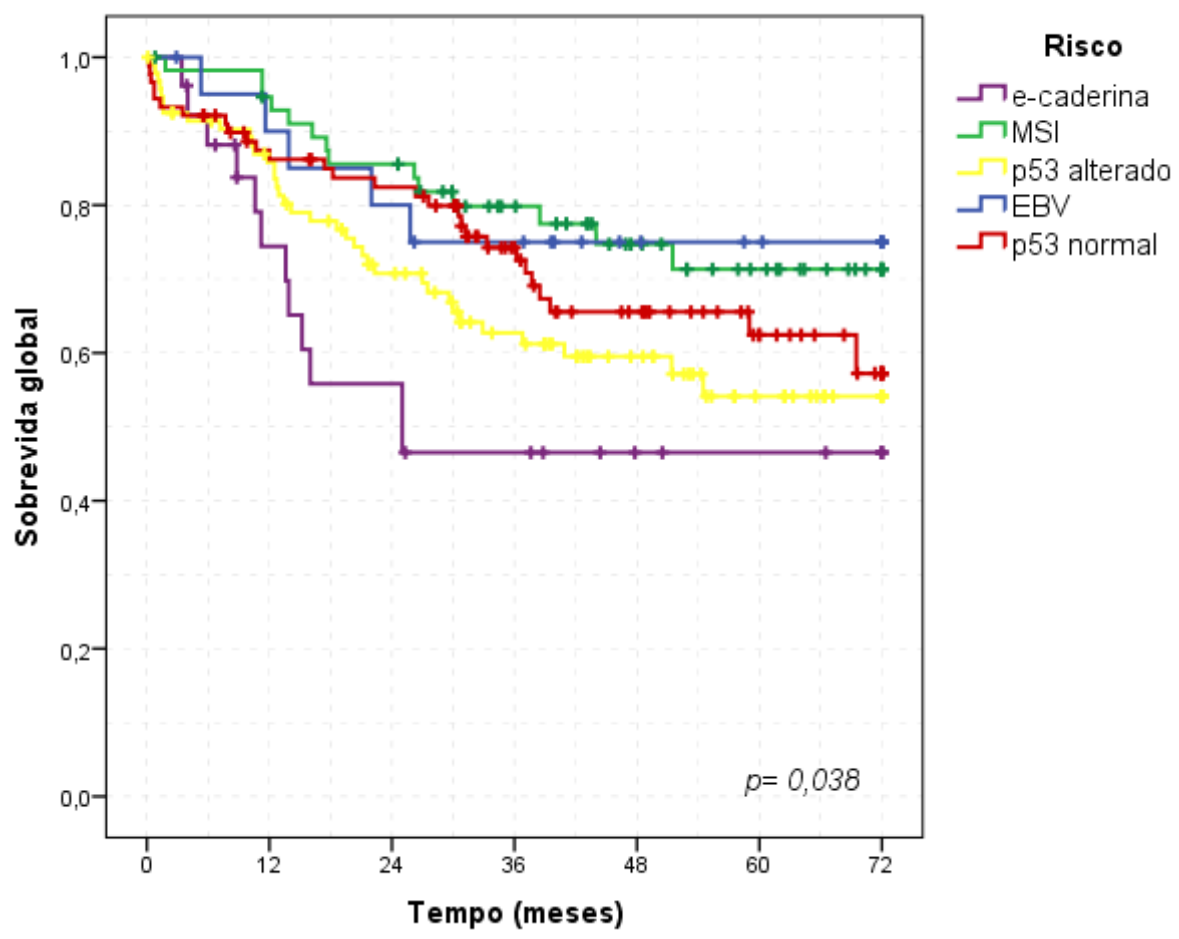

Figura 26 - Sobrevida global de acordo com classificação por risco.

\section{Comparação entres as classificações}

As principais características das quatro classificações, em relação aos subtipos tumorais, grupos de referência e observações são demonstradas na tabela 9. 
Tabela 9 - Comparação entre os grupos de cada classificação

\begin{tabular}{|c|c|c|c|c|c|}
\hline CLASSIFICAÇÃO & & GRUPOS MC & DLECULARES & & OBSERVAÇÕES \\
\hline TCGA & EBV & MSI & CIN & & \\
\hline Ref. GS & 0.075 & $<0.001$ & 0.011 & & $\begin{array}{l}\text { Não distingue grupos EBV e } \\
\text { CIN }\end{array}$ \\
\hline Asiática & MSI & MSS/P53 nl & MSS/P53 alt & & \\
\hline Ref. MSS/EMT & $<0.001$ & $<0.001$ & 0.032 & & $\begin{array}{l}\text { Grupo MSS/p53 normal } \\
\text { contaminado com EBV }\end{array}$ \\
\hline Cluster & EBV & MSI & p53 alt & p53 nl & \\
\hline Ref. EMT & 0.075 & $<0.001$ & 0.063 & 0.005 & Só 2 grupos com significância \\
\hline Risco & MSI & p53 alt & EBV & p53 nl & \\
\hline Ref. E-caderina & $<0.001$ & 0.053 & 0.016 & 0.003 & $\begin{array}{l}\text { Quase todos os grupos com } \\
\text { significância; separa grupo } \\
\text { EBV com melhor prognóstico }\end{array}$ \\
\hline
\end{tabular}

NOTA: Ref.=grupo de referência; $\mathrm{nl}=$ normal; alt=alterado

Para comparar e avaliar o desempenho das diferentes classificações na determinação prognóstica, as medidas de sensibilidade e especificidade para a ocorrência de recidiva e óbito foram obtidas por meio da construção da curva ROC. Em relação à área sob a curva (AUC) apresentada por cada classificação, a classificação por risco foi a que apresentou o melhor desempenho na determinação de recidiva (tabela 10 e figura 27).

Tabela 10 - Desempenho das classificações para determinação de recidiva

\begin{tabular}{lccc}
\hline \multicolumn{1}{c}{ CLASSIFICAÇÃO } & AUC (\%) & IC 95\% & $\boldsymbol{p}$ \\
\hline TCGA & 58,5 & $0,51-0,66$ & 0,028 \\
Asiática & 60,9 & $0,53-0,68$ & 0,005 \\
Cluster & 59,8 & $0,53-0,67$ & 0,011 \\
Risco & 61,6 & $0,54-0,69$ & 0,003 \\
\hline
\end{tabular}




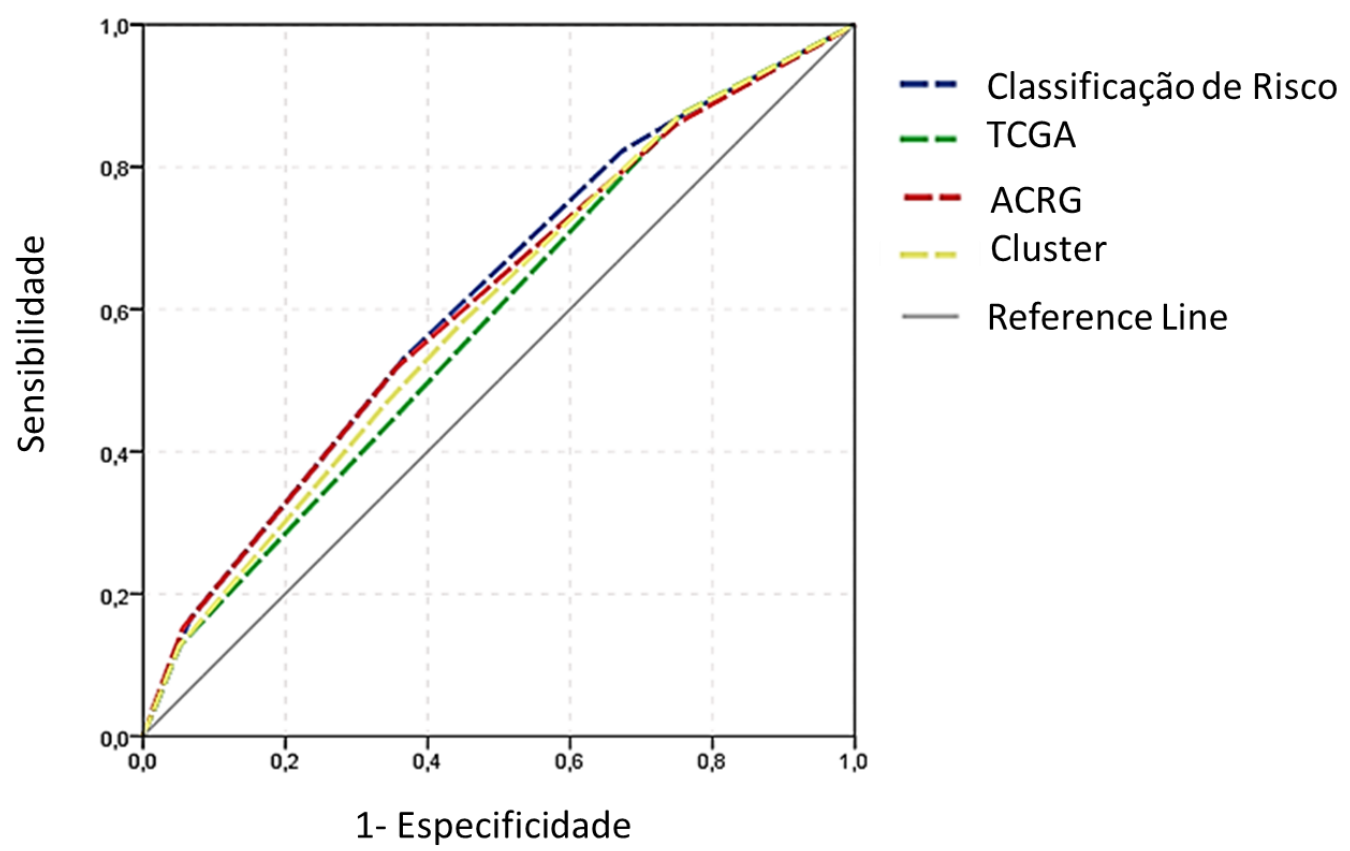

Figura 27 - Curva ROC para determinação de recidiva.

Com relação ao evento óbito, a classificação por cluster apresentou melhor poder discriminante, seguida da classificação por risco (tabela 11 e figura 28).

Tabela 11- Desempenho das classificações para determinação de óbito

\begin{tabular}{lcrr}
\hline \multicolumn{1}{c}{ CLASSIFICAÇÃO } & AUC (\%) & IC 95\% & \multicolumn{1}{c}{$\boldsymbol{p}$} \\
\hline TCGA & 57,7 & $0,51-0,65$ & 0,033 \\
Asiática & 58 & $0,51-0,65$ & 0,028 \\
Cluster & 59,1 & $0,52-0,66$ & 0,012 \\
Risco & 58,4 & $0,51-0,65$ & 0,02 \\
\hline
\end{tabular}




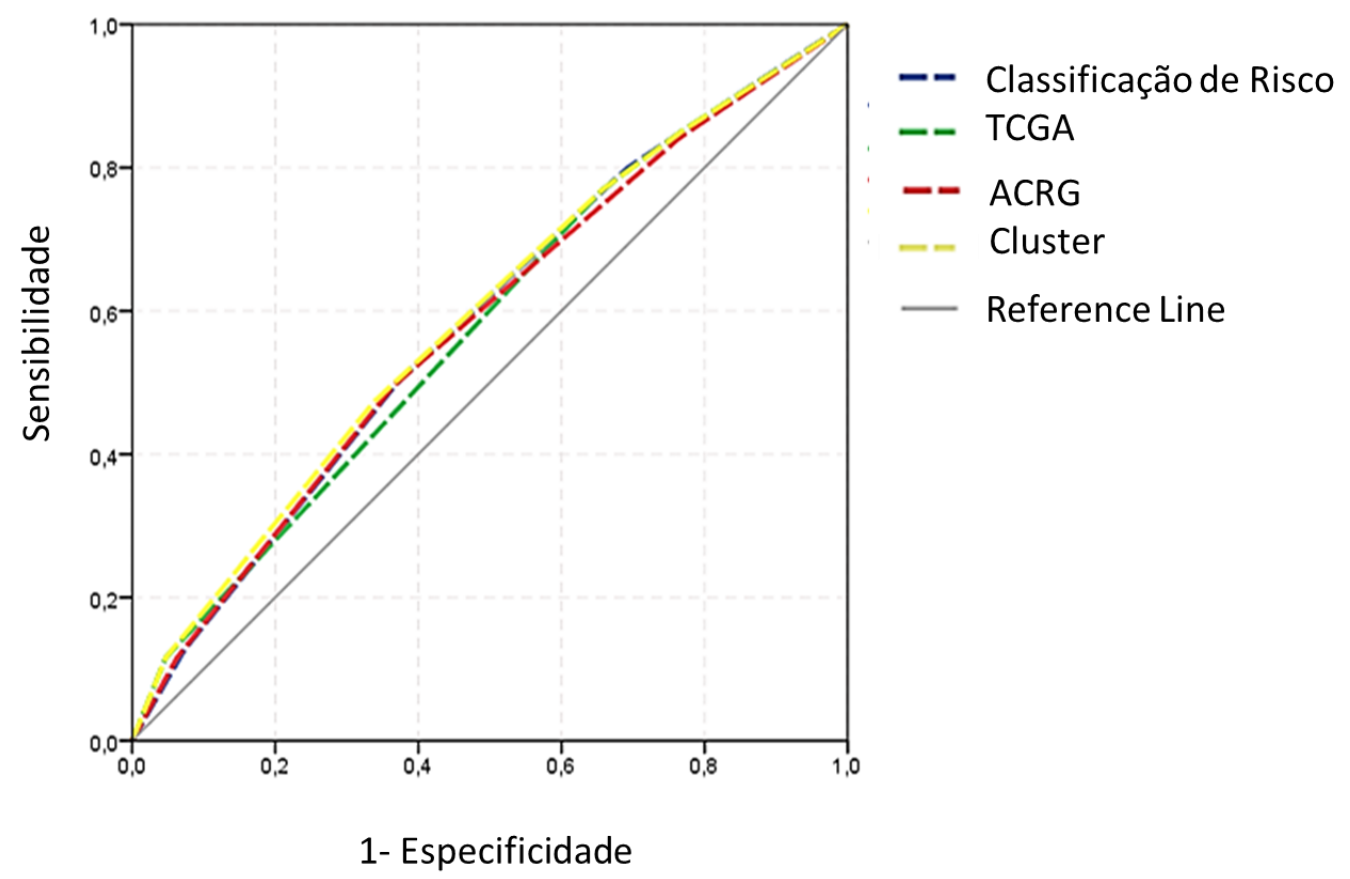

Figura 28 - Curva ROC para determinação de óbito. 


\section{DISCUSSÃO}

A avaliação da expressão gênica e proteica mostrou ser um método capaz de reproduzir a classificação molecular, apresentando resultados consistentes com os subtipos propostos pela TCGA. Os subtipos tumorais foram adequadamente identificados, de modo que apresentaram características clinicopatológicas condizentes com os relatos da Literatura (TCGA, 2014; Cristescu et al., 2015; Setia et al., 2015; Ahn et al., 2016). Neste sentido, alguns resultados merecem ser destacados novamente.

Tumores EBV positivos ocorreram predominantemente em homens com maior acometimento do estômago proximal. Este grupo apresentou lesões com maiores dimensões, além de associação com presença de intenso infiltrado inflamatório peritumoral. Os tumores associados a MSI foram mais frequentes em pacientes com idade mais avançada e, consequentemente, apresentavam mais comorbidades de acordo com a classificação de Charlson. As lesões eram, em sua maioria, localizadas no terço distal, do tipo intestinal, e foram mais submetidas a ressecções subtotais. Em relação ao prognóstico, esse foi o grupo que apresentou a melhor SLD e SG.

Tumores classificados como CIN representaram o maior grupo estudado $(62,4 \%)$. Também apresentaram predomínio de lesões distais e do tipo intestinal, ainda que em menor proporção daqueles associados à MSI.

Por fim, o grupo de tumores GS apresentou baixo grau de diferenciação histológica (G3), maior proporção de tumores difusos, metástases linfonodais e estádios mais avançados. Foi o grupo que apresentou as piores SLD e SG.

Apesar dos resultados encontrados, a abordagem pela análise de expressão gênica e proteica apresenta alguns aspectos que devem ser considerados no contexto de uma classificação categórica de expressão de um marcador, uma vez que um mesmo tumor pode apresentar alteração na expressão de mais de um marcador. A definição de a qual grupo pertence o paciente com mais de um marcador alterado se torna dependente do fluxo de teste dos marcadores estabelecidos. 
No grupo de pacientes com mais de um marcador alterado, verificou-se que os tumores associados ao EBV foram os que sofreram maior interferência na sobrevida, quando associados à alteração de outro marcador. Frente a esta observação, optou-se por adotar um fluxo de classificação com base na ordem do risco de recidiva que cada marcador apresentasse. Essa nova maneira de classificar denominou-se classificação por risco. A avaliação das características clinicopatológicas e a análise de sobrevida comprovaram a validade dessa nova classificação.

Por fim, contemplados os objetivos secundários planejados no estudo, realizouse a comparação entre as diferentes classificações moleculares descritas na Literatura, por meio da construção da curva ROC. A classificação por cluster e a classificação por risco emergiram como as de melhores resultados.

\subsection{Vírus Epstein-Barr}

Tumores associados ao EBV representam o grande ponto de discórdia entre as diferentes classificações moleculares. No TCGA e na classificação por cluster, ele é o primeiro grupo a ser discriminado, enquanto a classificação asiática não contempla tumores EBV positivos como um subtipo. No fluxo da classificação por risco proposta, o EBV foi o último subtipo discriminado, com base no menor impacto que o grupo apresentou no prognóstico em relação aos demais parâmetros. O que podemos verificar na análise de sobrevida é que, quando os tumores associados ao EBV apresentam alterações na expressão de outro marcador, eles tendem a apresentar um prognóstico mais semelhante ao do grupo do outro marcador alterado. Mesmo que o tumor tenha origem clonal a partir de uma célula neoplásica EBV positiva, as múltiplas alterações genéticas e epigenéticas ocorridas na sua carcinogênese vão alterando suas características e prognóstico. Deste modo, sugere-se que o grupo de pacientes EBV positivo seja considerado apenas quando a sua expressão aparece isolada, sem se observar a expressão alterada de outro marcador, pois são esses pacientes que apresentam um melhor prognóstico. A possibilidade de essa forma de classificação implicar uma reposta terapêutica diferente a drogas distintas é algo que não se pode verificar. 
A possibilidade da expressão alterada de mais marcadores também foi relatada em outros estudos. Anh et al. (2016), quando realizaram a classificação por cluster com base em IH e ISH, verificaram que a expressão de EBV, alteração de MLH1 e Ecaderina eram raramente vistas simultaneamente em um mesmo tumor, sendo, portanto, eventos quase mutuamente exclusivos. Neste estudo, apenas dois dos 26 casos EBV positivos apresentaram expressão alterada de MLH-1, e um caso de E-caderina.

Analisando-se as outras classificações, é interessante verificar que a classificação asiática não discrimina os tumores EBV positivos como um subtipo. Esta estratégia pode facilitar a caracterização dos subtipos. No entanto, com o crescente emprego da imunoterapia no tratamento do $\mathrm{CG}$ e seu potencial benefício nos tumores EBV, considera-se válido manter esse grupo como um dos subtipos tumorais para a prática clínica.

\subsection{Instabilidade de microssatélites}

A incidência de MSI no CG varia de 5,6\% a 33,3\% em diferentes países (Polom et al., 2018). No presente estudo, ela ocorreu em $20,9 \%$ dos casos.

Definiu-se a instabilidade de microssatélite por meio da pesquisa das quatro proteínas MMR por IH, sendo o fenótipo MSI caracterizado pela perda da expressão de uma ou mais proteínas de reparo. A avaliação da expressão das MMR é uma técnica bem estabelecida e eficiente na determinação do status MSI. Bae et al. (2015) verificaram que, comparada às análises baseadas em PCR, a IH apresenta sensibilidade de $91,1 \%$ e especificidade de $98,5 \%$ na detecção do fenótipo MSI no CG. O uso da técnica de PCR para a instabilidade dos microssatélites foi também equivalente à IH para a detecção de câncer colorretal hereditário não polipóide (Halling et al., 1999). O American College of Gastroenterology recomendou a pesquisa de deficiência de genes de reparo de DNA (MMR) em todos os casos novos diagnosticados de câncer colorretal (Syngal et al. 2015). Essa análise dever ser feita preferencialmente antes da cirurgia, por meio de IH para proteínas MLH1, MSH2, MSH6 e PMS2.

Em relação às características observadas no CG com MSI, estudo realizado no Brasil em 2004 por Perez et al. relatou frequência de 21\% de MSI em 24 casos de CG operados. Houve tendência para os tumores MSI apresentarem menor acometimento 
linfonodal, estádios menos avançados e localização proximal, ainda que sem significância estatística.

O motivo de os tumores associados a MSI geralmente apresentarem melhor prognóstico ainda não está completamente definido. Evidências sugerem que o infiltrado peritumoral linfocitário, em resposta aos peptídeos imunogênicos gerados pelos tumores com MSI, desempenha um papel importante na indução de apoptose de células tumorais por meio do estímulo de citocinas (Mathiak et al. 2017).

Igualmente buscando favorecer o melhor prognóstico naqueles casos, o menor acometimento linfonodal é uma característica marcante. Roviello et al. (2018) em série de casos italianos iniciados em 1988, verificou que os tumores com MSI não apresentavam metástase linfonodal em 53,7\% dos casos, enquanto que apenas $29,7 \%$ do MSS não tinham acometimento linfonodal $(p<0,001)$. Mesmo nos casos com MSI marcados pela presença de metástase linfonodal, esta afetava menor número de linfonodos e cadeias linfonodais, além de as cadeias acometidas se localizarem mais próximas ao tumor primário.

Outra característica que pode estar associada a tumores MSI é a menor resposta à quimioterapia com base em fluopirimidinas. An et al. (2012) avaliaram a SLD de pacientes com CG, estádio clínico II e III, que realizaram quimioterapia adjuvante. Pacientes com MSI não tiveram melhora da SLD após realização da quimioterapia adjuvante com fluopirimidinas. Posteriormente, Kim et al. (2015), pertencentes ao mesmo grupo, ampliaram a casuística e confirmaram que pacientes CG e MSI apresentavam melhor prognóstico do que o grupo MSS nos estádios II e III tratados apenas com cirurgia, mas que esse benefício era atenuado nos casos que recebiam quimioterapia adjuvante.

Ainda em relação aos efeitos da MSI na quimioterapia adjuvante, Smyth et al. (2017), em uma análise post hoc do MAGIC trial (Cunningham et al., 2006), mostraram que $8,5 \%$ dos pacientes tinham MSI. Sua ocorrência associou-se a lesões de localização gástrica. Nenhum tumor com MSI apresentou boa reposta patológica à quimioterapia. Pacientes com MSI tratados apenas com cirurgia apresentaram melhor SG do que pacientes com MSS. No entanto, nos pacientes do grupo que realizou quimioterapia peri-operatória, a presença de MSI associou-se à pior SG, inclusive evidenciando efeito deletério da realização de quimioterapia nesse grupo. Esses resultados colocam em 
questionamento o papel da quimioterapia com fluopirimidinas nos tumores gástricos com MSI.

Choi et al. (2014) realizaram meta-análise visando a avaliar o valor prognóstico da MSI no CG. Após análise de dezessete estudos, os autores verificaram que tumores MSI apresentavam melhor prognóstico ( $H R=0,76$; IC95\%: 0,65-0,88) em comparação aos MSS. Os autores destacaram que houve muita heterogeneidade entres os estudos analisados, principalmente no que se refere à realização que quimioterapia.

Polom et al. (2018) publicaram meta-análise, avaliando 48 estudos. MSI estava presente em $1.718(9,2 \%)$ pacientes dos 18.612 incluídos, sendo associada às seguintes características clinicopatológicas: sexo feminino, idade superior a 65 anos, tipo histológico intestinal, localização terço médio e distal, ausência de acometimento linfonodal e estádios mais precoces. Pacientes com MSI apresentaram uma melhor SG em relação aos MSS (HR=0,69; IC95\%: 0,56-0,86; $p<0,001)$. Análises de subgrupos exploratórias, avaliando qualidade do estudo, ano de publicação, país de origem, e tamanho da amostra do estudo não alteraram substancialmente o papel prognóstico da MSI na SG. Apenas o número de marcadores utilizados para detecção da MSI influenciou a análise $(p=0,014)$.

\subsection{Proteína p53}

A avaliação da expressão da proteína p53 é o maior desafio dentre todos os marcadores analisados. O acúmulo nuclear da p53 pode ser resultado do aumento da expressão da proteína selvagem (wild-type) ou diminuição da degradação em reposta a inúmeros estresses celulares, incluindo dano ao DNA. Hiperexpressão da proteína selvagem é uma resposta fisiológica normal para diminuir o ciclo celular na fase G1 e possibilitar o reparo do DNA danificado. Portanto, baixos níveis da proteína selvagem p53 podem ser detectados no núcleo. Algumas mutações missense resultam em uma proteína truncada, que não é detectável por IH. Além disso, anormalidades genéticas, como mutações pontuais, não estabilizam a proteína suficientemente para ocasionar acúmulo nuclear que possibilite detecção por técnicas IH (Fenoglio-Presier et al., 2003).

Ando et al. (2015) verificaram que $20 \%$ dos tumores p53 negativos na IH tinham mutações do gene TP53, e 19\% dos tumores p53 positivos tinham mutação do 
gene TP53. A princípio, isso levou os autores a concluir que não havia relação entre a ocorrência de mutação do gene TP53 e a expressão da proteína p53 na IH. Posteriormente, analisando o padrão de marcação nuclear do p53 em aberrante e difuso, os autores verificaram que todos tumores com mutação missense do TP53 tiveram marcação aberrante nuclear, e todos com marcação difusa não apresentaram mutação do gene TP53. Análise do locus da p53 no cromossomo 17 confirmou que a marcação difusa da p53 na IH apresentou estrutura normal do gene TP53 no cromossomo. Desta forma, esperava-se, pelo conceito anterior, que os tumores sem mutação do gene TP53 não apresentassem qualquer expressão da p53 na IH. Após esses achados, sugeriu-se que a marcação difusa pode refletir o acúmulo da proteína wild-type p53 em resposta a erros genéticos espontâneos. Essa marcação ocorre com maior intensidade no tecido com tumoração do que no normal adjacente. Adicionalmente, a ocorrência de tumores com marcação aberrante na IH, sem presença de mutação do gene TP53, pode ser explicada pela ocorrência de outros mecanismos diferentes de mutações de inativação como alterações aberrantes do cromossomo 17, além de alterações pós-translacionais.

Outra característica relativa à p53 é sua relação com a positividade para EBV. Infecções virais e bacterianas podem modular a frequência de mutações do gene TP53 por meio da inativação direta da proteína, por interação gene a gene (Wei et al., 2010). Não obstante, neoplasias associadas ao EBV são caracterizadas pela baixa ocorrência de mutações no TP53.

Ao avaliar a expressão da p53 em tumores gástricos EBV positivos, Ribeiro et al. (2017) verificaram que estes apresentaram maior frequência de marcação $\geq 50 \% \mathrm{em}$ comparação aos EBV negativos ( $p=0,027)$. Porém, na análise de DNA, apenas um caso dentre quinze tumores gástricos EBV positivos apresentaram uma mutação missense. Polimorfismos (SNP) no códon 72 do TP53 ocorreram em três casos. Desses quatros casos com alteração no DNA, apenas um apresentou expressão aberrante da p53. Isso demonstra que GC associado à infecção pelo EBV é caracterizado pela baixa frequência ou ausência de mutações do TP53 (Ribeiro et al., 2017). Portanto, a expressão da p53 pode ser alterada por meio de vias não mutacionais. Infecção pelo $H$. pylori e algumas proteínas do EBV têm potencial oncogênico ao inativar a expressão da p53 como parte do seu ciclo celular (Wei et al., 2010). 
Baek et al. (2017) avaliaram 117 casos de adenocarcinoma gástrico EBV positivos e analisaram a expressão da p53, HER2 e beta-catenina por IH. Os autores consideraram como alterada a marcação intensa da p53 em pelo menos 50\% dos núcleos das células tumorais. Expressão positiva da p53 ocorreu em 23,8\% dos casos, esteve associada a categorias pT mais avançadas $(p=0,006)$ e maior número de metástases linfonodais $(p=0,013)$. Pacientes com p53 alterada apresentaram pior SLD $(p=0,022)$ e uma tendência a pior sobrevida global $(p=0,080)$. Em acordo com o resultado deste estudo, tais achados sugerem um comportamento mais agressivo dos tumores EBV positivos quando exibem aumento da expressão da proteína p53.

Diferentes impactos na sobrevida com expressão da p53 no CG foram relatados na Literatura. Relatos de melhor resposta à quimioterapia em casos da p53 selvagem têm ocorrido. Entretanto, o significado clínico de sua expressão continua controverso. Fenoglio-Preiser et al. (2003) referiram ser mais comum em tumores da cárdia e no tecido metastático em relação ao tumor primário. Em seu estudo, houve $80 \%$ de concordância da análise da expressão na biópsia com a análise da peça. Heterogeneidade de marcação também ocorreu, visto que metade dos casos marcou mais de $75 \%$ das células tumorais e $25 \%$ marcou menos.

No Brasil, Gonçalves et al. avaliaram, em 2011, a expressão da p53 em 80 casos de câncer gástrico precoce. Os autores consideraram a expressão nuclear superior a $10 \%$ como casos p53 positivos e inferior como p53 negativos. Os autores classificaram $27,5 \%$ dos tumores como p53 positivos e estes se associaram à histologia do tipo intestinal $(p=0,003)$, bem diferenciados $(p=0,007)$, e lesões macroscopicamente elevados $(p=0,038)$. A expressão da p53 não apresentou associação com a sobrevida global em cinco anos, nem com frequência de acometimento linfonodal.

Finalizando, Wei et al. (2015) publicaram meta-análise que incluiu 34 estudos, totalizando 6.599 indivíduos na análise final. Foram incluídos apenas estudos que analisaram a expressão da p53 por IH. Hiperexpressão da p53 foi associada a pior SG $(H R=1,56 ; \quad$ IC95\%:1,23-1,98) e SLD $(H R=1,52 ;$ IC95\%:1,35-1,73). Resultados semelhantes, relacionando-se o impacto da expressão da p53 na sobrevida, já haviam sido relatados para tumores hepatocelulares, vias biliares, bexiga, urotelial, osteosarcoma, pulmão e esôfago. Com relação às características clinicopatológicas, a expressão associou-se ao sexo masculino, tumores do tipo histológico intestinal, 
categoria pT mais avançada, presença de metástase linfonodal e à distância, além de invasão vascular e linfática.

\subsection{E-caderina}

A expressão da E-caderina por IH é avaliada pela presença de marcação contínua e linear na membrana celular, nos limites entre as células, assim como na base da glândula gástrica. Marcação citoplasmática, também relatada como "marcação paranuclear" ou "heterogênea", é considerada aberrante. Sugere-se que isso ocorra por aprisionamento da E-caderina no complexo de Golgi, pela falta de modificações póstranslacionais que permitem seu transporte para a membrana celular (Carpenter et al., 2002). Os valores de corte para a definição da perda de expressão na membrana variam de 5\% a 90\% em relação ao tecido não tumoral. Assim como na análise do p53, essa avaliação é subjetiva. Porém, apresenta maior homogeneidade entres diferentes trabalhos avaliados (Li et al., 2014). Emprego de imunofluorescência com determinação de perfis de expressão nas células alteradas e normais podem, no futuro, facilitar essa definição (Sanches et al., 2015).

Shimoyama et al., em 1991, foram pioneiros na avaliação da expressão da Ecaderina em adenocarcinomas gástricos. Avaliando 54 casos de CG, os autores encontraram diminuição ou perda da expressão em diversas amostras tumorais, ainda que sem impacto na sobrevida. Gabbert et al., em 1996, verificaram, em uma grande série de casos, que a ausência da expressão da E-caderina era um fator independente associado à pior sobrevida em três e cinco anos.

No Brasil, Silva et al. (2008) avaliaram a expressão em 515 pacientes com CG. Alteração da expressão ocorreu em $73 \%$ dos pacientes, sendo mais frequente em pacientes acima de 40 anos, em comparação ao grupo abaixo de 40 anos (74,9\% vs. $57,4 \% ; p<0,01)$. Entretanto, não houve associação da sobrevida com a expressão da Ecaderina.

Importante ressaltar que a associação de expressão da E-caderina e alterações no gene CDH1 ainda não está claramente definida. Apenas uma minoria dos casos de CG apresenta mutação do gene CDH1. A Mutação somática tem sido relatada em cerca de $3 \%$ a $50 \%$ dos CG, com componente difuso (Corso et al., 2013). Perda de heterozigose 
(LOH), silenciamento epigenético por hipermetilação, alterações mediadas por microRNA e histonas também podem ocorrer (Carvalho et al., 2012).

Corso et al. (2013) analisaram a presença de mutações e expressão do CDH1 em uma coorte italiana de 246 pacientes. Alterações estruturais do gene (mutação, LOH) foram encontradas em 10,6\% dos casos e alterações epigenéticas (metilação) foram verificadas em 20,7\% dos casos. Com relação às características clinicopatológicas dos pacientes, verificou-se que tumores com alteração do gene CDH1 apresentaram mais metástase linfonodais e tumores mais avançados. Dado interessante desse estudo foi que tumores com alteração estrutural estiveram mais associados ao tipo histológico intestinal e sexo masculino, enquanto que tumores com alterações epigenéticas associaram-se mais ao tipo difuso.

Ao relacionar o impacto prognóstico do tipo histológico com a origem da alteração genética, Corso et al. verificaram que tumores do tipo intestinal, com alterações estruturais do gene, têm pior prognóstico. Tumores do tipo difuso tiveram alterações estruturais em $7 \%$ dos casos e epigenéticas em $31,4 \%$ dos casos, sem impacto na sobrevida. De maneira geral, verificou-se que pacientes com alterações epigenéticas do CDH1 apresentaram melhor prognóstico do que os com mutação ou LOH.

Por fim, Corso et al. avaliaram a expressão da E-caderina por IH. Expressão aberrante foi encontrada em 73,4\% dos casos, ausência de expressão em 14,5\% e expressão preservada na membrana celular em 12,1\%. Perda de expressão foi associada a tumores de histologia difusa. O tipo de alteração do gene CDH1, estrutural ou epigenética, não esteve associado a nenhum padrão específico de expressão IH da Ecaderina. Interessante notar que $70 \%$ dos pacientes com ausência da expressão da Ecaderina não apresentaram mutação do gene CDH1. Esse fato sugere a interação de outros mecanismos pós-translacionais relacionados à expressão da E-caderina (Carvalho et al., 2012).

Exemplificando mais uma vez a complexidade e diversidade de alterações moleculares envolvidas na carcinogênese gástrica, estudos de polimorfismos de nucleotídeo único (SNPs) relacionados ao gene CDH1 também foram realizados (Jiang et al., 2014). SNPs, na região promotora do gene CDH1, influenciam sua capacidade de transcrição e alteram a expressão da E-caderina. Foi postulado em alguns estudos que esses SNPs podem estar associados ao desenvolvimento de câncer. O polimorfismo 
mais estudado é o CDH1 C-160A, em que o alelo A diminui sua eficiência de transcrição alterando a expressão da E-caderina.

Jiang et al. em 2014 realizaram meta-análise envolvendo 4.218 casos de adenocarcinoma gástrico e 5.461 controles para análise daquele polimorfismo. Apesar de alguns subgrupos terem associação positiva, a análise global não confirmou associação do polimorfismo CDH1 C-160A ao risco de desenvolvimento de CG.

A metilação do gene CDH1 também está envolvida na carcinogênese, especialmente nos casos de gastrite crônica associada a infecção pelo H.pylori (Liu et $a l ., 2014)$. Detectou-se diminuição da expressão da E-caderina por metilação em lesões gástricas pré-cancerosas, sugerindo-se o papel da E-caderina na iniciação da carcinogênese (Perri et al., 2007). A erradicação do H.pylori permite a reversão da hipermetilação do CDH1, interrompendo a carcinogênese. Pacientes com câncer gástrico difuso hereditário, que já possuem um alelo CDH1 com mutação germinativa, têm na hipermetilação do alelo CDH1 a causa mais comum de "second hit" para inativação completa do gene e desenvolvimento do tumor (Park et al., 2014).

Na tentativa de verificar o impacto da expressão da E-caderina no CG, Xing et al. publicaram meta-análise em 2012 englobando 26 estudos e 4.383 pacientes com câncer gástrico. A expressão reduzida de E-caderina teve associação significativa com pior sobrevida global ( $H R=1,62$; IC95\%: 1,34-1,96). Expressão alterada também se associou com estádio clínico mais avançado, profundidade de invasão tumoral, presença de acometimento linfonodal, metástases a distância, grau de diferenciação e tipo histológico. Pacientes asiáticos também apresentaram pior sobrevida.

Posteriormente, Li et al. (2014) realizaram meta-análise avaliando a expressão da E-caderina apenas em pacientes asiáticos. Alteração da expressão associou-se à pior sobrevida em cinco anos (HR=1,5; IC95\%: 1,36-1,66). Além disso, a expressão alterada associou-se à maior invasão tumoral, à presença de metástase linfonodal e a distância. Sexo, localização e tipo histológico não apresentaram associação.

Ambas as revisões apresentam considerável heterogeneidade dos estudos incluídos. Método de avaliação da expressão, tipo de anticorpo, diluição e valor de corte de expressão são os principais fatores apontados como responsáveis por isso. No entanto, acredita-se que os resultados desta pesquisa, assim como os resultados das 
outras classificações moleculares previamente discutidas confirmam a expressão da Ecaderina como fator de mau prognóstico para pacientes de câncer gástrico.

Além do CDH1, outros genes relacionados à adesão celular, citoesqueleto e motilidade celular parecem ter impacto negativo no prognóstico dos tumores considerados com genoma estável (Chia et al., 2016). Entre eles, podemos citar o FAT4, um gene supressor tumoral da família da E-caderina relacionado à adesão celular; o CTNNA1, responsável por codificar a alfa-E-catenina relacionada à adesão do citoesqueleto; e o RHOA, que participa da função de regulação da actina do citoesqueleto. Deste modo, a avaliação desses outros marcadores pode ser útil para ampliar a caracterização de subtipo com genoma estável.

\subsection{Considerações sobre classificações com base na expressão gênica e proteica}

A análise de expressão gênica e proteica mostrou-se factível, todavia também sujeita a algumas limitações metodológicas. O emprego da IH implica utilização de diferentes anticorpos, preparação de tecidos e técnicas de detecção. Critérios para julgar a reação como positiva ou negativa também variam. No final, a definição do padrão de expressão acaba sendo subjetiva e sujeita a variação entre observadores. Resultados falsos negativos podem ocorrer quando o tecido é fixado de maneira inadequada ou quando as reações são realizadas em lâminas que foram cortadas e armazenados por longos períodos (Ilyas et al., 2013).

Cientes dessas características, alguns cuidados foram tomados para contornar tais limitações. Os anticorpos utilizados foram os comercializados e utilizados por laboratórios de patologia na sua rotina. Todas as lâminas foram provenientes do mesmo Hospital. A presença do antígeno EBER, avaliada por ISH, e das proteínas MMR avaliadas por IH foram definidas de maneira categórica, evitando-se, portanto, a variação entre observadores. A análise da expressão da p53 e da E-caderina utilizou critérios já estabelecidos, conforme descrito na seção métodos.

O TMA é uma metodologia que permite o estudo de diferentes amostras de tecido em larga escala. Cada tumor é representado de forma amostral por meio de pequenos fragmentos de tumor ("spots"). Isso pode levar a uma estimativa errada da expressão do marcador, considerando-se a heterogeneidade de expressão intratumoral. 
No presente estudo, foram utilizados três spots, na tentativa de minimizar essa possibilidade e aumentar a representatividade das diferentes regiões tumorais. Como comparação, Setia et al. (2015) utilizaram dois spots, e Birkman et al. (2017) utilizaram quatro spots.

A ocorrência de alteração na expressão de diferentes marcadores em um mesmo tumor, que determine mais de um subtipo de CG, também é uma limitação à acurácia da classificação. Mesmo selecionando-se e limitando-se o número de marcadores analisados, alguns casos ainda podem apresentar alterações em mais de um marcador. Tal fato destaca a importância de se determinar uma hierarquia na avaliação dos marcadores, por meio de um fluxo de decisão para definição de cada subtipo molecular.

A importância da escolha dos marcadores pode ser exemplificada pelo trabalho de Lee et al. (2007). Os autores analisaram 659 casos de adenocarcinomas gástricos operados na Coréia do Sul por meio de IH associado com método de tissue array. A expressão de 56 proteínas relacionadas ao CG foi verificada. Dentre os marcadores utilizados, estavam o p53, E-caderina, c-erbB2, p16, VEGF. Entretanto, na formação dos diferentes grupos de perfil molecular para análise, os autores utilizaram uma análise hierárquica de cluster. No final, os autores definiram dois clusters que apresentavam diferentes estádios e prognósticos sem, no entanto, ficar claro quais marcadores seriam os principais determinantes de cada grupo molecular. Isto evidenciou que o emprego de muitos marcadores, sem a definição de quais seriam os mais relevantes, acabou limitando a aplicação prática da classificação.

Ainda com relação à expressão alterada simultânea dos marcadores, vale citar o trabalho de Kim et al. (2016) que avaliou e expressão de dez marcadores, incluindo EBV, proteínas de MMR e p53. Os autores verificaram alteração na expressão de cinco marcadores em 0,2\% dos casos, quatro em 3,7\% dos casos, três em 15,8\% dos casos, dois em 27,4\% dos casos e apenas um marcador em 35,2\% dos casos. Em outro estudo, Gonzalez et al. (2016) verificaram que três entre sete casos classificados como EBV positivos tinham expressão aberrante de p53. Já no grupo classificado como MSI, cinco dos 17 casos apresentavam expressão aberrante de p53.

Birkman et al. (2017) também realizaram outra forma de classificação molecular, utilizando IH. Naquele caso, o primeiro passo da caracterização teve como base o tipo histológico do tumor, de acordo com a classificação de Laurén. Os tumores 
foram inicialmente divididos em tipo intestinal e difuso e, posteriormente, nos quatro tipos moleculares de acordo com o TCGA. Os autores verificaram que os tumores do tipo intestinal e difuso se diferenciaram como duas entidades moleculares distintas. Tumores do tipo intestinal apresentaram perfil molecular mais variado que o do tipo difuso, os quais correspondiam basicamente aos tumores do tipo com genoma estável. Tumores do tipo intestinal, por sua vez, raramente expressaram alteração de E-caderina. Ao iniciar a classificação pelo tipo histológico, foi possível concentrar $89 \%$ dos tumores com expressão aberrante de E-caderina no grupo de tumores difusos. Importante destacar que nenhum tumor do tipo intestinal EBV negativo, MSS e com expressão da p53 normal apresentou expressão aberrante de E-caderina. Entre os tumores do tipo difusos, a ocorrência de casos EBV positivos, MSI e com expressão aberrante da p53 foram mutuamente exclusivas. Entretanto, dentre os tumores do tipo intestinal, uma lesão EBV positivo apresentou p53 aberrante e quatro lesões com MSI apresentaram também expressão aberrante da p53.

No presente estudo, os grupos caracterizados pela expressão alterada da Ecaderina (GS) e com MSI, ocorreram de forma associada em apenas três casos, além de apresentar características clínicas e patológicas marcantes. A baixa associação, e o impacto na sobrevida, reforçam a estratégia de colocá-los no topo do fluxo de decisão para classificação molecular.

O fato de analisar-se a expressão gênica e proteica sem o conhecimento das bases moleculares que desencadearam a alteração observada leva a não se ter uma correlação com a via de carcinogênese. A análise proteica pode não ser adequada para representar a intrincada e complexa cascata de alterações moleculares de cada subtipo de câncer gástrico. Infelizmente, este fato pode ocasionar a classificação equivocada de alguns casos. Mesmo avaliando-se a expressão de quatro marcadores chaves relacionados às alterações moleculares do CG, essa associação ainda não está claramente definida.

Outra limitação da classificação baseada na expressão gênica e proteica é a impossibilidade de definir se a alteração molecular primordial para carcinogênese é germinativa ou adquirida. Esta diferenciação é relevante, principalmente no contexto de tumores com alteração de E-caderina que podem estar relacionados ao câncer gástrico difuso hereditário e alterar a conduta cirúrgica dos casos. 


\subsection{Considerações Metodológicas}

Estudos retrospectivos apresentam particularidades próprias de seu desenho, as quais precisam ser consideradas, principalmente em relação à coleta de dados clínicos e ocorrência de algum viés na análise dos mesmos.

No presente estudo, utilizaram-se dados coletados de maneira prospectiva no serviço de cirurgia do aparelho digestivo do ICESP-HCFMUSP. A coleta de dados fez parte de um projeto de pesquisa registrado na Plataforma Brasil, que tem como objetivo a formação de um banco de dados contendo as características clinicopatológicas e desfechos de pacientes operados no serviço. Os dados utilizados são permanentemente checados e também utilizados em outros estudos que envolvem pacientes com câncer gástrico no serviço. A análise permanente garante maior confiabilidade aos dados utilizados no presente estudo.

Viés é um erro sistemático que pode estar presente durante a realização de qualquer estudo, resultando em estimativa incorreta de associação entre variáveis e desfechos (Rothman, 2008). Os dois principais tipos de vieses são relacionados à identificação da população do estudo (viés de seleção) e à aferição da variável ou desfecho do estudo (viés de classificação).

Na tentativa de tornar a população estudada mais homogênea em relação à terapia cirúrgica aplicada e prognóstico esperado, optou-se por incluir apenas pacientes submetidos a cirurgia com intenção curativa e linfadenectomia D2. A seleção foi realizada de maneira consecutiva de todos os pacientes operados no período selecionado. Se, por um lado, isso padronizou o impacto da modalidade terapêutica principal empregada - que é o tratamento cirúrgico -, essa seleção excluiu pacientes com doença avançada, submetidos a procedimentos paliativos, ou pacientes com condições clínicas desfavoráveis, submetidos à linfadenectomia D1. Estes fatos levantam o seguinte questionamento: será que os subtipos tumorais têm a mesma distribuição nos pacientes paliativos com doença mais avançada? Para responder essa pergunta seria necessária a inclusão de todos os pacientes com tumores gástricos atendidos no serviço. Isto demandaria um número maior de recursos para análise da expressão e acabaria incluindo um grupo de pacientes que já têm uma sobrevida esperada limitada, dificultando a análise de sobrevida.

Obtenção de material histológico adequado em casos não operados também é uma limitação, visto que muitos pacientes paliativos têm apenas biópsias do tumor. 
O viés de classificação ocorre quando os indivíduos são classificados de modo incorreto, tanto em relação às variáveis quanto ao desfecho. Sem dúvida, neste estudo o viés de classificação da variável de expressão dos marcadores é o mais importante, e isso já foi amplamente debatido na subseção 5.5 da Discussão. Com relação às demais variáveis avaliadas, vale lembrar que todas seguem a padronização de classificação do banco de dados. As variáveis escolhidas foram as habitualmente empregadas em estudos relacionados ao $\mathrm{CG}$, e seus subgrupos também foram definidos a partir de referências bem conhecidas na Literatura.

Com relação ao desfecho, empregou-se a análise da sobrevida livre de doença e da sobrevida global. O diagnóstico da recidiva foi feito por exame de imagem ou por estudo anatomopatológico de material obtido em exames diagnósticos, ou por cirurgia. Vale ressaltar que os exames de imagem não foram realizados de rotina no pósoperatório, mas com base na presença de sintomas. Este fato pôde retardar o diagnóstico da recidiva e prolongar erroneamente a SLD. Considera-se o diagnóstico anatomopatológico da recidiva como definitivo, mas os exames de imagem podem ser duvidosos entre condições benignas, como alterações inflamatórias cicatriciais pósoperatórias e recidiva. Em caso de dúvida, aguardou-se um novo exame de seguimento de imagem para confirmação da recidiva. Supõe-se que o valor preditivo positivo do diagnóstico do desfecho recidiva foi elevado. Como o ICESP-HCFMUSP é a referência na rede pública para tratamento oncológico, pacientes que apresentem recidiva, mesmo que diagnosticada em outro serviço, dificilmente deixam de retornar ao Hospital para nova avaliação.

Outra característica da SLD é o desfecho recidiva ocorrer antes do óbito na história natural da doença e ser menos influenciado por condições clínicas do paciente. Portanto, optou-se por realizar a classificação de risco com base no risco do desfecho recidiva. O seguimento mediano da população foi de 31,6 meses, um valor adequado, mas que ainda possibilita a ocorrência de novos episódios de recidiva promotores de alteração nos resultados. Oba et al. (2013), avaliando catorze estudos clínicos prospectivos de emprego da adjuvância no câncer gástrico, verificaram a concordância da análise de SLD com a SG em $97 \%$ dos casos.

A SG foi outro desfecho analisado. A sobrevida global sofre grande impacto da idade e comorbidades dos pacientes. Como os subtipos tumorais apresentaram variação 
da média de idade entre si, fica a dúvida se diferenças na SG podem ser decorrentes da idade mais elevada e comorbidades ou se é realmente relacionada ao subtipo. Seria necessário o ajuste dessas covariáveis para correta associação com SG. Entretanto, o pequeno número de casos de alguns grupos moleculares acaba limitando essa análise. Uma maneira de corrigir o efeito da idade e comorbidades na SG seria analisar a sobrevida câncer específica (SCE). Em tal análise, apenas óbitos relacionados à recidiva do tumor seriam incluídos como desfecho. Atualmente, temos confiança nos dados relacionados ao diagnóstico da recidiva, conforme explicados anteriormente, e ao óbito, que é o desfecho final. Devido à fragilidade das condições socioeconômicas e culturais da população brasileira, confirmação da causa do óbito desses pacientes frequentemente não é realizada.

Para comparação entre as diferentes classificações foi empregada a curva ROC, avaliando-se acurácia para detecção dos eventos recidiva e óbito. A curva ROC é uma representação gráfica que ilustra a habilidade diagnóstica de um método para discriminar a taxa de verdadeiros positivos (sensibilidade) dos falsos positivos (1 especificidade). Ela é muito empregada para validação de testes diagnósticos e determinação de pontos de corte. Um palpite aleatório perfeitamente balanceado, $50 \%$ de sensibilidade e $50 \%$ de especificidade, é representado por uma linha diagonal que se inicia no canto inferior esquerdo em direção ao canto superior direito. Quanto mais perto do canto superior esquerdo do gráfico a curva se desenha, melhor sua capacidade de predição do evento - $100 \%$ sensibilidade e $100 \%$ de especificidade. A área sob a curva (AUC) resume a localização total da curva ROC, sem depender da análise de um ponto específico. A AUC é uma maneira efetiva de combinar a sensibilidade e especificidade do método diagnóstico. O desempenho das diferentes classificações foi muito semelhante. Porém, todas as classificações apresentaram AUC abaixo de 70\%, o que é considerado um valor pobre para avaliação de desempenho de um teste diagnóstico.

\subsection{Perspectivas da aplicação prática da classificação molecular}

O câncer gástrico é um tumor de apresentação heterogênea e os resultados de pacientes com mesmo estádio clínico e patológico variam muito. Essa característica é muito influenciada pelo perfil molecular do tumor. Além de permitir melhor 
caracterização e entendimento da patogênese do CG, a nova classificação também permitirá a adoção de uma proposta terapêutica mais individualizada (Chen et al., 2016).

O ToGA trial representou um grande marco nesse sentido, ao evidenciar que tumores gástricos que expressavam marcador HER2 apresentavam melhora da sobrevida com o emprego do trastuzumabe como primeira linha do tratamento paliativo (Bang et al., 2010). Desde então, inúmeros marcadores têm sido selecionados como potenciais alvos terapêuticos. Ramucirumabe, um anticorpo cujo alvo é o VEGFR2, também foi aprovado para uso como segunda linha em tratamentos paliativos (Fuchs et al., 2014). Ambos os marcadores associam-se a tumores com instabilidade cromossômica.

Se, atualmente, ainda não é possível direcionar adequadamente e prever consistentemente a reposta terapêutica das drogas apenas pelos tipos moleculares, o emprego da análise de marcadores auxilia na realização de estudos tipo guarda-chuva (“Umbrella Trials"). Neste tipo de estudo, pacientes com o mesmo tipo de câncer são locados em diferentes braços do estudo com base em uma mutação ou alvos moleculares semelhantes. Tome-se como exemplo o estudo iniciado em 2016, na Coreia do Sul, "The Master Protocol for Biomarker-Integrated Umbrella trial in advanced gastric cancer", com objetivo de incluir 400 casos com câncer gástrico metastático, com indicação de quimioterapia de segunda linha, tendo como base expressões de EBV, MSI, HER2, EGFR, cMET e PTEN (Rha et al., 2016).

O conhecimento molecular dos tumores gástricos também auxilia na seleção de pacientes para estudos do tipo "Basket trials". Neste tipo de estudo, os pacientes são selecionados de acordo com a mutação ou alvo molecular alterado. $\mathrm{O}$ uso deste modelo permite que mais pacientes participem dos estudos, e tratamentos podem ser testados mais rapidamente. Além disso, pacientes com subtipos de tumores mais raros podem ter mais opções de tratamento.

O imunoterápico pembrolizumabe foi testado em diferentes tipos de tumores em diversos estudos do grupo denominado "Keynote Clinical Trials". Recentemente, em maio de 2017, o Food and Drug Administration (FDA) (2017a), dos Estados Unidos da América, aprovou o emprego de pembrolizumabe para pacientes adultos e pediátricos com tumores sólidos irressecáveis, ou metastáticos, que apresentavam perfil de 
marcador com instabilidade de microssatélites. Até então, o FDA aprovava os tratamentos com base no órgão que o câncer era originado e aquela foi a primeira aprovação baseada apenas na expressão do marcador, independentemente da localização do tumor. Posteriormente, em setembro de 2017, o pembrolizumabe foi aprovado pelo FDA (2017b) para pacientes com câncer gástrico metastático, ou recidivado localmente, que expressavam o marcador PD-L1.

Considerando-se a classificação molecular, certamente pode-se vislumbrar o emprego do pembrolizumabe em grupo que apresenta instabilidade de microssatélites e, também, em grupo associado ao EBV.

Tumores gástricos associados ao EBV apresentam maior expressão de PD-L1 do que outros subtipos moleculares (TCGA, 2014). Esse achado foi confirmado na população brasileira, em que $50 \%$ dos tumores gástricos com expressão do PD-L1 eram associados ao EBV (Pereira et al., 2018). Tumores associados ao EBV, assim como os com MSI, também apresentam alta taxa mutacional, o que os torna um potencial alvo para diferentes imunoterápicos, como o nivolumabe. Em contrapartida, os tumores classificados como genomicamente estáveis, associados a alterações na expressão da Ecaderina, ainda carecem de uma droga mais específica para uso, além de possuir um comportamento biológico mais agressivo de princípio (Chen et al., 2016).

Não apenas no contexto do tratamento quimioterápico adjuvante a classificação molecular está mudando de paradigma. Paciente com GS tem maior risco de disseminação peritoneal, sugerindo, assim, o emprego de alguma terapia quimioterápica peritoneal profilática, após o procedimento cirúrgico. Acrescente-se a isso que pacientes com CG associado à MSI demonstraram menor ocorrência de metástase linfonodal e idade mais avançada (Roviello et al., 2018), o que propõe o seguinte questionamento: vale a pena expor esse grupo de pacientes mais frágeis à quimioterapia neoadjuvante? A linfadenectomia D1 é suficiente nesses casos? Os dados deste estudo e alguns relatos sugerem que tais condutas fora do padrão, e individualizadas, podem ser adotadas naquele grupo (Ramos et al., 2018b).

Após a verificação da possibilidade de classificação molecular com emprego da IH, a identificação do comportamento de cada subtipo frente às diferentes modalidades terapêuticas é a sequência planejada desta linha de pesquisa. 


\section{CONCLUSÃO}

O emprego de técnicas de análise de expressão gênica e proteica conseguiu caracterizar adequadamente subtipos moleculares de CG. Estes apresentaram características clinicopatológicas e prognóstico distintos, condizentes com relatos prévios. Foi proposta nova classificação dos subtipos moleculares com base na expressão do marcador associado ao risco de recidiva. A nova classificação apresentou desempenho semelhante a outras previamente descritas, podendo ser uma opção para caracterizar os subtipos moleculares de CG. 


\section{ANEXOS}

Anexo 1. Aprovação do projeto "Caracterização da infecção por Helicobacter pylori, vírus Epstein-Barr e perfil gênico-proteico dos adenocarcinomas gástricos"

Rel. Solicitaço de execuçao de estudo: Caracterização da infecçăo por Helicobacter Pylori, virus Epstein. Barr e perfil da expressão génico-profeica nos adenocarcinomas gástricos

Pesquisodar responsóvet. Prol. Ulysses Ribeiro Junior / Dr. Marcus femondo Kodama P. Ramos CONSIDERAÇÕES

Trata-se de uma avaliaçco retrospectiva entre os pacientes submetidos à gastrectomia pro adenacarcinoma cusstrico no inslifuiçõo no periodo de 2009 e 2014 será reaízada através métodos imunohistoquímicos e pela técrica de hibridizaçào in șitu (HIS) o porlir da construçðo de microarays de fecido com amostras de fuma viável obtidas de blocos de parafina de cada pocientes.

O objelivo do estudo é determinar a treqüéncia do infecçdo por HP e EBV nos pacientes com CG do instiluto do Cáncer do Estodo de Sõo Paulo (ICESP) e caracterizar o perfli do populaçoo poro as varióveis genélicas HER-2 e MMR, anolisando-os Juntomente com porómetros clínico-patologicos, incluindo idade. sexo, tipo de fumar, nivel de invas 00 fumoral, stalus lintonodal, estágio patológico do tumor, caracterizaçào do perfil de mucinas e repercussoo clinica.

OBRIGAÇÕES DO PESQUISADOR

Antes do inicio dos procedimentos relacionados ao estudo:

- Iniciar as afividades do estudo somente após aprovaçào do Comite de ftica em Pesquisa do FMUSP para execução no ICESP segundo a Res. 46\$/12:

- Após oprovação do CEP. fornecer cósia da Carla de Aprovaçỏo e Relatório final com ciência do CEP oO NP. ICESP:

- Enviar Publicaçõo dos resultados do estudo:

Informamos que sua solleltaçỗo fol DEFERIDA.

Atenciosomente.

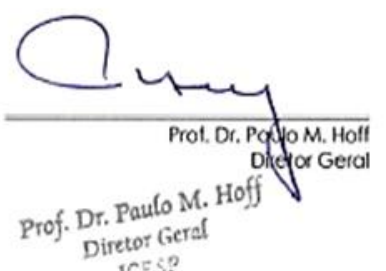




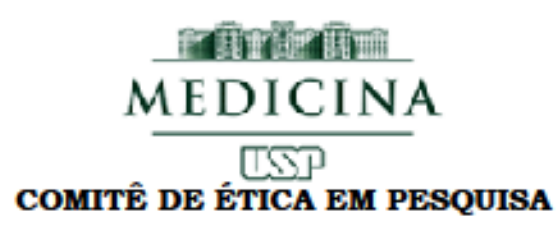

APROVAÇÃo

o Comitê de Ética em Pesquisa da Faculdade de Medicina da Universidade de São Paulo, em sessão de 08/04/2015, APROVOU o Protocolo de Pesquisa $\mathrm{n}^{0}$ 102/15 intitulado: "CARACTERIZAÇÃo DA INFECÇÃo POR HELICOBACTER PYLORI, VÍRUS EPSTEIN-BARR E PERFIL DA EXPRESSÃO GÊNICO-PROTEICA NOS ADENOCARCINOMAS GÁSTRICOS " apresentado pelo Instituto do Câncer do Estado de São Paulo - Octávio Frias de Oliveria

Cabe ao pesquisador elaborar e apresentar ao CEPFMUSP, os relatórios parciais e final sobre a pesquisa (Resolução do Conselho Nacional de Saúde $n^{\circ}$ 466/12, inciso IX.2, letra "c").

Pesquisador (a) Responsável: Ulysses Ribeiro Junior

Pesquisador (a) Executante: Marcus Fernando Kodama Pertille Ramos

CEP-FMUSP, o9 de Abril de 2015.

\author{
2landens \\ Prof. Dr. Roger Chammas \\ Coordenador \\ Comitê de Ética em Pesquisa
}


Anexo 2 Aprovação do projeto "Banco de dados de pacientes do Serviço de Cirurgia Oncológica do aparelho Digestivo do ICESP-HCFMUSP”

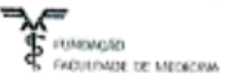

Sôo Poulo, 05 de agosto de 2016.

Registro: NP 993/16

Ref. Solicitação de execução de estudo: Banco de dados de pacientes do Serviço de Clrurgia Oncológica do aparelho Digestivo do ICESP-HCFMUSP

Pesquiscador Responsóvet: Prot. Dr. Uysses Riberio Junic

Pesquisadior Executante: Dr. Marcus Fernando Kodama

Dra. Morina Alessandra Pereía

\section{CONSIDERAÇŌES}

Irato-se de ume estudo retrospectivo com a fincidade de uma pesquisa cientifica regular. O projeto visa criar um instrumento de registros de dados completos e padronizados para auxiica futuras projetos de pesquisa no Serviço de Churgia Oncológica do Apareho Digestivo do ICESP. Os pacientes atendidos no ICESP teráo suas infarmaçoes inseridas no Banco de Dadas. Os dados serdo coletados a par lir de prontućrio eletrórico e laudos de exames, ndo havendo necessidode de coleta de informç̧ốes direta com o paciente.

\section{RESPONSABILIDADES DO PESQUISADOR}

Antes do inicio dos afividodes relocionadas ao estudo:

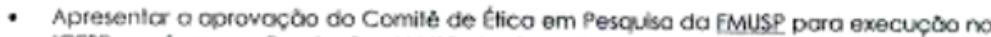
ICESP conforme a Resoluç̧ó $466 / 12$ do Conselho Nocional de Saúde. Ministétio do Saúde:

- Envior relatónio final do estudo. Projetos sem informaçôes por mass de 1 ano serố cancelados aulomalicamente e impedirá a submissâo de novos projetos pelos
investigadores:

- Envicar resultados do projeto (publicaçōes, defesa de tese, apresentaçỗo em congressos $\theta$ outros):

Informamos que sua solicitaçâo foi DEFERIDA

Alenciosamente.

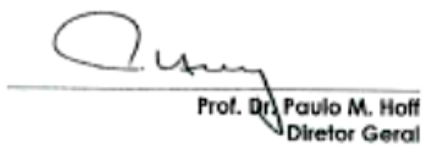

Prof. Dr. Pualo M. Hof

Disctor ciend

ICE.SP
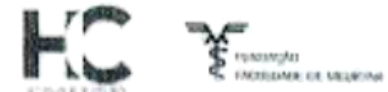


\section{REFERÊNCIAS}

1. Altman DG, McShane LS, Sauerbrei W, Taube SE. Reporting recommendations for tumor marker prognostic studies (REMARK): explanation and elaboration. PLoS Med 2012; 9(5): e1001216.

2. An JY, Kim H, Cheong JH, Hyung WJ, Kim H, Noh SH. Microsatellite instability in sporadic gastric cancer: its prognostic role and guidance for 5-FU based chemotherapy after R0 resection. Int J Cancer 2012; 131(2):505-11.

3. Ando K, Oki E, Saeki H, Yan Z, Tsuda Y, Hidaka G, Kasagi Y, Otsu H, Kawano H, Kitao H, Morita M, Maehara Y. Discrimination of p53 immunohistochemistrypositive tumors by its staining pattern in gastric cancer. Cancer Med 2015; 4(1):7583.

4. Anh S, Lee S, Kim Y, Kim A, Shin N, Kyung UC, Lee CH, Huh GH, Kim KM, Setia N, Lauwers G, Park DY. High-throughput protein and mRNA expressionbased classification of gastric cancers can identify clinically distinct subtpypes, concordant with recent molecular classifications. Am J Surg Pathol 2017; 41(1):106-15.

5. Bae YS, Kim H, NOh SH, Kim H. Usefulness of Immunohistochemistry for Microsatellite Instability Screening in Gastric Cancer. Gut Liver 2015; 9(5): 62935 .

6. Baek DW, Kamg DW, Hwang S, Kim JG, Seo AN, Bae HI, Kwon OK, Lee SS, Cung HY, Yu W. Clinical Significance os p53 Protein Expression, Beta-catenin Expression and HER2 Expression for Epstein-Barr Virus-associated Gastric Cancer. Chonnam Med J 2017; 53(2):140-6.

7. Bang YJ, Van Cutsem E, Feyereislova A, Chung HC, Shen L, Sawaki A, Lordick F, Ohtsu A, Omuro Y, Satoh T, Aprile G, Kulikov E, Hill J, Lehle M, Rüschoff J, Kan YK, ToGA Trial Investigators. Trastuzumab in combination with chemotherapy versus chemotherapy alone for treatment of HER2-positive advanced gastric or gastro-oesophageal junction cancer (ToGA): a phase 3, open-label, randomised controlled trial. Lancet 2010; 376(9742):687-97.

8. Birkman EM, Mansuri N, Kurki S, Algars A, Lintunen M, Ristamäki R, Sundström J, Carpén O. Gastric cancer: immunohistochemical classification of molecular subtypes and their association with clinicopathological characteristics. Virchows Arch 2017; Epub ahead of print. 
9. Bosman TF, Carneiro F, Hruban RH, Theise ND (Eds). WHO Classification of Tumours of the Digestive System, 4th ed. International Agency for Research on cancer (IARC), Lyon 2010.

10. Brasil, Ministério da Saúde. Instituto Nacional do Câncer José Alencar Gomes da Silva. Estimativa 2018 - Incidência de câncer no Brasil. Rio de Janeiro (RJ): INCA; 2018. p. 37-9.

11. Bray F, Ferlay J, Soerjomataram I, Siegel RL, Torre LA, Jemal A. Global Cancer Statistics 2018: GLOBOCAN Estimates of Incidence and Mortality Worldwide for 36 cancers in 185 Countries. Ca Cancer J Clin 2018; 0: 1-31.

12. Carneiro P, Fernandes MS, Figueiredo J, Caldeira J, Carvalho J, Pinheiro H, Leite M, Melo S, Oliveira P, Simões-Correia J, Oliveira MJ, Carneiro F, Figueiredo C, Paredes J, Oliveira C, Seruca R. E-cadherin dysfunction in gastric cancer-cellular consequences, clinical applications and open questions. FEBS Lett 2012; 586(18): 2981-9.

13. Carpenter PM, Al-Kuran RA, Theuer CP. Paranuclear E-cadherin in gastric adenocarcinoma. Am J Clin Pathol 2002; 118(6): 887-94.

14. Carvalho J, van Grieken NC, Pereira PM, Sousa S,Tijssen M, Buffart TE, Diosdado B, Grabsch H, Santos MAS, Meijer G, Seruca R, Carvalho B, Oliveira C. Lack of microRNA-101 causes E-cadherin functional deregulation through EZH2 upregulation in intestinal gastric cancer. J Pathol 2012; 22891):31-44.

15. Chang KK, Cho SJ, Yoon C, Lee JH, Park DJ, Yoon SS. Increased RhoA Activity Predicts Worse Overall Survival in Patients Undergoing Surgical Resection for Lauren Diffuse-Type Gastric Adenocarcinoma. Ann Surg Oncol 2016; 23(13): 4238-46.

16. Charlson ME, Pompei P, Ales K, MacKenzie CR. A new method of classifying prognostic comorbidity in longitudinal studies: development and validation. $J$ Chron Dis 1987; 40(5): 373-83.

17. Chen $\mathrm{T}, \mathrm{Xu} \mathrm{XY}$, Zhou PH. Emerging molecular classifications and therapeutic implications for gastric cancer. Chin J Cancer 2016; 35:49.

18. Chia NY, Tan P. Molecular classification of gastric cancer. Ann Oncol 2016; 27(5):763-9.

19. Choi YY, Bae JM, An JY, Kwon IG, Cho I, Shin HB, Eiji T, Aburahmah M, Kim $\mathrm{HI}$, Cheong JH, Hyung WJ, Noh SH. Is microsatellite instability a prognostic marker in gastric cancer? A systematic review with meta-analysis. J Surg Oncol 2014; 110(2): 129-35.

20. Connolly SA, Jackson JO, Jardetzky TS, Longnecker R. Fusing structure and function: a structural view of the herpesvirus entry machinery. Nat Rev Microbiol 2011; 9(5): 369-81. 
21. Correa P. Human gastric carcinogenesis: a multistep and multifactorial process-First American Cancer Society Award Lecture on Cancer Epidemiology and Prevention. Cancer Res 1992; 52(24): 6735-40.

22. Corso G, Carvalho J, Marrelli D, Vindigni C, Carvalho B, Seruca R, Roviello F, Oliveira C. Somatic mutations and deletions of the E-cadherin gene predict poor survival of patients with gastric cancer. J Clin Oncol 2013; 31(7): 868-75.

23. Cristescu R, Lee J, Nebozhyn M, Kim KM, Ting JC, Wong SS, Liu J, Yue YG, Wang J, Yu K, Ye XS, Do IG, Liu S, Gong L, Fu J, Jin JG, Choi MG, Sohn TS, Lee JH, Bae JM, Kim ST, Park SH, Sohn I, Jung SH, Tan P, Chen R, Hardwick J, Kang WK, Ayers M, Hongyue D, Reinhard C, Loboda A, Kim S, Aggarwal A. Molecular analysis of gastric cancer identifies subtypes associated with distinct clinical outcomes. Nat Med 2015; 21(5): 449-56.

24. Cunningham D, Allum WH, Stenning SP, Thompson JN, Van de Velde CJ, Nicolson M, Scarffe JH, Lofts FJ, Iveson TJ, Smith DB, Langley RE, Verma M, Weeden S, Chua YJ, MAGIC Trial Participants. Perioperative chemotherapy versus surgery alone for resectable gastroesophageal cancer. $N$ Engl J Med 2006; 366(1):11-20.

25. De Martel C, Ferlay J, Franceschi S, Vignat J, Bray F, Forman D, Plummer M. Global burden of cancer attributable to infections in 2008: a review and synthetic analysis. Lancet Oncol 2012;13(6):607-15.

26. Dindo D, Demartines N, Clavien PA. Classification of surgical complications: a new proposal with evaluation in a cohort of 6336 patients and results of a survey. Ann Surg 2004; 240(2): 205-13.

27. Doyle DJ, Garmon EH. American Society of Anesthesiologists Classification (ASA class). StatPearls. Treasure Island FL: StatPearls Publishing LLC., 2017.

28. Falchetti M, Saieva C, Lupi R, Masala G, Rizzolo P, Zanna I, Ceccarelli K, Sera F, Mariani-Costantini R, Nesi G, Palli D, Ottini L. Gastric cancer with high-level microsatellite instability: target gene mutations, clinicopathologic features, and long-term survival. Hum Pathol 2008; 39(6): 925-32.

29. Fenoglio-Preiser CM, Wang J, Stemmermann GN, Noffsinger A. TP53 and gastric carcinoma: a review. Hum Mutat 2003; 21(3): 258-70.

30. Food and drug administration (FDA); 2017 [documento on line]. Disponível em: https://www.fda.gov/drugs/informationondrugs/approveddrugs/ucm560040.htm

31. Food and drug administration (FDA); 2017 [documento on line]. Disponível em: https://www.fda.gov/drugs/informationondrugs/approveddrugs/ucm577093.htm.

32. Fuchs CS, Tomasek J, Yong CJ, Dumitru F, Passalacqua R, Goswami C, Safran H, dos Santos LV, Aprile G, Ferry DR, Melichar B, Tehfe M, Topuzov E, Zalcberg JR, Chau I, Campbell W, Sivanandan C, Pikiel J, Koshiji M, Liepa AM, Hsu, Y, 
Gao L, Schwartz JD, Tabernero J, Regard Trial Investigators. Ramucirumab monotherapy for previously treated advanced gastric or gastri-oesophageal junction adenocarcinoma (REGARD): an international, randomized, multicenter, placebocontrolled, phase 3 trial. Lancet 2014; 383(9911): 31-9.

33. Fukayama M, Hayashi Y, Iwasaki Y, Chong J, Ooba T, Takizawa T, Koike M, Mizutani S, Miyaki M, Hirai K. Epstein-Barr virus-associated gastric carcinoma and Epstein-Barr virus infection of the stomach. Lab Invest 1994; 71(1): 73-81.

34. Fukayama M, Ushiku T: Epstein-Barr virus-associated gastric carcinoma. Pathol Res Pract. 2011; 207(9): 529-537.

35. Gabbert HE, Mueller W, Schneiders A, Meier S, Moll R, Birchmeier W, Hommel G. Prognostic value of E-cadherin expression in 413 gastric carcinomas. Int $J$ Cancer 1996; 69(3): 184-9.

36. Gervaz P, Cerottini JP, Bouzourene H, Hahnloser D, Doan CL, Benhattar J, Chaubert J, Secic M, Gillet M, Carether JM. Comparison of microsatellite instability and chromosomal instability in predicting survival of patients with T3N0 colorectal cancer. Surgery 2002;131(2): 190-7.

37. Gonçalves AR, Carneiro AJV, Martins I, Faria PAS, Ferreira MA, Mello ELR, Fogaça HS, Elia CCS, Souza HSP. Prognostic significance of p53 protein expression in early gastric cancer. Pathol Oncol Res 2011; 17:349-55.

38. Gonzalez RS, Messing $\mathrm{S}$, Tu X, McMahon LA, Whitney-Miller CL. Immunohistochemistry as a surrogate for molecular subtyping of gastric adenocarcinoma. Hum Pathol 2016; 56:16-21.

39. Halling KC, Harper J, Moskaluk CA, Thibodeau SN, Petroni GR, Yustein AS, Tosi P, Minacci C, Roviello F, Piva P, Hamilton SR, Jackson CE, Powell SM. Origin of microsatellite instability in gastric cancer. Am J Pathol 1999; 155(1): 205-11.

40. Iizasa H, Nanbo A, Nishikawa J, Jinushi M, Yoshiyama H. Epstein-Barr Virus (EBV)-associated gastric carcinoma. Viruses 2012; 4(12): 3420-39.

41. Ilyas M, Grabsch H, Ellis IO, Womack C, Brown R, Berney D, Fennel D, SaltoTellez M, Jenkins M, Landberg G, Byers D, Treanor D, Harrison D, Grenn A, Ball G, Hamilton P. Guidelines and considerations for conducting experiments using tissue microarrays. Histopathology 2013; 62(6): 827-39.

42. International Agency for Research on Cancer. Monographs on the Evaluation of Carcinogenic Risk to Humans, volume 100B. Biological Agents. Lion, França: IARC; 2012.

43. Japanese Gastric Cancer Association. Japanese classification of gastric carcinoma — 2nd English edition —. Gastric Cancer 1998;1(1):10-24. 
44. Japanese Gastric Cancer Association. Japanese gastric cancer treatment guidelines 2014 (ver. 4). Gastric cancer 2017; 21(1): 1-19.

45. Jeon CH, Lee HI, Shin IH, Park JW. Genetic alterations of APC, K-ras, p53, MSI, and MAGE in Korean colorectal cancer patients. Int J Colorectal Dis. 2008; 23(1): 29-35.

46. Jiang B, Zhu K, Shao H, Bao C, Ou J, Sun W. Lack of association between the CDH1 polymorphism and gastric cancer susceptibility: a meta-analysis. Sci $R p$ 2015; 5: 7891.

47. Kim HS, Shin SJ, Beom SH, Jung M, Choi YY, Son T, Kim HI, Cheong JH, Hyung WJ, Noh SH, Chung H, Park JC, Shin SK, Lee SK, Lee YC, Koom WS, Lim JS, Chung HC, Rha SY, Kim H. Comprehensive expression profiles of gastric cancer molecular subtypes by immunohistochemistry: implications for individualized therapy. Oncotarget 2016; 7(28): 44608-20.

48. Kim JW, Nam KH, Ahn SH, Park DJ, Kim HH, Kim SH, Chang H, Lee JO, Kim YJ, Lee HS, Kim JH, Bang SM, Lee JS, Lee KW. Prognostic implications of immunosuppressive protein expression in tumors as well as immune cell infiltration within the tumor microenvironment in gastric cancer. Gastric Cancer. 2014;19(1):42-52.

49. Kim SY, Choi YY, An JY, Shin HB, Jo A, Choi H, Seo SH, Bang HJ, Cheong JH, Hyung WJ, Noh SH. The benefit of microsatellite instability is attenuated by chemotherapy in stage II and stage III gastric cancer: Results from a large cohort with subgroup analyses. Int J Cancer 2015; 137(4): 819-25.

50. Laurén P. The Two Histological Main Types of Gastric Carcinoma: diffuse and socalled intestinal-type carcinoma. An attempt at a histo-clinical classification. Acta Pathol Microbiol Scand 1965; 64: 31-49.

51. Lee HS, Cho SB, Lee He, Kim MA, Kim JH, Park DJ, Kim JH, Yang HK, Lee BL, Kim WH. Protein expression profiling and molecular classification of gastric cancer by tissue array method. Clin Cacer Res 2007; 13(14): 4154-63.

52. Lee JH, Kim SH, Han SH, An JS, Lee ES, Kim YS. Clinicopathological and molecular characteristics of Epstein-Barr virus-associated gastric carcinoma: a meta-analysis. J Gastroenterol Hepatol 2009; 24(3): 354-365.

53. Lehrbach DM, Cecconello I, Ribeiro UJr, Capelozzi VL, Ab'saber AM, Alves VA. Adenocarcinoma of the esophagogastric junction: relationship between clinicopathological data and p53, cyclin D1 and Bcl-2 immunoexpressions. Arq Gastroenterol 2009; 46(4): 315-20.

54. Li T, Chen J, Liu QL, Huo ZH, Wang ZW. Meta-analysis: E-cadherin immunoexpression as a potential prognosis biomarker related to gastric cancer metastasis in Asian patients. Eur Rev Med Pharmacol Sci 2014; 18(18): 2693-703. 
55. Liu X, Chu KM. E-cadherin and gastric cancer: cause, consequence, and applications. Biomed Res Int 2014; 2014:637308.

56. Mathiak M, Warneke VS, Behrens HM, Haag J, Böger C, Krüger S, Röcken C. Clinicopathologic characteristics of microsatellite instable gastric carcinomas revisited: urgent need for standardizatiom. Appl Immunihistochem Mol Morphol 2017; 25(1): 12-24.

57. McLean MH, El-Omar EM. Genetics of gastric cancer. Nat Rev Gastroenterol Hepatol 2014; 11(11): 664-74.

58. Murphy G, Pfeiffer R, Camargo MC, Rabkin CS. Meta-analysis shows that prevalence of Epstein-Barr virus-positive gastric cancer differs based on sex and anatomic location. Gastroenterology 2009; 137(3): 824-33.

59. Oba K, Paoletti X, Albert S, Bang YJ, Benedetti J, Bleiberg H, Catalano P, Lordick F, Michiels S, Morita S, Ohashi Y, Pignon JP, Rougier P, Sasako M, Sakamoto J, Sargent D, Shitara K, Cutsem EV, Buyse M, Burzykowski, GASTRIC group. Disease-free survival as a surrogate for overall survival in adjuvant trials of gastric cancer: a meta-analysis. J Natl Cancer Inst 2013; 105(21):1600-7.

60. Ooi CH, Ivanova T, Wu J, Lee M, Tan IB, Tao J, Ward L, Koo JH, Gopalakrishnan V, Zhu Y, Cheng LL, Lee J, Rha SY, Chung HC, Ganesan K, So J, Soo KC, Lim D, Chan WH, Wong WK, Bowtell D, Yeoh KG, Grabsch H, Boussioutas A, Tan P. Oncogenic pathway combinations predict clinical prognosis in gastric cancer. PLoS Genet 2009; 5(10): e1000676.

61. Park JW, Jang SH, Park DM, Lim NJ, Deng C, Kim DY, Green JE, Kim HK. Cooperativity of E-cadherin and Smad4 loss to promote diffuse-type gastric adenocarcinoma and metastasis. Mol Cancer Res 2014; 12(8): 1088-99.

62. Pereira MA, Ramos MFKP, Faraj SF, Dias AR, Yagi OK, Zilberstein B, Cecconello I, Alves VAF, de Mello ES, Ribeiro U Jr. Clinicopathological and prognostic features of Epstein-Barr vírus infection, microsatellite instability and PD-L1 expression in gastric cancer. J Surg Oncol 2018; 117(5): 829-39.

63. Perez RO, Jacob CE, D’Ottaviano FL, Alvarenga C, Ribeiro AS, Ribeiro UJr, Bresciani CJ, Zilberstein B, Krieger JE, Habr-Gama A, Gama-Rodrigues JJ. Microsatellite instability in solitary and sporadic gastric cancer. Rev. Hosp. Clín. Fac. Med. S. Paulo 2004; 59(5): 279-285.

64. Pernot S, Voron T, Perkins G, Lagorce-Pages C, Berger A, Taieb J. Signet-ring cell carcinoma of the stomach: Impact on prognosis and specific therapeutic challenge. World J Gastroentrol 2015; 21(40): 11428-38.

65. Perri F, Cotugno R, Piepoli A, Merla A, Quitadamo M, Gentile A, Pilotto A, Annese V, Andriulli A. Aberrant DNA methylation in non-neoplastic gastric mucosa of H. Pylori infected patients and effect of eradication. Am J Gastroenterol 2007; 102(7): 1361-71. 
66. Polom K, Marano L, Marrelli D, De Luca R, Roviello G, Savelli V, Tan P, Roviello F. Meta-analysis of microsatellite instability in relation to clinicopathological charactristics and overall survival in gastric cancer. Br J Surg 2018; 105(3):159-67.

67. Ramos MFKP, Pereira MA, Dias AR, Faraj SF, Zilberstein B, Cecconello I, de Mello ES, Ribeiro Junior U. Lymphoepithelioma-like gastric carcinoma: clinicopathological characteristics and infection status. J Surg Res 2017; 210: 159168.

68. Ramos MFKP, Ribeiro Júnior U, Viscondi JKY, Zilberstein B, Cecconello I, ElufNeto J. Risk factors associated with the development of gastric cancer - casecontrol study. Rev Assoc Med Bras (1992) 2018; 64(7): 611-9.

69. Ramos MFKP, Pereira MA, Dias AR, Yagi OK, Zaidan EP, Ribeiro-Júnior U, Zilberstein B, Cecconello I. Surgical outcomes of gastrectomy with D1 lymph node dissection performed for patients with unfavorable clinical condition. Eur J Surg Oncol 2018; [Epub ahead of print].

70. Rha YR. The Master Protocol for Biomarker-Integrated Umbrella Trial in Advanced Gastric Cancer [registro de pesquisa on line]. Disponível em: https://clinicaltrials.gov/ct2/show/NCT02951091.

71. Ribeiro J, Malta M, Galaghar A, Silva F, Afonso LP, Medeiros R, Sousa H. P53 deregulation in Epstein-Barr vírus-associated gastric cancer. Cancer Lett 2017; 404: $37-43$.

72. Ribeiro U Jr, Jorge UM, Safatle-Ribeiro AV, Yagi OK, Scapulatempo C, Perez RO, Corbett CE, Alves VA, Zilberstein B, Gama-Rodrigues J. Clinicopathologic and immunohistochemistry characterization of synchronous multiple primary gastric adenocarcinoma. J Gastrointestinal Surg 2007; 11(3): 233-9.

73. Rothman K, Greeland S, Lash TL. Modern Epidemiology, $3^{\text {rd }}$ Edition. Philadelphia, PA: Lippincott Williams and Wilkins; 2008.

74. Roviello F, Polom K, D'Ignazio, Pascale V, Marrelli D. Potential impact of molecular classification on tailored lymphadenectomy for gastric cancer. Eur $J$ Cancer 2018; Suppl2: S8.

75. Sanches JM, Figueiredo J, Fonseca M, Durães C, Melo S, Esménio S, Seruca R. Quantification of mutante E-cadherin using bioimaging analysis of in situ fluorescence microscopy. A new approach to CDH1 missense variants. Eur J Hum Genet 2015; 23(8): 1072-9.

76. Safatle-Ribeiro AV, Ribeiro Júnior U, Reynolds JC, Gama-Rodrigues JJ, Iriya K, Kim R, Bakker A, Swalsky PA, Pinotti HW, Finkelstein SD. Morphologic, histologic, and molecular similarities between adenocarcinomas arising in the gastric stump and the intact stomach. Cancer 1996; 78(11): 2288-99. 
77. Seo HM, Chang YS, Joo SH, Kim YW, Park YK, Hong SW, Lee SH. Clinicopathologic characteristics and outcomes of gastric cancers with the MSI-H phenotype. J Surg Oncol 2009; 99(3): 143-7.

78. Setia N, Agoston AT, Han HS, Mullen JT, Duda DG, Clark JW, Deshpande V, Mino-Kenudson M, Srivastava A, Lennerz JK, Hong TS, Kwak EL, Lauwers GY. A protein and mRNA expression-based classification of gastric cancer. Mod Pathol 2016; 29(7): 772-84.

79. Shibata D, Weiss LM. Epstein-Barr virus associated gastric adenocarcinoma. Am J Pathl 1992; 140(4): 769-74.

80. Shimoyama Y, Hirohashi S. Expression of E- and P-cadherin in gastric carcinomas. Cancer Res 1991; 51(8): 2185-92.

81. Shinozaki-Ushiku A, Kunita A, Fukayama M. Update on Epstein-Barr virus and gastric cancer. Int J Oncol 2015; 46(4): 1421-34.

82. Silva EM, Begnami MD, Fregnani JH, Pelosof AG, Zitron C, Montagnini AL, Soares FA. Cadherin-catenin adhesion system and mucin expression: a comparison between young and older patients with gastric carcinoma. Gastric Cancer 2008; 11(3): 149-59.

83. Smyth EC, Wotherspoon A, Peckitt C, Gonzalez D, Hulkki-Wilson S, Eltahir Z, Fassan M, Rugge M, Valeri N, Okines A, Hewish M, Allum W, Stenning S, Nankivell M, Langley R, Cunningham D. Mismatch Repair Deficiency, Microsatellite Instability, and Survival: An Exploratoy analysis of the Medical Research Council Adjuvant Gastric Infusional Chemotherapy (MAGIC) Trial. JAMA Oncol 2017; 3(9): 1197-203.

84. Sohn BW, Hwang JE, Jang HJ, Lee HS, Oh SC, Shim JJ, Lee KW, Kim EH, Yim SY, Lee SH, Cheong JH, Jeong W, Cho JY, Kim J, Chae J, Lee J, Kang WK, Kim S, Noh SH, Ajani JA, Lee JS. Clinical significance of four molecular subtypes of gastric cancer identified by The Cancer Genome Atlas Project. Clin Cancer Res 2017; Epub ahead of print.

85. Syngal S, Brand RE, Church JM, Giardello FM, Hampel HL, Burt RW, American College of Gastroenterology. ACG clinical guideline: Genetic testing and management of hereditary gastrointestinal cancer syndromes. Am J Gastroenterol 2015; 110(2): 223-62.

86. Takahashi H, Endo T, Yamashita K, Arimura Y, Yamamoto H, Sasaki S, itoh F, Hirata K, Imamura A, Kondo M, Sato T, Imai K. Mucin phenotype and microsatellite instability in early multiple gastric cancers. Int J Cancer 2002; 100(4): 419-24.

87. Tan IB, Ivanova T, Lim KH, Ong CW, Deng N, Lee J, Tan SH, Wu J, Lee MH, Ooi $\mathrm{CH}$, Rha SH, Wong WK, Boussioutas A, Yeoh KG, So J, Yong WP, Tsuburaya A, Grabsch H, Toh HC, Rozen S, Cheong JH, Noh SH, Wan WK, Ajani JA, Lee JS, 
Salto-Tellez M, Tan P. Intrinsic subtypes of gastric cancer, based on gene expression pattern, predict survival and respond differently to chemotherapy. Gastroenterology 2011; 141(2): 476-85.

88. Tan P, Yeoh KG. Genetics and molecular pathogenesis of gastric adenocarcinoma. Gastroenterology 2015; 149(5): 1153-62.

89. The Cancer Genome Atlas Research Network (TCGA). Comprehensive molecular characterization of gastric adenocarcinoma. Nature 2014; 513(7517): 202-9.

90. Tsao SW, Tsang CM, To KF, Lo KW. The role of Epstein-Barr virus in epithelial malignancies. J Pathol 2015; 235(2): 323-33.

91. Tsuchiya S. Diagnosis of Epstein-Barr virus-associated diseases. Crit Rev Oncol Hematol 2002; 44(3): 227-38.

92. Umar A, Boland CR, Terdiman JP, Syngal S, de la Chapelle A, Rüschoff J, Fishel R, Lindor NM, Burgart LJ, Hamelin R, Hamilton SR, Hiatt RA, Jass J, Lindblom A, Lynch HT, Peltomaki P, Ramsey SD, Rodrigues-Bigas MA, Vasen HF, Hawk ET, Barrett JC, Freedman AN, Srivastava S. Revised Bethesda Guidelines for hereditary nonpolyposis colorectal cancer (Lynch syndrome) and microsatellite instability. J Natl Cancer Inst 2004; 96(4):261-8.

93. Union for International Cancer Control. TNM Classification of Malignant Tumours - 8 th ed. 2016.

94. Waki T, Tamura G, Tsuchiya T, Sato K, Nishizuka S, Motoyama T. Promoter methylation status of E-cadherin, hMLH1, and p16 genes in nonneoplastic gastric epithelia. Am J Pathol 2002:1 61(2): 399-403.

95. Wei J, Nagy TA, Vilgelm A, Zaika E, Ogden SR, Romero-Gallo J, Piazuelo MB, Correa P, Washington MK, El-Rifai W, Peek RM, Zaika A. Regulationa of p53 tumor suppressor by Helicobacter pylori in gastric epithelial cells. Gastroenterology 2010; 139(4): 1333-43.

96. Wei K, Jiang L, Wei Y, Wang Y, Qian X, Dai Q, Guan Q. The prognostic significance of p53 expression in gastric cancer: a meta-analysis. J Cancer Res Clin Oncol 2015; 141(4): 735-48.

97. Xing X, Tang YB, Yuan G, Wang Y, Wang J, Yang Y, Chen M. The prognostic value os E-cadherin in gastric cancer: a meta-analysis. Int J Cancer 2013; 132(11): 2589-96.

98. Yasui W, Oue N, Aung PP, Matsumura S, Shutoh M, Nakayama H. Molecularpathological prognostic factors of gastric cancer: a review. Gastric Cancer 2005; 8(2): 86-94. 
99. Yildirim M, Kaya V, Demirpence O, Gunduz S, Bozcuk H. Prognostic significance of p53 in gastric cancer: a meta-analysis. Asian Pac J Cancer Prev 2015; 16(1):327-32.

100. Yoda Y, Takeshima H, Niwa T, Kim JG, Ando T, Kushima R, Sugiyama T, Katai H, Noshiro H, Ushijima T. Integrated analysis of cancer-related pathways affected by genetic and epigenetic alterations in gastric cancer. Gastric Cancer 2015; 18(1): 65-76.

101. Xing X, Tang YB, Yun G, Wang Y, Wang J, Yang Y, Chen M. the prognostic value of E-cadherin in gastric cancer: a meta-analysis. Int J Cancer 2013; 132(11): 2589-96.

102. Zhu L, Li Z, Wang Y, Zhang C, Liu Y, Qu X. Microsatellite instability and survival in gastric cancer: A systematic review and meta-analysis. Mol Clin Oncol 2015; 3(3): 699-705. 
Apêndices

Apêndice 1 - Estratificação dos marcadores baseado no risco de óbito. Retirada do marcador menos significativo a cada passo

Apêndice 1 - Estratificação dos marcadores baseado no risco de óbito. Retirada do marcador menos significativo a cada passo.

\begin{tabular}{llcccc}
\hline Step & Expressão* & $\boldsymbol{\beta}$ & $\boldsymbol{H R}$ & IC 95\% & $\boldsymbol{p}$ \\
\hline $\mathbf{1}$ & EBV-negativo vs. EBV-positivo & 0,385 & 1,20 & $0,57-2,56$ & 0,633 \\
& MSI vs. MSS & 0,310 & 1,42 & $0,77-2,61$ & 0,255 \\
& p53 normal vs. alterada & 0,241 & 1,23 & $0,77-1,97$ & 0,398 \\
& E-caderina normal vs. alterada & 0,318 & 2,41 & $1,29-4,49$ & 0,006 \\
\hline $\mathbf{2}$ & MSI vs. MSS & 0,305 & 1,38 & $0,76-2,52$ & 0,287 \\
& p53 normal vs. alterada & 0,235 & 1,26 & $0,79-2,00$ & 0,325 \\
& E-caderina normal vs. alterada & 0,317 & 2,43 & $1,30-4,52$ & 0,005 \\
\hline $\mathbf{3}$ & MSI vs. MSS & 0,294 & 1,49 & $0,84-2,66$ & 0,173 \\
& E-caderina normal vs. alterada & 0,314 & 2,32 & $1,25-4,29$ & 0,007 \\
\hline
\end{tabular}

* primeira categoria serviu como referência 
Apêndice 2 - Certificado de apresentação na Semana Brasileira do Aparelho Digestivo de 2018. Premiado como "Melhor trabalho do CBCD da SBAD-2018 - $1^{\text {o }}$ lugar"

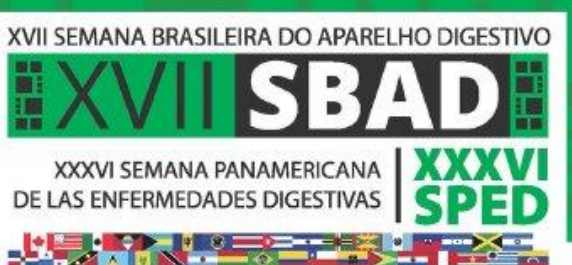

17 a 20 novembro $\mid 2018$ | Transamérica Expo Center | Săo Paulo | SP

Conferimos ao trabalho

CLASSIFICAÇÃO MOLECULAR DO CÂNCER GÁSTRICO: O NOVO PARADIGMA PARA CLASSIFICAÇÁO

dos autores MARCUS FERNANDO KODAMA PERTILLE RAMOS; MARINA ALESSANDRA PEREIRA; SHEILA FRIEDRICH FARAJ; CINTHYA DOS SANTOS CIRQUEIRA; ANDRE RONCON DIAS; LEANDRO CARDOSO BARCHI; VENANCIO AVANCINI FERREIRA ALVES; EVANDRO SOBROZA DE MELLO; OSMAR KENJI YAGI; BRUNO ZILBERSTEIN; IVAN CECCONELLO; ULYSSES RIBEIRO JUNIOR o prêmio de "Melhor trabalho do CBCD da SBAD-2018 - $1^{\circ}$ Lugar" pelo trabalho apresentado na modalidade Aprovado para Tema Livre - CBCD, durante o XVII Semana Brasileira do Aparelho Digestivo \& XXXVI Semana Panamericana de las Enfermidades Digestivas, realizado de 17 a 20 de novembro de 2018 no Transamerica Expo Center em São Paulo/SP. São Paulo, 20 de novembro de 2018

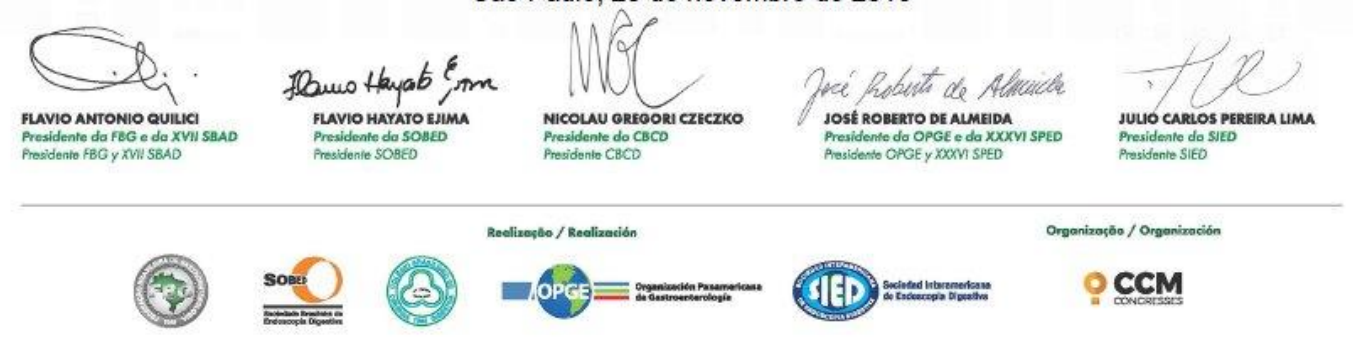


Apêndice 3 - Registro do resumo para apresentação no $13^{\circ}$ International Gastric Cancer Congress 2019 que será realizado em Praga, República Checa

\section{Overview of the Submitted Abstracts}

The Abstract Submission is closed! (deadline was 30 November)

Would you need any assistance please do not hesitate to contact us at abstracts@igcc2019-prague.org.

Abstract:

Molecular subtypes of gastric cancer based on immunohistochemical profile IGCC-0441 
Apêndice 4 - Submissão no periódico Gastric Cancer

Gastric Cancer

A feasible gastric cancer classification of molecular subtypes based on immunohistochemistry and in situ hybridization

\begin{tabular}{|c|c|c|}
\hline \multicolumn{3}{|l|}{ Menuserlet Number: } \\
\hline Fua The. & \multicolumn{2}{|c|}{ 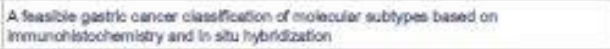 } \\
\hline Arlde Type & \multicolumn{2}{|l|}{ Orgher arthin } \\
\hline 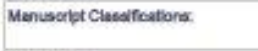 & \multicolumn{2}{|c|}{ 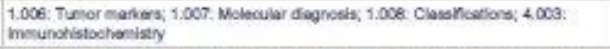 } \\
\hline Konwondix & \multicolumn{2}{|c|}{ 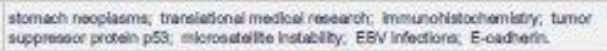 } \\
\hline Corresponding Author. & \multicolumn{2}{|c|}{ 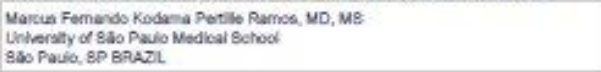 } \\
\hline \multicolumn{3}{|l|}{$\begin{array}{l}\text { Corroponsing Author Bocondey } \\
\text { intemation. }\end{array}$} \\
\hline Corresponding Authors insthution: & \multicolumn{2}{|l|}{ Unversty of swo Paulo Modieal Schood } \\
\hline \multicolumn{3}{|l|}{$\begin{array}{l}\text { Corrosponding Authors Becendiary } \\
\text { Insthison: }\end{array}$} \\
\hline Fist Authoc: & \multicolumn{2}{|c|}{ 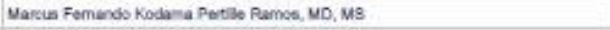 } \\
\hline \multicolumn{3}{|l|}{ Fist Author Becondary ifformation: } \\
\hline \multirow[t]{9}{*}{ Ondar of Aubles: } & \multicolumn{2}{|c|}{ Yarus Femendo Kodarea Patilo Pamce, vD, MS } \\
\hline & \multicolumn{2}{|l|}{ Matne Alensendra Porroika, MS } \\
\hline & \multicolumn{2}{|l|}{ Evantro Bobroze Mola, MD, PHD } \\
\hline & \multicolumn{2}{|l|}{ Sheila Fledneh Faro, MD, PHD } \\
\hline & \multicolumn{2}{|l|}{ Cinthye des sevtcos Crequeke } \\
\hline & \multicolumn{2}{|l|}{ Bruno Zlearsatin WO, PHD } \\
\hline & \multicolumn{2}{|c|}{ 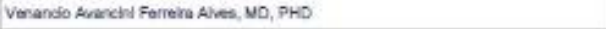 } \\
\hline & \multicolumn{2}{|l|}{ Uyenes Rbdro $k$, MD, PHD } \\
\hline & \multicolumn{2}{|l|}{ When Cocionella, MD, PHO } \\
\hline \multicolumn{3}{|c|}{ Order of Authens seoondary infom afion: } \\
\hline Funching intomation & 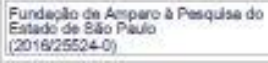 & Aor Ulygens Febolio dr \\
\hline Alerinet: & \multicolumn{2}{|c|}{ 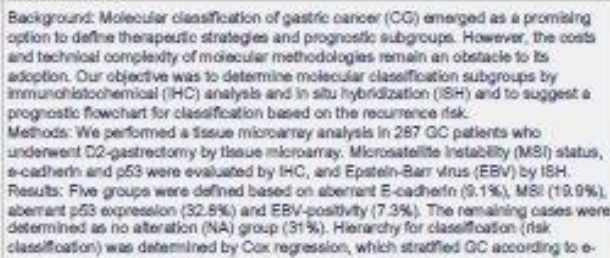 } \\
\hline
\end{tabular}

